\title{
Diccionario de referencias culturales en la literatura inglesa
}

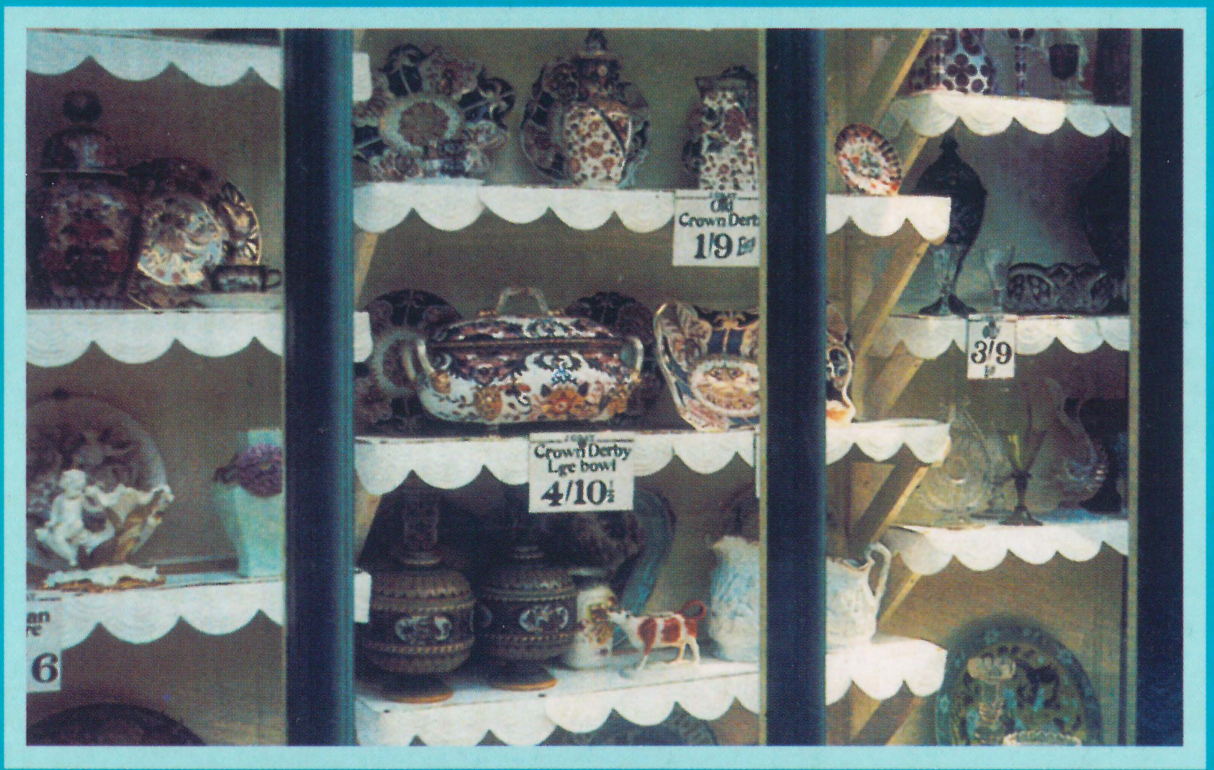

Elizabeth Woodward Smith 


\section{DICCIONARIO DE REFERENCIAS CULTURALES EN LA LITERATURA INGLESA}




DOI: https://doi.org/10.17979/spudc.9788497497794

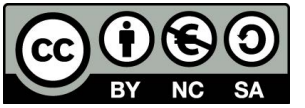

Esta obra se publica bajo una licencia Creative Commons Atribución-NoComercial-CompartirIgual 4.0 Internacional (CC BY-NC-SA 4.0)

(C) Elizabeth Woodward Smith

Santiago de Compostela, 2002

I.S.B.N.: 978-84-9749-779-4 (electrónico)

I.S.B.N.: 84-9749-011-8 (impreso)

D.L.: C-442-2002

Imprime: Tórculo Artes Gráficas, S.A.L.

Santiago de Compostela

Fotografía de portada: Una selección de piezas antiguas de porcelana fina de las marcas Crown Derby y Parian, expuestas en el Museo de Preston Park, Stockton-on-Tees, County Durham. Los precios indicados son los originales de la época de fabricación. La fotografía se reproduce con el permiso de This England International Ltd. 


\section{ÍNDICE}

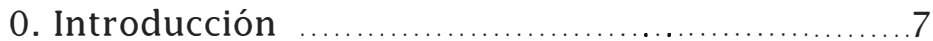

1. Diccionario .............................................. 15

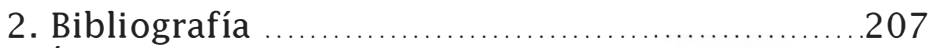

3. Índice de claves ......................................211

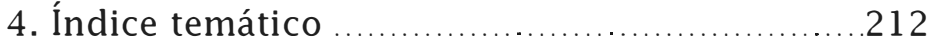

4.1. Abreviaturas y acrónimos ….............2212

4.2. Comidas, bebidas, costumbres

asociadas y enseres ............................ 212

4.3. Enseñanza ...................................213

4.4. Acontecimientos históricos,

batallas y ámbito militar .........................2 213

4.5. Ocio: juegos, espectáculos,

deportes, aficiones, lugares de reunión .....213

4.6. Edificios, calles, barrios,

ciudades y condados

214

4.7. Nombres propios en la

ficción: connotaciones y onomatopeya ….....2215

4.8. Personajes en la ficción

y la leyenda ...................................... 215

4.9. Personajes históricos ......................216

4.10. Artes plásticas y compositores .........216

4.11. Vestimenta, moda y complementos ...216

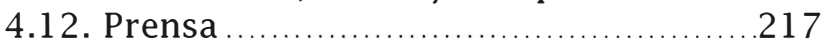

4.13. Mitología y fuentes bíblicas ............217

4.14. Grupos políticos, administración del estado, derecho y monarquía …..........217

4.15. Refranes, proverbios y rimas ...........218

4.16. Conceptos relacionados

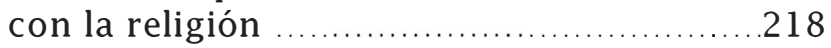

4.17. Profesiones e indicadores

de rango social ........................................ 218

4.18. Unidades de medida ....................219

4.19. Arquitectura, vivienda,

muebles y enseres ....

4.20. Literatura: títulos,

alusiones y géneros

4.21. Autores 
4.22. Léxico:lenguaje coloquial, usos idiomáticos y formas dialectales ......220

4.23. Bibliotecas y museos ......................221

4.24. Costumbres y normas sociales .........221

4.25. Transporte y comunicaciones ..........222

4.26. Rasgos del paisaje y flora ..............222

4.27. Miscelánea ...................................222

5. Índice alfabético ....................................223

6. A Picture Alphabet ....................................231 


\section{INTRODUCCIÓN}

Este Diccionario pretende ser un instrumento de ayuda al lector de la literatura inglesa de los siglos XIX y XX, para que comprenda multitud de pequeños detalles que se ofrecen al lector a través de referencias y connotaciones culturales. Según nuestra experiencia, la mayoría de estas referencias presentan pocas dificultades para el lector nativo, pero para el no nativo constituyen una barrera de cara a la comprensión total del texto. Es posible responder a un texto inadecuadamente debido a una comprensión parcial o errónea de una serie de factores entre los que se incluyen las referencias culturales basadas en acontecimientos de la vida real distantes en el tiempo y el espacio. Hemos observado que a menudo una referencia indirecta acerca de un aspecto social, una actitud, un comportamiento o la connotación asociada a un lugar añade un elemento más al conjunto cultural literario-lingüístico del texto.

Los antropólogos y lingüistas coinciden en que la lengua constituye una manera de ordenar y expresar la forma de vida de una comunidad, y la expresión de esta forma de ser en obras literarias engloba un sistema de creencias, de valores sobre la aceptabilidad social, y de actitudes que pueden resultar extraños e incomprensibles en otros ámbitos. Sin la ayuda que ofrecemos en este Diccionario, pensamos que el lector no nativo pierde datos que el autor presuponía que eran conocimientos compartidos entre él $y$ el lector.

En todo caso, para comprender las referencias más opacas, el lector (tanto nativo como no nativo) tendría que 
acudir a un gran número de obras de referencia muy distintas (diccionarios monolingües y bilingües, diccionarios de citas, refranes, de nombres propios, de nombres de lugares, de argot, de abreviaturas y acrónimos, enciclopedias, mapas, callejeros, libros de historia y mitología, etc.). Al no disponer de todas estas obras de referencia, o incluso simplemente por la pereza que supone dejar la lectura para ir en busca de una obra de consulta, es posible que el lector opte por pasar por alto el término cultural en cuestión, y así perder pequeños matices de significado. Con esta obra pretendemos pues facilitar la comprensión de la manera más completa posible.

Las obras de las cuales proceden las referencias culturales que explicamos aquí son las obligatorias habitualmente en los programas de Filología Inglesa en las diversas facultades de Filología. Sin embargo debemos aclarar que hay algunas ediciones de obras que traen incorporadas unas notas explicativas muy buenas, y por lo tanto hemos considerado que los aspectos de interés sociocultural están suficientemente explicados en estas obras, siendo poco lo que podríamos aportar nosotros a mayores sin repetir lo que ya han aclarado otros autores. Por consiguiente, las obras de las cuales proceden nuestras referencias son las que aparecen, por regla general, en ediciones que aportan pocas notas, o ninguna, y que considerábamos deficientes en este aspecto. En la mayoría de los casos damos una explicación del término en cuestión que sirve para todos los contextos literarios en los cuales lo hemos localizado, pero en otros casos hemos incluido la cita textual de una obra en concreto para que se vea la referencia en su contexto, destacando así que se trata de algo muy específico (véase el Índice de Claves).

No hemos tratado aspectos de tipo literario (interpretación o comentario de estilo, técnica, género, etc.), puesto que suponemos que serán objeto de estudio en el ámbito de literatura inglesa, y dado que, además, a menudo aparecen en las notas que acompañan algunas ediciones. Cuando un autor o sus personajes mencionan a otros autores, damos unas indicaciones biográficas breves para que 
el lector sepa de quién se trata, y para que pueda investigar más a fondo si le parece oportuno. De esta forma esperamos no duplicar explicaciones, sino aportar unas orientaciones culturales que hasta ahora han faltado.

Para la elaboración de este Diccionario hemos elegido obras publicadas en los siglos XIX y XX, porque pensamos que el lector medio presupone (erróneamente) que hay bastantes semejanzas entre la sociedad de esa época y la nuestra actual. Ya que el lenguaje no es difícil de entender, aparte de unos pocos aspectos aislados, el lector confiado supone que los conceptos expresados tampoco serán muy diferentes o difíciles de encajar. Sin embargo, esto es un error, y un engaño, puesto que las semejanzas lingüísticas a veces esconden trampas para la comprensión, y si no, tomamos como ejemplo "falsos amigos" como actually (de hecho) y actualmente (en el momento presente), o pretend (disimular) y pretender (procurar, hacer esfuerzos para conseguir algo). En cambio, el lector se aproxima a una obra escrita en una época más lejana (siglos XV, XVI o XVII) generalmente con más cautela precisamente porque el lenguaje es muy distinto y actúa como una señal de alarma: es lógico suponer que la sociedad descrita con una sintaxis diferente a la nuestra pueda tener costumbres y valores también diferentes. Nuestro propósito es, entonces, deshacer los engaños de tipo lingüístico cultural, arrojar luz sobre conceptos y valores inexplicables a primera vista, y ayudar a disfrutar de la lectura de la literatura en lengua inglesa.

\section{Guía de uso}

El Diccionario de Referencias Culturales contiene un millar de entradas, ordenadas alfabéticamente. Las voces aparecen en inglés, seguidas de la glosa de cada una en español. Hemos redactado esta obra en español precisamente pensando en los usuarios, estudiantes de Filología Inglesa con distintos niveles de dominio de la lengua inglesa, esperando facilitar de este modo la comprensión.

Las referencias que forman parte de esta obra de consulta abarcan casi todos los campos de la vida diaria de la 
época objeto de estudio:

Abreviaturas y acrónimos comunes.

- Comidas y bebidas (indicativas de clase, lugar geográfico, estado de salud).

- Costumbres y normas sociales.

- Enseñanza (centros, niveles del sistema, exámenes, titulaciones).

- Hechos históricos (y su interpretación según el punto de vista del lector nativo).

- Juegos, espectáculos, aficiones, lugares de reunión.

- Lugares (indicaciones indirectas de clase social y de rango).

- Nombres propios de personas y lugares en la ficción (sus connotaciones y onomatopeya).

- Personajes de ficción y leyendas.

- Personajes históricos (reyes, políticos, navegantes, científicos, héroes nacionales que forman parte de la herencia cultural del lector nativo).

- Pintores británicos y extranjeros que influyen en los movimientos artístico-literarios.

- Vestimenta y moda.

- Prensa (y sus connotaciones socio-políticas).

- Referencias a la mitología y a fuentes bíblicas

- Referencias políticas (partidos, legislación, figuras destacadas)

- Refranes populares, rimas y cuentos infantiles

- Religión (distintas confesiones y actitudes)

- Títulos y puestos (condecoraciones, profesiones de prestigio, indicaciones de nivel socioeconómico)

- Unidades de medida (longitud, peso, monedas)

- Vivienda (distribución del espacio y los nombres que se le atribuyen, muebles, estilos arquitectónicos, enseres).

Cuando en el texto de una entrada se hace referencia a un término sobre el que el Diccionario contiene una entrada propia, esta circunstancia se señala tipográficamente escribiendo la voz en negrita.

Ejemplo:

Erebus

Nombre de uno de los dos barcos (véase también 
Terror) bajo el mando de Sir John Franklin (1786-1847) que buscaban una ruta para pasar por el norte de Canadá. Ambos barcos quedaron atrapados en el hielo, y los tripulantes murieron a causa de las pésimas condiciones climatológicas. Según la mitología griega, Erebo era una caverna oscura a la entrada del infierno.

Cuando el Diccionario contiene entradas con información complementaria relacionada con la mencionada en una entrada determinada, y por otra parte no se hace referencia directa a dichas entradas en el texto, se remite al lector a ellas, escribiéndolas en negrita precedidas de Véase:

\section{Athenaeum}

Un "club" londinense para caballeros, fundado en 1824 , frecuentado por hombres interesados en la literatura, el arte y la ciencia. Véase club (gentlemen's club).

Este Diccionario también incluye un Índice Alfabético en el que aparecen todas las voces contenidas en él, además de un Índice Temático para que el lector tenga una idea clara de la información que puede encontrar en este volumen. La obra se completa con una bibliografía de obras que han servido como fuente de consulta para la realización de este texto.

\section{Agradecimientos}

La investigación necesaria para la primera fase de recopilación de datos y realización de cuestionarios se llevó a cabo con la valiosa colaboración de dos miembros del equipo original del Proyecto de Investigación: $\mathrm{D}^{\mathrm{a}}$ Teresa Álvarez Acuña y $\mathrm{D}^{\mathrm{a}}$ Olga Kirk Martínez. Finalmente, quisiéramos señalar que la investigación llevada a cabo para la elaboración de esta obra ha sido financiada por la Secretaría Xeral de Investigación e Desenvolvemento de la Xunta de Galicia, Proyecto XUGA10401A98. 

A Miguel, Pablo, Daniel y José Ramón 



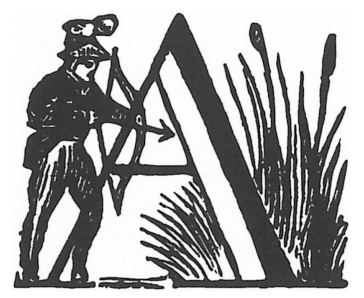

O! Many a shaft, at random sent, Finds mark the archer little meant! And many a word, at random spoken, May soothe or wound a heart that's broken. W. Scott. (1771-1832). The Lord of the Isles (1813). 



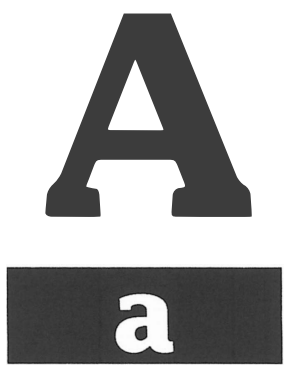

Admiralty Messages were passing from the Fleet to the Admiralty.(DAL)

La marina británica tenía su cuartel general junto a Admiralty Arch, un edificio que se asemeja a un puente debajo del cual pasa el tráfico entre The Mall, Whitehall, The Strand y Trafalgar Square. Fue construido entre 1906 y 1910 en homenaje a la reina Victoria, que falleció en 1901 . "Fleet" significa la flota de buques de guerra británicos. El departamento gubernamental del almirantazgo se integró en el ministerio de defensa en 1964.

Agincourt La batalla de Agincourt (1415) tuvo lugar en el norte de Francia, y dio la victoria a Enrique $V$, que luchaba contra los franceses, que eran más numerosos. Por este motivo, se recuerda como una gran victoria, y porque forma parte del drama Henry $V$ de Shakespeare.

Agnostic writings Ensayos escritos por T.H. Huxley (1825-1895) y Matthew Arnold (1822-1888).

Agricola Agrícola, Gnaeus Iulius: gobernador romano de Gran Bretaña (77-83 d.C.)

Alamo Una población de Estados Unidos (Texas) y nombre de un edificio militar de la zona famoso por ser el escenario del asalto y conquista de la ciudad por las tropas mexi- 
canas del general López de Santa Ana en 1836. Los 187 americanos liderados por Davy Crockett murieron pero su coraje los convirtió en héroes. Hoy en día la frase "Remember the Alamo" (Acordaos de El Alamo) se utiliza como grito de combate, sobre todo para animar a alguien a continuar con una tarea, proyecto o empresa difícil.

Albany The Albany era un inmueble de apartamentos lujosos para solteros, cerca de Piccadilly, en Londres. Era la residencia de George Ives, un amigo de Wilde en la vida real, homosexual y partidario de la emancipación. Ernest Worthing (IMP) vive en este edificio, y su dirección aparece en sus tarjetas de visita.

Aldgate Es un barrio popular de Londres, al este de la zona central.

Alfred the Great Rey de Wessex (871-899), luchó contra los invasores vikingos; protector de la Iglesia, promotor de la enseñanza, y padre de la prosa inglesa.

All Souls Uno de los colegios universitarios de Oxford. Las universidades de Oxford y Cambridge se organizan según el modelo de colegios independientes, que a menudo llevan el nombre de sus ilustres fundadores y patronos, mientras que la mayoría de las universidades británicas se dividen en escuelas y facultades.

Almack's He went to Almack's rather than to the Almighty for consolation. (FLW) El protagonista se refugió en un establecimiento de apuestas y juegos, ("Almack's"), en busca de consuelo, en lugar de confiar en la religión.

Almighty (Véase Almack's.) El Todo-poderoso, Dios.

Amadis of Gaul Alusión a un romance español de caballería, posiblemente de origen portugués del cual circulan versiones a partir del siglo XIV aunque el primer texto conocido data de 1508. Amadis era el más apuesto y valiente de los caballeros.

Anabaptists Nombre aplicado a una secta religiosa que surgió en Europa durante la Reforma (siglo XVI). El nombre significa "el que se bautiza nuevamente"; se refiere a la 
práctica anabaptista de bautizar a adultos creyentes, aunque la persona ya hubiera sido bautizada en su infancia.

Andersen Andersen, Hans Christian (1805-1875): autor danés de más de 150 cuentos infantiles. Abrió nuevas perspectivas tanto de estilo como de contenido en la literatura creada para un público infantil. Entre sus principales innovaciones cabe destacar el uso de un lenguaje cotidiano y dar salida a las expresiones de los sentimientos e ideas que previamente se pensaba que estaban lejos de la comprensión de un niño.

Angel Un distrito al este del centro de Londres donde había, hasta 1819 , una posada con el nombre de "The Angel". Cuando se derribó se conservó el nombre para la zona, y la estación del metro fue bautizada con ese nombre en 1901 .

Anglican Un miembro de la Iglesia anglicana o Iglesia de Inglaterra ("Church of England"), nombres que recibe la Iglesia nacional surgida en Inglaterra tras la Reforma protestante.

\section{Anglo Saxon Chronicle}

Crónica en inglés antiguo que narra la historia de Inglaterra desde la época cristiana hasta 1154 .

antimacassar Un rectángulo de tela decorada con bordados o encaje para adornar el respaldo de un sillón y protegerlo de las manchas de los productos que los hombres solían echarse en el pelo.

apartment En inglés británico sería "flat" (piso).

apothecary "Apothecary" es un sinónimo de "pharmacist" (boticario). A principios del siglo XIX también cubrían las funciones de los médicos de familia, especialmente en las zonas rurales. En 1815, cuando Austen estaba escribiendo Emma, fue aprobada una ley ("Apothecaries Act"), que regulaba sus funciones y estatus, y que provocó mucha polémica.

apple dumplings Es un postre de manzana dentro de una masa dulce, cocido en el horno.

apple jelly Este postre de manzana se realiza cociendo manzanas y azúcar hasta conse- 
guir una consistencia gelatinosa.

Arden Arden, Elizabeth: esteticista norteamericana famosa por poseer su propia marca de productos cosméticos.

Armada "Armada" es el nombre que recibe en inglés la flota de 129 barcos enviada por Felipe II para atacar Inglaterra. Fue derrotada por la flota inglesa, bajo el mando de Lord Howard of Effingham y Francis Drake, y por las adversidades climatológicas, en 1588. Todavía hoy en día, los libros de historia la llaman "Invincible Armada", con fina ironía, ya que resultó ser un fracaso para las pretensiones de Felipe II. Con minúscula, se usa para referirse a cualquier grupo grande de barcos.

Army Lists Eran listas de oficiales del ejército, con su rango, servicios prestados en tiempos de guerra, etc., para saber quién era quién en el ámbito militar en el siglo XIX.

arrange music Se trataba de programar la música adecuada para acompañar una recepción, cena, o reunión social en una casa particular de la clase alta durante el siglo XIX y a principios del XX.

arrow-root Un almidón comestible utilizado para fortalecer a la gente enferma e inválida.

Ascot (Royal Ascot) Un hipódromo cerca de Windsor, al oeste de Londres. Es tradición que la aristocracia, incluyendo miembros de la familia real, se reúna allí en junio para presenciar una serie de carreras que dura cuatro días. No sólo es una cita importante en el mundo de la hípica, sino que también es un gran acontecimiento social.

Ashmolean Museum Importante museo de arqueología en Oxford que reúne pinturas, esculturas y monedas. Creado por Elias Ashmole en 1683, es el museo público más antiguo de Gran Bretaña.

Asquith Asquith, Herbert Henry (1852-1928): estadista británico del partido liberal y primer ministro de 1908 a 1916. Su gobierno introdujo pensiones para los ancianos, redujo los poderes de la cámara alta ("House of Lords"), e hizo que Gran Bretaña participara en la Primera Guerra Mundial. 
Asquith Asquith, Margot (18641945): esposa de Herbert Henry Asquith, que escribió una autobiografía (Mrs. Asquith's Memoirs). Fue muy activa como anfitriona en acontecimientos sociales, y se hizo famosa por sus opiniones expresadas con humor fino sobre figuras de la política contemporánea.

Assembly Rooms Salas para reuniones públicas (conciertos, conferencias, etc.) o para actos sociales, especialmente en balnearios y lugares de veraneo en los siglos XVIII y XIX. El conjunto de salas con este nombre en Bath fue construido entre 1769 y 1771 . La Sala de Bailes, la Sala Octagonal, y la Sala del Té se utilizaban para los bailes, la música, las cartas y para tomar el té. Estas salas estaban suntuosamente decoradas con cuadros y valiosas lámparas de cristal.

Astley's Un teatro de Londres ("Astley's Amphitheatre") que fue fundado en 1768 por Philip Astley (1742-1814). Astley era antiguo sargento mayor de la caballería inglesa, y actuaba en las representa- ciones como jinete acróbata, junto con un payaso, músicos $y$ otros artistas. El término "circus" fue utilizado por primera vez en 1782 cuando su competidor, Charles Hughes, abrió las puertas de su "Royal Circus" muy cerca del anfiteatro. En 1772, y a partir de una serie de actuaciones en París, Astley acabó introduciendo el circo a través de la Europa continental y se le debe el establecimiento de circos permanentes en diversos países del continente.

Athenaeum Un "club" londinense para caballeros, fundado en 1824 , frecuentado por hombres interesados en la literatura, el arte y la ciencia. Véase club (gentlemen's club).

ATS Siglas que corresponden a "Auxiliary Territorial Service", una sección para las mujeres en el ejército británico. Realizaban tareas variadas de apoyo, como conductoras, mecánicas, administrativas, etc.

Aubrey Aubrey, John (16261697): escritor y arqueólogo inglés. Estudió las piedras 
megalíticas de Stonehenge y descubrió las de Avebury. Se le recuerda también por su obra Brief Lives, (1690) unos apuntes breves con anécdotas sobre la vida de personajes del siglo XVII.

Aunt Sally Un juego de feria en el cual la gente lanza pelotas contra una silueta de madera de mujer, intentando ganar pequeños premios.

Austerlitz That dinner at the King's Arms with his friends had been Henchard's Austerlitz: he had had his successes since, but his course had not been upward. (MOC) En esta batalla (1805) Napoleón I derrotó a los austríacos y rusos, y acabó con el Sacro Imperio Romano Germánico. Fue, por lo tanto, un momento de victoria para él, pero unos años después fue derrotado definitivamente en la batalla de Waterloo (1815).

\section{Australia (Véase send to} Australia y transported.)

Ave... Morituri te salutant Hail Caesar, those who are about to die salute you. (HOD) Pronunciado por los gladiadores al saludar al emperador romano. 


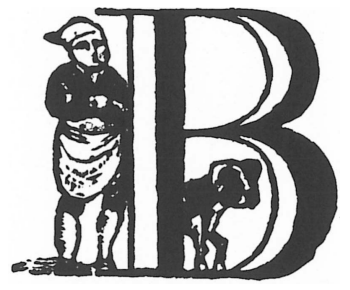

I want to know a butcher paints A baker rhymes for his pursuit, Candle-stick maker much acquaints His soul with song, or, haply mute, Blows out his brains upon the flute! R. Browning (1812-1889). Shop (1876) 



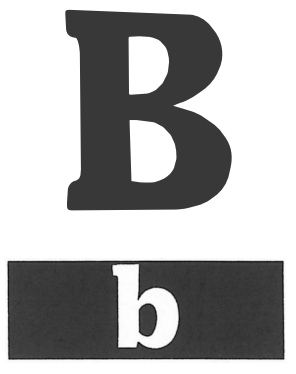

B.A. Siglas de "Bachelor of Arts": licenciado en letras o humanidades.

Bacchante Una sacerdotisa del dios Baco.

Bachelor of Arts Licenciado en letras o humanidades. Existe la variante "B.A. Hons.", que significa la misma licenciatura, pero "con honores", es decir, alcanzando un nivel más alto de exigencia.

bad odour Expresión idiomática que significa que algo o alguien está mal considerado; que se tiene una mala opinión acerca de algo o alguien.

badly Enfermo, indispuesto (dialecto del centro/norte de Inglaterra).

Baedeker Baedeker, Karl (18011859), editor alemán que en 1839 publicó su Rhein Handbuch (Manual del Rin), que inauguraba una serie de guías turísticas de bolsillo. Esta colección, que se publicó en alemán, francés e inglés, comprendía guías de casi todos los países europeos. Destacaban por sus excelentes mapas, su precisa información y un sistema de estrellas para distinguir los lugares de mayor interés.

bairn Forma dialectal de Escocia y Yorkshire que significa niño o niña.

bake "To be in a (great) bake": estar muy enfadado en lenguaje coloquial. 
bally Un eufemismo por "bloody" (condenado, maldito).

banditti Forma plural alternativa de "bandits" (bandidos), siguiendo su etimología italiana.

Bar Con mayúscula, significa la abogacía como profesión, o ser abogado de alto nivel con derecho a defender causas en los tribunales superiores.

bard Un poeta que recita poemas épicos. Cuando se dice "the Bard", se alude en concreto a Shakespeare.

barkled Their barkled shoes hung heavy on their steps. (SAL) Sus zapatos están endurecidos con barro, incrustados de suciedad. Es una forma dialectal del norte/centro de Inglaterra.

barm-man "Barm" es levadura natural, y "barm-man" era el repartidor que visitaba los pueblos y núcleos más apartados, vendiendo levadura para que la gente hiciera su propio pan. Es una forma arcaica y dialectal del norte/centro de Inglaterra.

Barnet Un pueblo limítrofe con Londres, al norte de la capital.
Baronne d'Almane Personaje de la novela Adelaide and Theodore escrita por la francesa Caroline Stéphanie Félicité Ducrest, condesa de Genlis en 1782.

barrow Un túmulo que contiene restos de un enterramiento prehistórico.

Barthes Barthes, Roland (19151980): crítico literario y ensayista francés, creador de la "nouvelle critique", en la cual utilizaba el psicoanálisis, la lingüística estructural y el pensamiento marxista para evaluar el texto.

Bath Una ciudad balnearia en el sudoeste de Inglaterra, muy popular en los siglos XVIII y XIX cuando los miembros de las clases acomodadas acudían a tomar los baños y beber el agua que se suponía mejorarían la salud, y al mismo tiempo descansar y hacer vida social.

Bath chair Una silla de ruedas cubierta con un pequeño toldo, utilizada especialmente por personas enfermas o por gente mayor.

Bath paper Periódico local de la ciudad de Bath que daba información acerca de las lle- 
gadas y estancias de personas de buena posición. Así, las personas que deseaban ascender en la escala social, conocer a personas influyentes, conocer a posibles futuros esposos, etc. leían con asiduidad las noticias acerca de los movimientos de los personajes importantes para poder planear su vida social, coincidiendo en las recepciones $y$ reuniones públicas. Véase también Assembly Rooms y Bath.

\section{battledores and shuttlecocks}

Raquetas y volantes usados en un juego parecido al bádminton.

Bayeux Tapestry Tapiz medieval que representa las Batalla de Hastings, además de los eventos previos a la conquista de Inglaterra por los normandos en 1066. Mide unos 70 metros de largo, y 50 centímetros de ancho y se conserva en el museo de la catedral de Bayeux, Normandía. Además de su valor artístico, se considera un importante documento visual de la historia del siglo XI.
Bayswater En la década de los 1890 , Bayswater era una zona vulgar de Londres.

beads La oración del rosario, o el rosario en sí, ya que "beads" son cuentas ensartadas.

beastly Desagradable, indeseable. Es un ejemplo del vocabulario exagerado, estereotipado de un antiguo alumno de un colegio privado del siglo XIX.

Beau Brummel Véase Brummel, George Bryan.

beaver fur. Piel de castor que era muy apreciada; por lo tanto las prendas hechas de esta piel eran caras.

Beckenham Reserves El equipo local de futbol correspondiente a Beckenham que se encuentra en el límite sudeste de Londres.

Becky Sharp Es el título del primer largometraje en color, producida en 1935. El argumento se basaba en Vanity Fair de Thackeray.

Bedford Square Una plaza londinense que se encuentra frente al Museo Británico.

Bedlam Un manicomio célebre de Londres. Su nombre proce- 
de de "St. Mary of Bethlehem". Se fundó en 1274 como monasterio, y en el siglo XIV se convirtió en manicomio. Se podía visitar como una forma de entretenimiento, viendo cómo se comportaban los internos. La palabra "bedlam" ha llegado a significar un lugar o una escena de confusión, ruido y desorden.

beet-root Remolacha de mesa. Es típica en una cena fría, acompañando la ensalada y el fiambre.

Belgrave Square Esta calle se encuentra en una zona residencial exclusiva de Londres. Según Lady Bracknell (IMP) el lado de los números pares es más elegante que el opuesto.

Belinda Título de una novela de Maria Edgeworth, escrita en 1801.

Bellerophon Belerofonte era el hijo de Glauco y Eurímeda, que mató a su hermano Béleros fortuitamente. En el exilio pretendieron asesinarlo varias veces. Intentó llegar hasta el dominio de Zeus, montado en su caballo Pegaso, pero Zeus lo arrojó otra vez a la tierra y murió.
Bench El cargo de juez o magistrado; también se utiliza para referirse al conjunto de jueces en un juicio. La expresión "to sit on the Bench" significa formar parte de un tribunal, o desempeñar el cargo de magistrado en una localidad. Nótese que se escribe con una "B" mayúscula, ya que con minúscula significa simplemente un asiento o banco de madera.

Bennet girls Son las cinco hermanas protagonistas de Pride and Prejudice (1813) de Jane Austen.

Bentham Bentham, Jeremy (1748-1832): abogado y filósofo británico, creador del utilitarismo. Quiso demostrar que el objetivo principal de la ciencia era conseguir el mayor bienestar para el mayor número de personas posible.

Berkeley Square Esta plaza está situada en la zona elegante de Green Park, perpendicular a la calle Piccadilly, en el centro de la vida social londinense del siglo XIX.

Berkeleyan Relacionado con George Berkeley (1685-1753), obispo y filósofo irlandés que escribió acerca del idealismo 
subjetivo en Principles of Human Knowledge (1710).

best man Un amigo o pariente del novio que hace las veces de padrino de boda.

bide Soportar (uso dialectal de Yorkshire).

bijou Palabra francesa incorporada al inglés que significa pequeño y elegante, especialmente en el contexto de una casa o un apartamento.

billy-o Es un intensificador coloquial. La expresión "freezing like billy-o" (DOH) significa que hace mucho frío.

bishop One was the younger son of a bishop and a famous disgrace to his father. (FLW) Hay que recordar que los sacerdotes de la Iglesia Anglicana pueden contraer matrimonio. Por lo tanto, el hecho de que el obispo en cuestión tenga un hijo no es motivo de vergüenza; el comportamiento del hijo es lo que provoca el comentario.

Bismarck Bismarck, Otto von (1815-1898): estadista alemán, opuesto a los principios liberales. El "Canciller de Hierro" fue capaz de unificar los estados alemanes bajo el mando de Prusia después de la guerra francoprusiana.

Bisurated Magnesia Medicina para el estómago para aliviar problemas de indigestión, acidez, etc.

Black Hole of Calcutta El 20 de junio de 1756, Nawab Sirajud-Daula encerró a 146 ciudadanos europeos capturados en Calcuta en una pequeña y oscura celda. A la mañana siguiente, sólo habían sobrevivido 21 de ellos. Esto sucedió durante la guerra entre Francia y Gran Bretaña por el control de los intereses comerciales en la India.

Black Horse The Alfred Brangwen of this period had married a woman from Heanor, daughter of the "Black Horse". (RAI) El Caballo Negro/Blanco, el León Rojo, El Hombre Verde, etc. son nombres típicos para los "pubs" en Gran Bretaña. Se entiende que la mujer en cuestión es hija del dueño de la taberna.

black twist Tabaco oscuro retorcido en forma de cordón.

Black Watch Nombre popular del "Royal Highland Regiment", regimiento escocés del ejérci- 
to británico. El color negro se refiere al tono oscuro de la tela de su falda escocesa.

blackout curtains Cortinas negras para ocultar la luz como medida de protección contra ataques aéreos. Se trataba de evitar que la luz de las casas diese pistas a los bombarderos enemigos que intentaban localizar de noche los centros urbanos y los blancos de sus bombas.

blazer $A$ team of cricketers passed, agile young men in flannels and blazers. (POR) La ropa típica para la práctica del críquet consistía en pantalones blancos de franela ("flannels") y una americana ("blazer") con el escudo del equipo en el bolsillo superior. El críquet era un deporte practicado en Inglaterra y entre los protestantes en Irlanda, mientras que los republicanos preferían el fútbol irlandés. Hoy en día los practicantes profesionales de este deporte llevan ropa deportiva más moderna y práctica, pero en los pequeños pueblos donde los aficionados juegan los domingos por la tarde (con una pausa para el té), la indumentaria tradicional aún se impone.

Blenheim Pueblo en el condado de Oxfordshire, famoso por su magnífico palacio y jardines. El palacio pertenece a la familia del Duque de Marlborough, y, nació allí el nieto del séptimo Duque, Winston Churchill.

Blimp Colonel Blimp es un personaje inventado por el dibujante Low. A través de la expresión de unas opiniones convencionales, poco fundamentadas, el dibujante se burla de los oficiales del ejército y de la gente de derechas en general. Se da la casualidad de que la persona que menciona este personaje (LBA) es un coronel retirado del ejército británico en la India.

blind-hookey Un juego de cartas, con apuestas.

blinking Un adjetivo de uso informal que significa maldito, condenado. Se usaba antes como eufemismo del más ofensivo "bloody".

Bloomsbury El distrito de Bloomsbury está en el centro de Londres. A principios del siglo $X X$ fue elegido como 
lugar de residencia por varios intelectuales y escritores de la época, entre ellos Virginia Woolf y su esposo Leonard.

bluddy Un adjetivo de carácter ofensivo y uso vulgar, que suele escribirse "bloody", y que significa condenado, maldito. A menudo se utiliza como intensificador, y en este caso pierde parte de su carácter ofensivo: "a bloody good lot".

blue Unos polvos azules que se añadían a la colada para mejorar el aspecto de la ropa blanca.

Blue (editor) The successful Yellow candidate for the borough of Old Topping, perhaps feels no meditative hatred toward the Blue editor who consoles his subscribers with vituperative rhetoric against Yellow men who sell their country and are the demons of private life. (MOF) El azul es el color del partido conservador británico, y el amarillo corresponde a los liberales (antes "Whigs"). Cuando se escribió The Mill on the Floss los miembros del parlamento se elegían en base a los "boroughs", o circunscripciones que a menudo no tenían habitantes ("rotten boroughs"). Se podía conseguir un escaño parlamentario con muy poco esfuerzo, siendo una manera cómoda de colocarse para los nuevos ricos. Este abuso desapareció con la ley de reforma electoral de 1832 ("Great Reform Act").

Blue Beard Nombre de un personaje de un cuento que mató a varias esposas, una tras otra, por desobedecer su orden de no abrir una habitación cerrada con llave. La última esposa de Blue Beard descubrió que la habitación estaba llena de los esqueletos de sus predecesoras.

blue books Los libros azules son informes gubernamentales sobre los ingresos y gastos de la nación.

Blue Lias. Tipo de piedra caliza que se encuentra en el sudoeste de Gran Bretaña.

blue moon "Once in a blue moon" es una expresión que significa no muy a menudo, en raras ocasiones.

Blue Vinny Una variedad de queso blanco con vetas azules. Parece que está lleno de gusanos. 
bob En lenguaje coloquial significaba un chelín ("shilling"). Ya no se usa esta moneda, dado que se pasó al sistema decimal en el año 1971.

bobby-dazzler Algo o alguien que sobresale por su belleza o elegancia; una persona que impresiona por estar muy bien vestida (dialecto del centro/norte de Inglaterra).

Bodleian La biblioteca de la universidad de Oxford restaurada en el siglo XVII por Sir Thomas Bodley.

boghole Gran parte del terreno en Irlanda era pantanoso. Se formaban charcos en la superficie de la turba, y estos huecos se llamaban "bogholes".

Bond Street Es una calle comercial de la zona oeste de Londres. Tiene las tiendas más exclusivas, además de una gran variedad de comercios de distintos tipos.

bonnet Un sombrero de señora, atado debajo del mentón, y con un ala enmarcando la cara. Estaba de moda durante el siglo XVIII.

book I see from your book that on Thursday night ... eight bottles of champagne are entered as having been consumed. (IMP) Se refiere al libro del mayordomo, en el cual apunta las bebidas servidas. Un mayordomo debía llevar este registro escrupulosamente.

boss Una especie de taburete para apoyar los pies.

Bossuet Bossuet, Jacques Bénigne (1627-1704): clérigo francés y escritor, uno de los más grandes oradores de púlpito franceses. Desde 1670 hasta 1681 desempeñó el cargo de preceptor del gran delfín, hijo del rey Luis XIV y María Teresa, para quien escribió su gran Discurso sobre la historia universal (1681), uno de los primeros intentos por dar un tratamiento filosófico a la historia. En él mantenía que toda la historia está impulsada por la providencia.

Boswell Boswell, James (17401795): escritor escocés, fue gran amigo y biógrafo del escritor Samuel Johnson. En 1763 Boswell había conocido a Johnson, y a partir de 1772 y hasta la muerte de Johnson, 
en 1784 , los dos mantuvieron estrechas relaciones. En 1773 Boswell fue admitido en el club literario de Johnson, del que formaban parte el estadista Edmund Burke, el escritor Oliver Goldsmith, el pintor Sir Joshua Reynolds y el actor David Garrick. A partir de entonces, Boswell dedicó gran parte de su tiempo a escribir notas detalladas de las actividades y conversaciones de Johnson.

Botany Bay En los siglos XVIII y XIX se utilizaba este nombre geográfico como sinónimo de Australia. James Cook había fundado este puerto en la costa este en 1770 , y a partir de 1787 el gobierno británico mandó a miles de criminales y deudores a esta colonia penal para deshacerse de ellos. Después, se empleó el nombre de Botany Bay para designar cualquier lugar en Australia donde había convictos transportados.

Bounderby Este apellido se ha formado del sustantivo "bounder": grosero, hortera, mal educado. (HAT)
Bourget Bourget, Paul-Charles Joseph (1852-1935): poeta, crítico y novelista francés, autor de la novela El discípulo (1889) que daba más importancia a la motivación psicológica que a la ambiental.

Bournemouth Ciudad en la costa sur de Inglaterra, en el Canal de la Mancha, conocida como un lugar de veraneo por su clima benigno, y también muy popular como ciudad de retiro para muchos jubilados.

bow window Una ventana curvada que sirve como mirador.

Bowdler Bowdler, Thomas (1754-1825): escritor norteamericano que publicó su Family Shakespeare en 1818, una versión expurgada de los textos que según él contenían muestras de obscenidad. Su obra dio lugar al verbo "to bowdlerize": editar una obra para quitar todo lo que podría considerarse ofensivo.

box Aparte de significar caja, también significa palco en un teatro. 
Box Brownie Una sencilla cámara de cajón, muy popular en los años treinta y cuarenta.

Box Hill Lugar turístico en el sur de Inglaterra, muy famoso por sus vistas y paseos.

Boy Scouts Organización de carácter educativo y deportivo para niños de 11 a 16 años conocida en España como los Exploradores o los Scouts. Fue fundada en 1908 por Lord Baden-Powell para estimular el sentido de la aventura y la responsabilidad hacia los demás. Sus miembros tienen fama de ser honrados y trabajadores y se ofrecen a menudo para tareas solidarias. (Vease Girl Guides.)

Boy's Own Paper. Revista que se publicó desde 1879 hasta 1967, dirigida a niños, y que incluía relatos de aventuras, noticias deportivas, crucigramas y otros pasatiempos. La frase "Boy's Own" se utiliza para describir algo emocionante en la vida real, como una hazaña, o una aventura propia de las páginas de la revista.
Bracknell Oh dear, oh dear! My wife's friends! Pass Lady Bracknell the cucumber sandwiches, will you? (LBA) Lady Bracknell es un personaje perteneciente a la aristocracia que aparece en The Importance of Being Earnest, de Oscar Wilde. Cuando viene de visita, su sobrino prepara la típica merienda fina para personas de su clase: emparedados de pepino y té. El personaje que pronuncia las palabras citadas aquí se burla de las amistades de clase alta de su mujer.

Bradlaugh Bradlaugh, Charles (1833-1891): conferenciante radical y republicano, fue elegido como diputado al parlamento británico en 1880 , sin ser admitido por no jurar lealtad a la corona. Consiguió entrar en 1886, y se interesó sobre todo por los asuntos relacionados con la India.

Brasso Marca de un producto para limpiar cobre, bronce, etc.

brat Forma peyorativa para niño, niña, semejante a mocoso. 
brew Hacer y tomar una taza de té.

bridge Un juego de cartas que se juega por parejas.

bridle-path Un camino estrecho donde los jinetes tienen preferencia de paso.

\section{Brief Lives Véase Aubrey, John.}

Brighton Line La ciudad costera de Brighton, al sur de Londres, era un lugar de veraneo muy popular, que debe su fama al patrocinio del Príncipe Regente (futuro Jorge IV). Una línea férrea unía la capital con esta ciudad.

brioche Bollito redondo francés hecho de pan dulce.

Britannia Nombre poético para Gran Bretaña. Se representa como una mujer sentada, con un tridente en la mano, símbolo del poder marítimo del país, y sosteniendo un escudo que lleva la bandera nacional.

British opera They whistle some dreadful popular air from a British opera. (IMP) Alguna de las óperas u operetas de los compositores británicos Gilbert y Sullivan, que eran muy populares en la época de Wilde. Tendrían su equivalente aproximado en la zarzuela española. El diálogo que sigue la cita, que es una indicación para la dramatización de la obra de teatro de Wilde, es una parodia del diálogo operístico.

broad hems Es una forma de expresar luto y consiste en llevar bandas negras cosidas en la ropa.

broadcloth Se trata de una tela gruesa de muy buena calidad, propia de personas acomodadas.

Broadwood's Una empresa que fabrica pianos desde 1728, y que se hizo famosa por construir uno para Beethoven en 1817. Frecuentemente estos pianos son considerados los mejores.

Brook's Marca prestigiosa de atuendos para caballero.

broth Una sopa hecha de carne y verduras.

brown En lenguaje coloquial, una moneda de un penique. Hasta la introducción del sistema decimal en 1971, las monedas de un penique eran de unos dos centímetros de diámetro y de cobre, y por lo tanto de color marrón. 
brown holland Una tela fuerte de algodón que se fabricaba en Holanda. Se usaba en cortinas, persianas, pantallas de lámparas, o para proteger los muebles. Se llama "brown" porque es de color crudo, sin blanquear.

Brown Brown, Ford Madox (1821-1893): pintor británico que influyó en el grupo prerrafaelista. Es reconocido por sus pinturas históricas y de temas literarios que se caracterizan por su rico colorido y minuciosidad en los detalles de atuendos y escenarios. Sus obras más conocidas son The Last of England (1852-1855) y Work (1852-1865).

\section{Brummel Brummel, George} Bryan (Beau Brummel) (17781840): el hombre elegante que marcaba la moda en Londres en la época de Jorge III y Jorge IV. Se Buscaba la perfección en el vestir, sin escatimar en gastos ni en el tiempo necesario para realizar su aseo.

Buckingham El nombre del palacio real en el centro de Londres. También es el nombre de una ciudad en el sur de
Inglaterra, a unos 100 kilómetros de Londres.

buckram Una tela muy tiesa (bucarán); metafóricamente, también significa una apariencia o actitud severa, o demasiado formal.

bunkum Conversación poco sincera o llena de disparates.

Burford Church La iglesia de San Juan Bautista de Burford en Oxfordshire, originalmente normanda, que presenta una capilla del siglo XIII y un chapitel (aguja) del siglo XIV-XV.

Burke Burke, Edmund (17291797): político, filósofo y ensayista británico, nacido en Irlanda, que se opuso a las leyes fiscales que provocaron la rebelión de las colonias norteamericanas. Fue famoso tanto por su brillante oratoria como por su crítica de la Revolución Francesa, así como por su ensayo $A$ Philosophical Enquiry into the Vindication of a Natural Society (1757). En 1758 fundó el Annual Register, anuario político británico, al que dedicó treinta años de su vida 
butterscotch Un caramelo duro y quebradizo, parecido al "toffee", hecho de mantequilla y azúcar.

Button $\mathrm{Mr}$ William Button of Tooley Street (HAT) era un personaje cómico de una obra de teatro muy popular en el siglo XIX. Se representaba en el circo, hasta convertirse en una especie de "pantomime".

butty Shall ter finish, Sorry? Cried Barker, his fellow butty. (SAL) Aparte de significar un compañero de trabajo, o un amigo en general, también era un intermediario entre los propietarios de las minas y los mineros. Fijaba las condiciones económicas para la extracción de carbón, y se quedaba con un porcentaje de los beneficios. (Shall ter finish: "will you have finished soon"; dialecto del centro/norte de Inglaterra.)

by hook or by crook Significa conseguir algo cueste lo que cueste, de forma legal o ilegal; por las buenas 0 por las malas. 



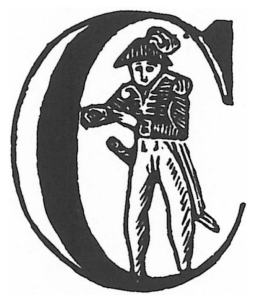

O captain! My Captain! Our fearful trip is done,

The ship has weathered every rack, the prize we sought is won,

The port is near, the bells I hear, the people all exulting.

W. Whitman (1819-1892).

O Captain! My Captain! (1871). 


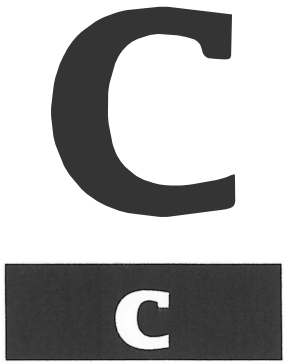

C.O. Siglas que corresponden a "Commanding Officer", que es el oficial al mando en las fuerzas armadas.

C.O.'s H.Q. Siglas correspondientes a "Commanding Officer's Headquarters", cuartel general del oficial al mando en las fuerzas armadas, generalmente durante una campaña militar, o durante unas maniobras.

Cader Idris Una cordillera situada en el oeste de Gales, de unos 900 metros de altura.

Caesar Caesar, contemplating the Sussex coast. (MOO) Alusión al intento de invasión de Inglaterra por Julio César en 55 a.C. No llegó a avanzar más allá de la costa sur. Los romanos realizaron una nueva invasión en 43 d.C., para quedarse en Gran Bretaña durante cuatro siglos.

Café Royal Un restaurante famoso en Regent Street, Londres. Durante el siglo XIX era un lugar de moda frecuentado por artistas y escritores.

call a spade When I see a spade I call it a spade. (IMP) Hablar con franqueza, llamar las cosas por su nombre. En español el refrán equivalente sería llamar al pan pan $y$ al vino vino.

Calvinism Una formación religiosa protestante extremista 
fundada por Juan Calvino (1509-1564). Sus miembros opinaban que el hombre está predestinado a la salvación o al infierno. (G. B. Shaw odiaba los seguidores de estas ideas.)

Camargo petticoat La enagua de una bailarina

Cambridge Tripos Exámenes finales de la universidad de Cambridge para licenciarse con honores y conseguir un B.A. en ciertas asignaturas.

Camden Town Es un barrio popular al norte de la zona centro de Londres.

Camilla El título de una novela de Francis (Fanny) Burney (1752-1840) publicada en 1796.

cant lass Una buena chica (dialecto del norte de Inglaterra).

canterbury Un mueble con divisiones verticales donde se guardaban las partituras, revistas, o papeles sueltos.

cap "To set one's cap at somebody": intentar conquistar a alguien.

castor En el contexto de los alimentos, es un recipiente para los condimentos para usar en la mesa. cat's cradle Un juego infantil en el cual un cordel sin fin colocado en los dedos de una persona se pasa a los dedos de otra persona formando una figura simétrica diferente en cada traslado.

Cecilia El título de una novela de Francis (Fanny) Burney (1752-1840) publicada en 1782.

cellery Apio, que se acostumbraba comer junto con el queso. Hoy en día se escribe "celery".

Champers En lenguaje coloquial significa champán.

Chancellor of the Exchequer Es el cargo de ministro de economía en Gran Bretaña. A veces se refiere al responsable de este ministerio sólo como "the Chancellor". No debe confundirse este término con otro igual que se usa en el contexto académico para designar al rector de una universidad, ni con el cargo de Lord (High) Chancellor.

Chanson de Roland La Chanson de Roland es probablemente la canción de gesta más antigua (hacia 1100). Narra la historia 
de la batalla de Roncesvalles en 778 .

chany Es una versión dialectal de "china": porcelana, vajilla, objetos asociados con la mesa.

chapel-goers Personas que asisten a los ritos religiosos celebrados en una capilla no conformista, y que no pertenecen a la Iglesia Anglicana. Es un término ligeramente peyorativo.

chaperon Carabina, señora de compañía.

chaps Las quijadas (de cerdo).

Char Bydis They've got you every way you turn: it's a choice between the Skilly of the workhouse and Char Bydis of the middle class. (PYG) Se trata de una pronunciación vulgar de "Scylla and Caribdis" (véase Episodio 9 de Ulysses de Joyce). "Scylla" representa las rocas y "Caribdis" es el remolino. El significado aquí es que el protagonista tiene que elegir entre dos alternativas igualmente desagradables.

Chartists Un movimiento que intentaba promocionar cambios electorales y parlamenta- rios. Fue muy popular en los tiempos de depresión, pero perdía adeptos en tiempos más prósperos.

Chausable El apellido del Reverendo Canon Chausable (en The Importance of Being Earnest) se parece a "chasuble", que es la túnica del sacerdote (la casulla).

Cheap Jack Un vendedor de artículos de calidad dudosa que opera en la calle o en la feria. También se escribe en una sola palabra y sin mayúsculas ("cheapjack").

Cheapside Una zona comercial en el este de Londres. La zona este ha sido habitada por las clases más humildes desde el siglo XVIII, cuando la corte se desplazó hacia el oeste para disfrutar del terreno más seco y del aire menos contaminado, dado que los vientos soplaban desde el oeste hacia el este, llevando el humo y los malos olores hacia los barrios menos favorecidos.

chemist And as there was noone of higher social importance than the doctors, the colliery-managers, and the chemists ...(RAI) El significado 
aquí no es químico, sino farmacéutico, boticario.

chesterfield Un sofá con respaldo y apoyabrazos, tapizado y mullido.

chevaux-de-frise (...) her long neck was protected by a chevaux-de-frise of miscellaneous frilling. (MOF) Una fila protectora de pinchos en la parte superior de un muro o una valla. En este ejemplo, los fruncidos del escote de la señora son tan tiesos que parecen una defensa.

chicken in aspic El pollo se prepara con una gelatina para aderezar este plato.

Childe Childe, Vere Gordon (1892-1957): antropólogo y arqueólogo británico, uno de los más destacados especialistas en el estudio de la prehistoria. Childe abordó grandes cuestiones, como los orígenes de la agricultura y el surgimiento de las ciudades y civilizaciones.

Children of the Abbey Una novela gótica de Ann Radcliffe (1764-1823) escrita en 1798.

chinless wonder Have you seen her brother? Brother
Nigel? The straight-backed, chinless wonder from Sandhurst? (LBA) En lenguaje coloquial esta expresión (una maravilla sin mentón) significa un hombre de buena familia, pero de carácter débil, que parece algo atontado, y que no tiene nada inteligente que decir. Sandhurst es la academia militar de más prestigio de Gran Bretaña. El hermano Nigel mantiene la espalda recta debido a su formación militar, pero no tiene carácter. La implicación de la expresión "chinless wonder" es que el ejército británico produce muchos oficiales de estas características.

chintz Una tela de algodón de tacto sedoso con grandes dibujos florales muy frecuente en la decoración de los hogares de clase media en Gran Bretaña. Se usa sobre todo en cojines, cortinas, colchas etc.

\section{chip of better quality Thomas} was a chip of better quality than the old block had been. (DOH) El refrán original es "a chip off the old block", equivalente al español "de tal palo tal 
astilla". Aquí se sugiere que Thomas era mejor que su padre.

Chippendale Chippendale, Thomas (1718-1779): nombre de un fabricante inglés de muebles en el siglo XVIII. Las piezas del estilo Chippendale se caracterizan por sus líneas fluidas, adornos finamente tallados, y una combinación de elegancia y resistencia.

\section{Christopher Robin Véase Robin, Christopher}

chucker-out Persona encargada de echar a los alborotadores y borrachos de un lugar público, o de impedir la entrada a las personas no invitadas a una fiesta privada en un local. El término más habitual es "bouncer".

\section{Churchill Churchill, Sir} Winston Leonard Spencer (1874-1965): político recordado como uno de los mejores estadistas de Gran Bretaña. Ocupó varios puestos importantes, pero tuvo un papel fundamental como Primer Ministro durante la Segunda Guerra Mundial. Es famoso además por sus discursos patrióticos durante los años difíciles de la guerra.

City of Sin Se refiere a París, que se asociaba en el siglo XIX con la vida bohemia y un estilo de vida poco decoroso. Aunque se miraba con horror desde Inglaterra, las familias acomodadas seguían enviando a sus hijos a París para que se "educaran" en algunos aspectos que no serían bien vistos en la Inglaterra victoriana.

Clane Un pueblo en County Kildare entre Clongowes y Bray, Irlanda.

Clapham Un barrio de la parte sur de Londres.

Clifton Una ciudad balnearia en el sudoeste de Inglaterra, muy popular en los siglos XVIII y XIX cuando los miembros de las clases acomodadas acudían a tomar los baños y beber el agua que se suponía mejorarían la salud, y al mismo tiempo descansar y hacer vida social.

cloak-room Es la consigna en una estación. A veces también es un eufemismo para los aseos. 
clothes horse Un tendedero plegable, tradicionalmente de madera.

club (gentlemen's club) Había, y aún hay, varios "clubs" de caballeros en la zona elegante de St. James y Pall Mall, en Londres. Se utilizaban como lugar de reunión para los hombres jóvenes de la clase alta. El ingreso era por recomendación de varios miembros, y había que obedecer ciertas reglas de comportamiento. Las mujeres no podían entrar. Estas instituciones se desarrollaron a mediados del siglo XVIII. Antes de esta fecha los hombres se reunían en los cafés. White's, el "club" más antiguo empezó como un salón donde se servía chocolate, $y$ en el de Edward Lloyd se reunían los hombres con intereses comerciales en la navegación. Este café y club se convirtió luego en la entidad aseguradora Lloyd's. Los que se interesaban por la ciencia y la literatura se hacían miembros del Athenaeum, los políticos se reunían en Brook's, en el Reform Club, o el Carlton Club, y los personajes relacionados con el teatro solicitaban el ingreso en el Garrick, que tomó su nombre del actor y empresario David Garrick.

CND Siglas que corresponden a "Campaign for Nuclear Disarmament". Esta organización británica empezó a protestar contra las armas nucleares en 1958, y se hizo famosa como organizadora de una serie de marchas de protesta entre Londres y Aldermaston entre 1958 y 1963. Este pueblo del sur de Inglaterra era el objetivo de sus protestas porque allí se encontraba el centro de investigación sobre las armas atómicas ("Atomic Weapons Research Establishment"). En la década de 1980 la CND volvió a tener protagonismo cuando promocionó conciertos, manifestaciones y otros eventos para protestar contra las bases norteamericanas en Gran Bretaña.

coconut man Tradicionalmente había un juego de feria en el cual la gente lanzaba pelotas contra unos cocos colocados en soportes. Si se derribaba el coco, la persona afortunada se llevaba el coco como premio. El puesto donde se realizaba 
este juego se llamaba "coconut shy".

cod Significa gastar una broma, engañar con bromas en el lenguaje coloquial.

coif Un gorro pequeño de tela blanca que se llevaba en la coronilla o la parte trasera de la cabeza de las mujeres.

Coketown Literalmente, ciudad del coque. No es un nombre muy atractivo por sus connotaciones de humo, suciedad, contaminación, etc.

collier Un trabajador de una mina de carbón.

colliery-manager El encargado de una mina de carbón.

Colonial. Una persona oriunda de una de las trece colonias que originalmente formaban los Estados Unidos.

colours of the rainbow ...a large shining map, marked with all the colours of the rainbow. There was a vast amount of red -- good to see at any time, because one knows that some real work is done in there, a deuce of a lot of blue, a little green, smears of orange, and on the East Coast, a purple patch, to show where the jolly pioneers of progress drink the jolly lager-beer. However, I wasn't going into any of these. I was going into the yellow. (HOD) Los mapas ingleses de finales del siglo XIX mostraban los territorios que pertenecían al impero británico en color rojo, los territotios franceses en color azul, los de Portugal en color naranja, los de Italia en verde, los de Alemania en violeta, y los de Bélgica en amarillo. La gran cantidad de rojo representa, por lo tanto, la extensión del imperio británico. A través de este código de colores, el narrador muestra sus prejuicios y opiniones acerca de la presencia de otras naciones y sus colonias. Para él, es reconfortante ver tanto rojo (donde además dice que se trabaja de verdad), opina que hay demasiado azul, es decir demasiada presencia francesa, se burla de los alemanes porque beben demasiada cerveza, y anuncia por medio del color amarillo que va a viajar hasta una zona bajo el control de los belgas.

come of age I am Miss Cardew's guardian, and she cannot 
marry without my consent until she comes of age. (IMP) Hoy en día los jóvenes alcanzan la mayoría de edad a los 18 años, pero en la época de Oscar Wilde se llegaba a este estado legal a los 21 años.

Commerce Un juego de cartas en el cual los jugadores pueden intercambiar cartas por turnos hasta que alguien se niega, y entonces el que tiene la mejor mano es el ganador. Para purple of commerce, véase purple.)

Communist Manifesto Obra publicada en 1848 en la que Karl Marx y Friedrich Engels desarrollan los principios del comunismo. Termina con la frase "Trabajadores del mundo, uniros".

compos mentis Expresión en latín que significa tener el control completo de la mente.

Comus Es el título de una mascarada cortesana (obra de teatro acompañada de música) escrita por John Milton en 1634.

Conduit Street Esta calle es perpendicular a Regent Street, en el centro de la vida social de Londres en el siglo XIX.

\section{Congregationalist Persona} que pertenece a una rama protestante de la iglesia cristiana ("Congregationalism") en la cual cada iglesia gobierna y gestiona sus propios asuntos.

Constable Constable, John (1776-1837): uno de los mejores pintores de paisajes ingleses. Consiguió un efecto natural pintando óleos y acuarelas al aire libre. Inspiró a los futuros Impresionistas con obras como The Hay Wain, que mereció la medalla de oro de la Exposición de París de 1824.

constitutional "Take one's constitutional" significa dar un paseo con cierta frecuencia para mantenerse en forma.

continental. Her own breakfast consisted of rusks in hot milk, which was, as she said to Portia, rather more Continental.(DOH) Adjetivo utilizado en Gran Bretaña para describir, con cierto desdén, lo europeo. Se da una valoración superior a un desayuno completo inglés, que a un desayuno continental, más escaso.

convenience Aseo público.

Cook Cook, James (1728-1779): navegante y explorador británico, casi siempre llamado "Captain Cook", famoso por los tres viajes de exploración que hizo al océano Pacífico 
sur $y$ a las costas de Norteamérica. Fue el primer europeo en llegar a la costa este de Australia en 1770, y trazó los primeros mapas de Nueva Zelanda y Nueva Guinea. También fue el primer europeo en llegar a Hawai, donde murió durante un enfrentemiento con los nativos. Por casualidad descubrió cómo evitar el escorbuto entre sus tripulantes mediante la ingesta de vitamina C. Cook fue un navegante muy competente, pero debe gran parte de su éxito al trabajo de John Harrison, un relojero inglés, quien inventó un cronómetro para determinar con precisión la longitud.

coomb Nombre empleado para referirse a un valle corto, sobre todo en el sur de Inglaterra. (También se escribe "combe".)

Co-op "The Co-op" o "The Cooperative Wholesale Society" era una asociación entre propietarios de tiendas y sus clientes. Los beneficios se devolvían a los socios de la asociación, como si fuesen accionistas. Fomentaban el ahorro, y premiaban a los clientes socios con dividendos dos veces al año.

Coptic Goddess Relativo a la iglesia cristiana en Egipto o Etiopía.

Coroner's Inquest La investigación de un juez de primera instancia sobre un accidente o una muerte violenta.

cosy Un cubretetera de tela gruesa, acolchada, para que el té se mantenga caliente más tiempo.

Coty Marca de productos cosméticos de calidad media y precios asequibles.

Country Life Revista mensual británica fundada en 1897, y que publica artículos acerca de la vida rural, tratando temas como la jardinería, la caza, la pesca y la vida social en el campo. Se asocia esta revista con gente acomodada que vive en el campo o que son dueños de grandes extensiones de tierra.

County Council El organismo elegido que administra un condado en Gran Bretaña. Nótese la expresión "to sit on the County Council", que sig- 
nifica ocupar un puesto en este organismo local.

Court Guides Unas guías anuales que contienen los nombres y direcciones de miembros de la aristocracia y la clase alta. Es una manera de saber quién es quién, y cuál es el rango de cada uno en la sociedad.

Court of Common Law El tribunal de derecho civil.

Coverley Roger de Coverley es el nombre de un baile popular ("country dance").

covert Un bosque pequeño de arbustos bajos donde suelen esconderse los animales susceptibles de ser presas de los cazadores.

Cowper Cowper, William (17311800): poeta británico que escribió acerca del aislamiento y la vulnerabilidad del hombre. Las tormentas y los naufragios aparecen en sus obras como imágenes de los caminos misteriosos de Dios. Sus poemas y cartas se valoran por su contenido intimista tranquilo, y por su humor fino. Escribió en defensa de los oprimidos y en contra de la esclavitud.
Cramer Cramer, Johann Baptiste (1771-1858): pianista y compositor alemán que se estableció en Londres a principios del siglo XIX y que fue el mayor responsable de la difusión de las sonatas de Beethoven. Las piezas que compuso Cramer aún se usan en la enseñanza del piano.

crape $^{1}$ Un tipo de seda negra usada para confeccionar ropa de luto. También se escribe "crêpe".

crape $^{2}$ Una tela suave y ligera, no necesariamente negra (véase arriba).

craped Este adjetivo procede del sustantivo "crape" y se refiere a la costumbre de llevar unas cintas negras cosidas a la ropa como símbolo de luto por el fallecimiento de un familiar. Así que una mujer "heavily craped" destacaría por la gran cantidad de cintas negras para mostrar la profundidad de su dolor.

cream cracker Una galleta salada que se suele servir con queso.

cricket. Schooldays distinguished for inability to construe Latin and ineptitude with a 
cricket bat. (MOO) El críquet es un juego de pelota inglés considerado por muchos, hasta la imposición del fútbol como espectáculo de masas, el juego nacional, aunque se practica más en determinados ambientes. Era tradicional jugar al críquet en los colegios privados, y se asociaba este juego con un comportamiento que reflejaba valores importantes para los ingleses como el honor y el juego limpio. El no saber jugar al críquet medianamente bien representaba no sólo un fracaso deportivo, sino también una carencia social e incluso moral.

crinoline Una enagua muy almidonada, a veces también con aros, que se usaba para que la falda larga abultara más.

Crown Derby Porcelana fina fabricada en Derby (centro de Inglaterra) entre 1786 y 1811 . Las piezas llevan como marca una corona encima de una D mayúscula, y los diseños son clásicos: siguiendo el estilo de Sèvres o imitando los dibujos Imari de Japón. Sigue fabricándose esta marca, e incluso las piezas nuevas alcanzan precios altos en el mercado al igual que las piezas antiguas. Que alguien usara esta porcelana valiosa a diario para tomar el té en los primeros años del siglo XX implica la pertenencia a la clase más acomodada. (LCC)

crumpet Bollo tostado que tradicionalmente se sirve con el té.

crumpled horn No little Gradgrind had ever associated a cow in a field with that famous cow with the crumpled horn who tossed the dog who worried the cat who killed the rat who ate the malt ...(HAT) Este fragmento forma parte de una rima infantil llena de oraciones relativas. En el fragmento citado se usa "who", pero en la versión tradicional el relativo es "that":

This is the farmer sowing his corn,

that kept the cock that crowed in the morn, that waked the priest all shaven and shorn, that kissed the maiden all forlorn, that milked the cow with the crumpled horn, 
that tossed the dog, that worried the cat, that killed the rat, that ate the malt, that lay in the house that Jack built.

Crystal Palace El nombre popular de un edificio enorme de cristal y hierro construido en Hyde Park, Londres, para la Gran Exposición de los conocimientos tecnológicos, artes plásticas y avances de la humanidad en 1851. Se decía también que era el invernadero más grande jamás construido, porque contenía una gran variedad de árboles y plantas exóticas. Ocupaba 19 acres, era tres veces más largo que la catedral de San Pablo, y contenía 294.000 vidrios. Los expertos decían que no resistiría, pero soportó la inauguración con un coro de muchas voces $y$ varias tormentas. Luego se trasladó al sur de Londres, donde fue destruido por un incendio en 1936.

cucumber sandwiches Emparedados de pepino; un tentempié típico y tradicional de la clase alta, para tomar con el té.

cuppa Deformación de "cup of (tea)".

Curzon Un cine londinense. 


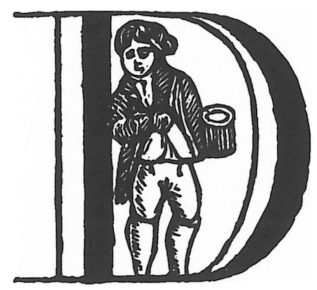

Reel in a drunkard, and reel out a saint. C. Churchill (1731-1764). Night (1761) 



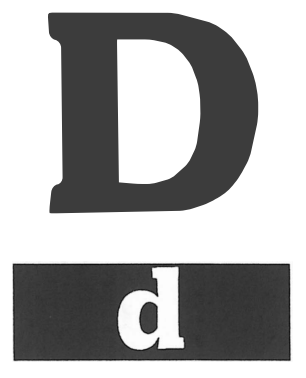

D.D. "Doctor of Divinity" entre los siglos V y XI, dado (Doctor en Teología).

Daily Telegraph Periódico británico de ámbito nacional y de tendencia centro-derecha, fundado en 1855. Es uno de los periódicos serios, o los llamados "quality papers" que contiene artículos, editoriales $y$ noticias nacionales e internacionales.

damson cheese Una mermelada hecha de ciruelas rojas, sin hueso ni piel, cocidas con azúcar hasta conseguir la consistencia de queso fresco.

Dark Ages Desde el punto de vista anglosajón es el período de historia europea previo a la Edad Media, concretamente que en gran parte de Europa fue un período de retroceso cultural.

Dartmoor Una zona de páramos en Devon en el sudoeste de Gran Bretaña. Es un parque nacional de unos mil kilómetros cuadrados.

Davy, Sir Humphry (17781829), químico británico, conocido especialmente por sus experimentos en electroquímica y por su invento de la lámpara de seguridad en la minas. En 1813 publicó Davy's Agricultural Chemistry.

Deal Una ciudad situada en la costa este de Kent (sudoeste de Gran Bretaña). 
Dean Este apellido significa o bien un alto cargo eclesiástico, o el decano de una facultad universitaria. En todo caso, las connotaciones indican una persona con cierta autoridad.(WUH)

\section{Deane Véase Dean.(MOF)}

demi-monde Palabra de origen francés que en su primera acepción se refiere a mujeres marginales que ejercen la prostitución, pero que también describe el toque vulgar de un ambiente cargado en cuanto a la decoración exagerada.

Depression Alusión a la crisis económica, conocida también como "Great Depression", que sufrió el mundo industrializado a principios de los años 1930. Empezó el 29 de octubre de 1929 (Martes Negro) cuando la bolsa de Nueva York sufrió un colapso. Fueron a la bancarrota muchos bancos y empresas, y millones de personas perdieron sus empleos. Sólo terminó cuando estalló la Segunda Guerra Mundial (1939), dado que la actividad industrial necesaria para la maquinaria de guerra supuso una recuperación de la economía occidental. En el caso de Gran Bretaña, afectó especialmente a las ciudades industriales del norte de Inglaterra.

Derbyshire Un condado del centro/norte de Inglaterra, famoso por su paisaje de montañas, valles y cuevas, y su parque nacional ("Peak District National Park").

Devonshire (Devon) Un condado del sudoeste de Inglaterra, que forma parte de la península de Devon y Cornwall. Tiene dos costas: norte y sur.

dewlaps Un pliegue de piel que cuelga del cuello de animales tales como las vacas.

Dieu e mon droit Esta frase en francés es el lema de los soberanos británicos desde el siglo XIV, y significa "Dios y mi derecho".

dine La costumbre local en Yorkshire, sobre todo en el campo, era tomar la comida más fuerte del día entre mediodía y la una, mientras que un habitante del sur la tomaría entre las tres y las cinco de la tarde. Es una diferencia cultural entre el norte y 
el sur del país, a causa, en parte, del clima y de las horas de luz en invierno, y puede dar lugar a un error de interpretación de intenciones (WUH).

dishabille Una forma anglicanizada de la palabra francesa "déshabillé", que significa parcialmente vestido, o con prendas casuales, sin abotonar, etc.

Disraeli Disraeli, Benjamin (1804-1881): estadista británico, líder del partido Conservador, que fue primer ministro en dos ocasiones. Aumentó la influencia de Gran Bretaña en el extranjero, y negoció la compra de la mitad del Canal de Suez para Gran Bretaña. Promocionó cambios en las leyes electorales para extender el voto, y se hizo amigo y asesor de la reina Victoria, que le concedió el título de "Earl of Beaconsfield". También escribió algunas novelas sobre temas sociales.

disrobe Women must put off their rich apparel. At midday they must disrobe. (DAL) Este verbo hace referencia a la costumbre de cambiarse de ropa varias veces durante el día de acuerdo con las exigencias de los distintos actos sociales en los que participaban las damas de alta sociedad, lo que implicaba vestirse con ropa más formal ("rich apparel") para recibir visitas, ponerse otro vestido para la hora del té, o un vestido de noche para una cena o una salida formal, etc.

Dissenter Miembro de una iglesia protestante no conformista.

\section{Divorces are made in Heaven}

El refrán debía ser: "Marriages are made in Heaven", que significa que el sacramento del matrimonio es algo muy serio. Oscar Wilde usa el humor para criticar las actitudes hacia el matrimonio $y$ el divorcio (IMP).

Doctors' Commons Una comisión de doctores civiles encargada de asuntos relacionados con el matrimonio y el divorcio.

dollar Here's half a dollar. (He feels in pocket, takes out a half-crown and tosses it at Davies feet.) (CAR) Este uso de dólar no está relacionado con 
la moneda norteamericana. En el lenguaje coloquial de Gran Bretaña, "half a dollar" significaba "a half-crown" (o "half-acrown"), una moneda inglesa equivalente a dos chelines $y$ medio. Desde 1971 esta moneda no se usa.

Dombey and Son Es el título de una novela de Charles Dickens escrita en 1848 .

don $^{1}$ Un profesor universitario, sobre todo en las universidades de Oxford y Cambridge.

don $^{2}$ Una forma de referirse a Don Quijote de la Mancha. Nótese que los dos significados de "don" se utilizan para crear un doble sentido que dice mucho de los conocimientos culturales de la interlocutora, casada con un profesor de la Universidad de Oxford: "... Fauntleroy on his pony, gallant little figure, the wind in his golden curls, all right, ... But the gloomy old don on Rosinante is quite another matter, and I can't face it." "Which gloomy old don?" asked Norma with interest. (LCC)

dormer window La ventana de una buhardilla.
Drake Drake, Sir Francis (15431596): navegante y aventurero de la época isabelina. Logró reunir treinta toneladas de tesoro español. Fue el primer inglés en dar la vuelta al mundo, y ayudó a dirigir la flota que impidió la invasión de Inglaterra por los tripulantes de la Armada Invencible de Felipe II. Por lo tanto, a pesar de ser pirata, sobre todo desde el punto de vista de los españoles, es un héroe nacional para los ingleses. Se dice que para sus vecinos de Plymouth, no tenía ningún defecto; para el resto de los súbditos británicos tenía unos pocos defectos; y para la reina Isabel I su único defecto consistía en haber sido descubierto actuando como pirata.

draughtsman Véase lacefactory.

Dresden Una ciudad universitaria en Alemania, frecuentada por los hijos de la clase alta en el siglo XIX.

dress If we want to get a good table at Willis's, we really must go and dress. (IMP) En el contexto del siglo XIX y principios del XX, no se trata sólo de ves- 
tirse, sino de vestirse con la ropa adecuada para la cena, en este caso una corbata blanca, con chaleco y frac. Habría que calcular el tiempo necesario para vestirse de esta manera formal y poder llegar con antelación a un restaurante muy de moda, y así conseguir una buena mesa sin tener que esperar turno.

dress circle El primer piso (anfiteatro) en un teatro. Los asientos son más caros en esta sección del local. Compárese con pit, stalls y gallery.

dripping Es la manteca para freír alimentos, y también la grasa que sale de la carne mientras se asa. Esta grasa se deja enfriar y luego una vez solidificada se unta en el pan. En el fondo del recipiente se encuentra la parte más sabrosa, así que para encontrar esta parte había que "excavar" un poco.

dripping pan Una cacerola grande en la cual se calienta la manteca para freír alimentos.

drisheens Un plato típico de la ciudad de Cork, Irlanda, consistente en los intestinos de oveja. drugget Una alfombra roja que se utiliza en el exterior de algunos establecimientos comerciales.

Drury Lane Una calle londinense famosa por los teatros que se hallan en ella. Está muy cerca del teatro de la ópera de Covent Garden.

duenna Palabra de origen español para referirse a una mujer mayor que acompaña a señoritas en público a modo de carabina.

Dulles Dulles, John Foster (1888-1959): Ministro de Asuntos Exteriores estadounidense responsable en gran medida de la estrategia defensiva de su país durante el período conocido como la guerra fría, desde el final de la Segunda Guerra Mundial hasta la década de 1990 cuando la Unión Soviética empezó a desintegrarse.

dundrearies. La moda de llevar patillas largas empezó con la representación teatral de la comedia Our American Cousin (1858), escrito por el dramaturgo británico Tom Taylor, en el cual uno de los protagonistas es el aristócrata estúpi- 
do Lord Dundreary. El actor encargado de su papel se caracterizaba con unas patillas muy largas, y se bautizaron desde entonces con el nombre del personaje. 


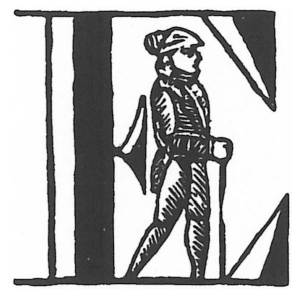

We are all esquires now, and we are none of us gentlemen any more.

E. Gowers (1880-1966). In H.W. Fowler A Dictionary of Modern English Usage (1965). 

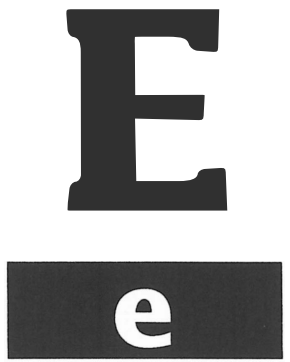

Earnshaw Este apellido consiste en dos partes: "earn", que es ganar un sueldo, y "shaw", que es un bosquecillo o grupo de matorrales.

Edgehill La batalla de Edgehill (1642) fue el primer enfrentamiento importante de la guerra civil inglesa (1642-1651). Carlos I se dedicaba a buscar seguidores en el oeste del centro de Inglaterra (West Midlands), mientras los parlamentarios reunían soldados para enfrentarse a él. El 23 de octubre de 1642 los dos ejércitos se encontraron en las colinas de Edgehill, cerca de Banbury. Cada bando tenía unos 12.000 hombres, y qui- zás por este motivo, no hubo un ganador claro. Después de esta batalla, el rey tenía camino libre para seguir hasta Londres, pero su lento avance, deteniéndose en Oxford, dio tiempo a sus adversarios a reagruparse y organizar la defensa de la capital.

Electrolux Una marca de electrodomésticos. Por extensión, una aspiradora (CAR).

Elegant Extracts Una colección de poesía y prosa editada por Vicesimus Knox (1752-1821).

Eliot Eliot, Thomas Stearns (1888-1965): Premio Nobel de Literatura de 1948. Poeta modernista y crítico literario, 
condecorado por el rey Jorge VI con el "Order of Merit". Nació y estudió en Estados Unidos, y después se hizo ciudadano británico. Su obra The Waste Land (1922) se considera un comentario sobre el fracaso de la civilización occidental después de la Primera Guerra Mundial.

Elton Elton, Charles Sutherland (1900-1991): biólogo británico que formuló los principios básicos referentes a la ecología animal.

Empire Un teatro de variedades en la zona de teatros (y posteriormente cines) en Leicester Square en el centro de Londres.

\section{engine-house El recinto donde} se encontraba la maquinaria utilizada para subir y bajar la jaula en el pozo de una mina, y para bombear agua del pozo.

Eno's Marca de sal de frutas, un remedio contra los problemas digestivos.

ENSA Siglas que corresponden a "Entertainments National Service Association", una entidad que organizaba actuaciones de cantantes, actores, cómicos, etc. para el personal militar durante la Segunda Guerra Mundial.

entailed Es un término legal que se aplica a una finca o casa que, por testamento del dueño, debe quedar como propiedad de una determinada familia durante varias generaciones.

\section{enter (to be entered at Oxford,}

Cambridge ...) Matricularse (en la universidad). Nótese que se expresa en el modo pasivo, lo cual es significativo, dado que antiguamente no se entraba por medio de un examen o nota, sino porque los padres inscribían a sus hijos en la universidad para tenerlos ocupados, ya que los herederos de las familias acomodadas no trabajaban para ganarse la vida.

Epping El bosque de Epping está situado al norte de Londres. Es un lugar popular para paseos y para montar a caballo.

Epsom Un pueblo al sur de Londres, en el condado de Surrey, famoso por sus carreras de caballos, entre los cua- 
les el más conocido es el "Derby".

Erebus Nombre de uno de los dos barcos (véase también Terror) bajo el mando de Sir John Franklin (1786-1847) que buscaban una ruta para pasar por el norte de Canadá. Ambos barcos quedaron atrapados en el hielo, y los tripulantes murieron a causa de las condiciones climatológicas. Según la mitología griega, Erebo era una caverna oscura a la entrada del infierno.

Erewash Valley El río Erewash $y$ el canal del mismo nombre forman el límite oriental entre el condado de Derbyshire y el condado vecino de Nottinghamshire. El sistema de canales fue muy importante como vía de comunicación para el transporte de mercancías como el carbón de las minas ("collieries") del norte y zona central de Inglaterra.

Eton Colegio masculino privado de régimen de internado. Fue fundado en 1440 por Enrique VI, y es el más famoso de un grupo selecto de colegios privados ("public schools"). Son colegios a los que asisten los hijos de familias de clase alta y de la aristocracia. Muchos de los líderes políticos de la nación han estudiado en los más famosos, Eton y Harrow. Los antiguos alumnos de Eton se llaman "Old Etonians".

Evening Standard El único periódico vespertino londinense, fundado en 1827. Incluye reportajes sobre asuntos locales y nacionales, y una vez al mes publica un suplemento en color que se titula ES - The Evening Standard Magazine.

Evensong Un acto religioso (rezos, salmos y cánticos) que se realiza por la tarde en la Iglesia Anglicana.

Exchequer Antiguamente era el departamento del gobierno británico que manejaba las finanzas del estado. Hoy en día este departamento se llama "Treasury". Véase

\section{Chancellor of the Exchequer.}

excise-rod Una vara utilizada para medir distintos productos y determinar el impuesto que había que pagar.

Exeter Una ciudad en el sudoeste de Inglaterra, cerca de la 
costa sur. Es el centro admi- Eyeties ['aitaiz] Este término nistrativo del condado de se utilizaba coloquialmente Devon.

Exmoor Una zona de páramos en Somerset y Devon en el sudoeste de Gran Bretaña. Es un parque nacional de casi 700 kilómetros cuadrados. para referirse despectivamente a los italianos. Representa una pronunciación burlona de "Italian" ("Eyetalian"), y tiene su origen en la década de 1920. 


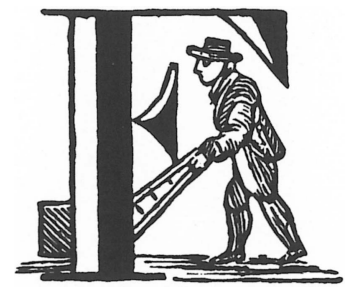

The Farmer will never be happy again; He carries his heart in his boots; For either the rain is destroying his grain Or the drought is destroying his roots. A.P. Herbert (1890-1971). The Farmer (1922). 



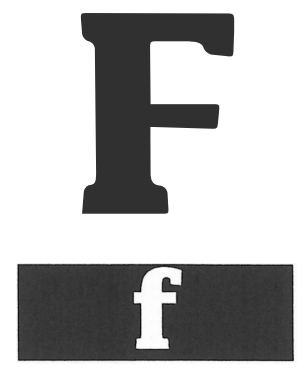

F.O. Siglas que corresponden a "Foreign Office", Ministerio de Asuntos Exteriores en Gran Bretaña.

familiarity The Cobb has invited what familiarity breeds for at least seven hundred years. (FLW)

Según el escritor americano Mark Twain, el desprecio y el desdén son el resultado de un exceso de confianza ("Familiarity breeds contempt - and children"). La cita significa que "the Cobb" es tan familiar para los habitantes de la zona que no le prestan atención ni valoran su belleza natural.

farthing La cuarta parte de un penique; una cantidad muy pequeña. faucet En inglés americano significa grifo.

Fauntleroy Protagonista de la novela Little Lord Fauntleroy, escrita por Frances Hodgson Burnett en 1886. Era un niño aristocrático con rizos largos y rubios, y el traje de terciopelo que llevaba originó una moda en esa época. Era el prototipo de niño rico, guapo y romántico.

fauteuil Palabra de origen francés que significa sillón.

fear no more ... Fear no more the heat o' the sun. (DAL) La cita es de Shakespeare: Cymbeline, act 4, sc.2, line 258. 
field sports Se refiere a los deportes tradicionales de las clases acomodadas: la caza del zorro a caballo, la caza de faisanes y urogallos con escopeta, y la pesca.

fifteen En el fútbol irlandés cada equipo tiene quince jugadores. Es sinónimo de un equipo completo.

finger in the pie ... neither do I want to put my finger in the pie. (RAI) Involucrarse, o meterse en líos.

Finsbury Park Es un barrio popular en el centro de Londres.

Finsbury Pavement Una calle en el nordeste de Londres, cerca del cementerio de Bunhill Fields.

Fish-and-chip shops En estas tiendas se vende pescado frito (bacalao o abadejo) con patatas fritas, un plato muy popular, y relativamente barato en Gran Bretaña. Se vende para llevar y comer fuera, y se envuelve en papel de periódico para mantenerlo caliente. Es frecuente ver a la gente caminar por la calle comiendo este plato con los dedos o con un tenedor de madera.

Flanagan and Allen Bud Flanagan y su compañero Chesney Allen eran una pareja de humoristas que cantaban y bailaban en el teatro de variedades. Se hicieron muy populares durante la Segunda Guerra Mundial, con sus canciones que hacían burla de Hitler y los alemanes.

flannels La ropa típica para la práctica del críquet consistía en pantalones blancos de franela ("flannels") y una americana (blazer) con el escudo del equipo en el bolsillo superior. El críquet era un deporte practicado en Inglaterra $y$ entre los protestantes en Irlanda, mientras que los republicanos preferían el fútbol irlandés.

Fleet Messages were passing from the Fleet to the Admiralty. (DAL)"Fleet" significa la flota de buques de guerra británicos. La marina tiene su cuartel general en Admiralty Arch, un edificio que parece un puente debajo del cual pasa el tráfico entre The Mall, Whitehall, The Strand y Trafalgar Square en Londres. 
florin Moneda plateada de dos chelines (una décima parte de una libra). Esta moneda no se usa desde 1971.

fly Un carruaje tirado por un solo caballo, utilizado como coche de alquiler hasta la aparición del automóvil. El plural de este término arcaico es "flys".

Fortnum's Nombre abreviado de la tienda de ultramarinos más prestigiosa de Londres: "Fortnum \& Mason of Piccadilly".

foster sister I had been his foster sister, and excused his behaviour more readily than a stranger would. (WUH) De recién nacidos, Hindley y Nelly habían compartido la misma nodriza, y por lo tanto son hermanos de leche.

fox En el lenguaje coloquial, "to fox" significa hacer trampa, engañar.

frame Mostrarse ágil y dispuesto a hacer algo en el dialecto de Yorkshire.

frame off En el dialecto de Yorkshire significa marcharse, desaparecer.
Franklin Franklin, Sir John (1786-1847): Después de una carrera distinguida en las guerras napoleónicas, se hizo famoso como explorador del Ártico. Partió con el Erebus y el Terror para buscar una ruta para pasar por el norte de Canadá, pero sus barcos quedaron atrapados en el hielo, y él y sus hombres murieron.

Free Library Una biblioteca pública, en la cual el servicio de préstamo era gratuito, y no era necesario subscribirse para poder disfrutar de sus servicios.

Friends "The Society of Friends" es el nombre formal de un grupo religioso fundado en Inglaterra alrededor de 1650 por George Fox, y conocido como los Cuáqueros. Reciben este nombre ("Quakers") porque se decía que sus adeptos se estremecían ("quaked") a causa del fervor religioso que sentían.

frisson Palabra de origen francés que se refiere al sentimiento momentáneo y fugaz de placer o emoción en relación con algo peligroso o 
prohibido que nos causa cierto temor.

frowsty Mal ventilado, de ambiente cargado, o que huele a cerrado.

Fulham Es un barrio popular de Londres, al sudoeste del centro de Londres.

Funds Acciones o bonos del estado ("British Government Securities"), una forma segura de invertir dinero.

funeral Mrs Linton's funeral was appointed to take place on the Friday following her decease. (WUH) Catherine Linton muere el domingo pero no recibe sepultura hasta el viernes, siguiendo la costumbre de la mayor parte de Gran Bretaña de esperar unos días entre el fallecimiento y el entierro.

furlough Período de permiso del ejército.

fuzz-ball Un balón de trapo, o de lana rizada. 


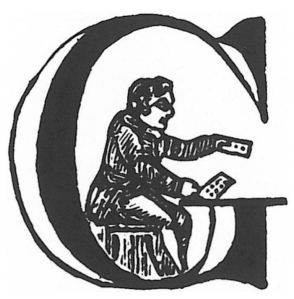

Life is a gamble, at terrible odds - if it was a bet, you wouldn't take it.

Tom Stoppard (1937-). Rosencrantz and

Guildenstern are Dead (1967). 


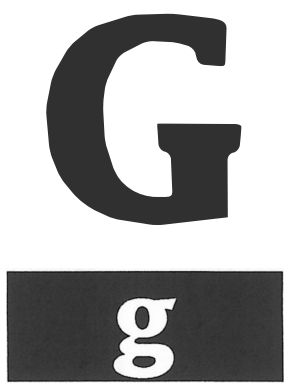

G and S Abreviatura de los autores de obras musicales Gilbert and Sullivan. Véase British opera.

G.H.Q. Siglas que corresponden a "General Headquarters", que significa el cuartel general de las fuerzas armadas en tiempo de guerra, o durante unas maniobras militares.

gaberlunzie Un mendigo.

gabey En el dialecto del centro y norte de Inglaterra, "gabey" (o "gaby", "gawby", "gauvey") significa un idiota.

galantine Plato frío de carne deshuesada o pescado sin espinas en una salsa de gelatina.
Galbraith Galbraith, John Kenneth (1908): economista estadounidense, nacido en Canadá. Está a favor de la intervención del gobierno para ayudar a los pobres y los desempleados. Fue asesor de John F. Kennedy, y embajador de EE.UU en la India.

gallery El balcón más alto en un teatro, donde se hallan los asientos más económicos.

gallivant Salir a divertirse, a pasarlo bien, o comportarse de manera frívola.

General Election En el contexto de Look Back in Anger, se refiere al final de la Segunda Guerra Mundial. En 1945 los 
ministros laboristas abandonaron la coalición que habían formado con Churchill. Como resultado, hubo elecciones generales en las cuales los laboristas consiguieron el doble de escaños en el parlamento que los conservadores.

George “... by George!” Una exclamación invocando a San Jorge, patrono de los ingleses.

German Jew Se refiere a Carl Marx (1818-1883) quien publicó el primer tomo de El Capital en 1867. Engels publicó otros dos tomos después de la muerte de Marx. Marx murió en Londres y su tumba se encuentra en el cementerio de Highgate.

Gervase Park Miss Cardew is the granddaughter of the late Mr. Thomas Cardew of 149 Belgrave Square, S.W.; Gervase Park, Dorking, Surrey; and the Sporran, Fifeshire, N.B.(IMP) Los miembros de la aristocracia y clase alta solían poseer más de una residencia. En este ejemplo, la primera es una casa en el centro de Londres, en un barrio elegante; la segunda es una casa solariega rodeada de terrenos en el sur de Inglaterra; la tercera es una propiedad en Escocia.

Gibson Girl Las "Gibson Girls" eran las primeras modelos modernas que se hicieron famosas por aparecer en los dibujos del americano Charles Dana Gibson (1867-1944). Tenían una silueta perfecta, como un "reloj de arena", y se usaron para promocionar la moda de la época.

Gilpin John Gilpin es el protagonista de un poema de William Cowper (1782) acerca de un mercero de un barrio comercial de Londres cuyo caballo se asusta y lo lleva hasta Ware, al norte de Londres, y de vuelta, sin parar (una distancia de unos setenta kilómetros):

John Gilpin was a citizen

of credit and renown,

A train-band captain eke was he

Of famous London town.

gingerbread Una especie de bizcocho (a veces en forma de galleta) hecho de melaza de jengibre.

Girl Guides Una asociación fundada en 1910 para chicas, equivalente a los "Boy Scouts" 
para chicos. Fomenta las habilidades prácticas y una actitud positiva hacia los demás ciudadanos. En el pasado, sus valores se consideraban bastante conservadores.

Gladstone bag Una especie de cartera de cuero con dos compartimientos unidos por una bisagra. Se llama así en honor al estadista liberal W. E. Gladstone.

Gladstone Gladstone, William Ewart (1809-1898): estadista británico; ocupó distintos puestos gubernamentales durante muchos años, empezando como conservador y al final como liberal radical. Fue primer ministro de 1868 a 1874,1880 a 1886 , y de 1892 a 1894 . Hizo uso de los discursos y las reuniones políticas para atraer la atención del pueblo sobre asuntos importantes, y así ayudó a integrar el electorado, marcando un estilo que ha influido en los países democráticos desde entonces. Estableció la educación a nivel nacional, introdujo la práctica del voto secreto, estuvo a favor del comercio libre y la autonomía de Irlanda. glee Una clase de canción sin acompañamiento instrumental para tres voces masculinas muy popular en los siglos XVIII y XIX.

glee-men Originalmente, eran trovadores medievales. En el siglo XIX, eran cantantes itinerantes profesionales que actuaban en las fiestas y reuniones sociales.

Glegg Unos de los tíos de los protagonistas de The Mill on the Floss, "Mr and Mrs Glegg", tienen como apellido una palabra que en el uso dialectal escocés significa astuto, listo o que percibe rápidamente los detalles de una situación. Estas características coinciden bastante con las de los personajes en cuestión.

Glyn Glyn, Elinor (1864-1943): novelista y escritora británica, autora de relatos cortos con historias románticas de aventuras inverosímiles que se desarrollan en lugares exóticos. Su obra más conocida es Three Weeks (1907).

God Save the Queen Es el título del himno nacional de Gran Bretaña:

God save our gracious Queen, Long live our noble Queen, 
God save the Queen.

Send her victorious, Happy and glorious, Long to reign over us, God save the Queen.

Godwin Godwin, William (17561836): autor de una obra anarquista (Investigación referente a la justicia política y su influencia en la virtud general y la felicidad).

Gold Rush La fiebre del oro, que resultó en una gran migración hacia el oeste de los Estados Unidos (California) en 1849.

Golden Hind Nombre del barco de Sir Francis Drake.

Goldsmith Goldsmith tells us, that when lovely woman stoops to folly, she has nothing to do but die. (EMA) Goldsmith, Oliver (1730-74): historiador, poeta y novelista inglés, cuya obra principal es The Vicar of Wakefield (1766). La cita completa es:

When lovely woman stoops to folly

And finds too late that men betray,

What charm can soothe her melancholy,

What art can wash her guilt away?

(The Vicar of Wakefield, capítulo 29).

Gooseberry "To play old Gooseberry": hacer de carabina.

gorgonzola Un queso azul fuerte de origen italiano.

gorse Planta silvestre de flores amarillas similar al tojo.

Gosse Gosse, Philip Henry (1810-1888): naturalista fundamentalista cristiano británico que propuso y desarrolló la idea de un acuario como institución científica.

Gower Street Una calle en la zona londinense de Bloomsbury, cerca del Museo Británico.

grace "To say (the) grace": bendecir la mesa.

Gracechurch Street Una calle importante en la zona este de Londres, cerca de las sedes de los bancos. Los señores Gardiner (tíos de las hermanas Bennet en Pride and Prejudice) tienen una casa en esta calle con connotaciones comerciales. Los miembros de las clases altas tales como Darcy y su amigo Bingley no pisarían, 
según Elizabeth, un lugar tan vulgar para ellos, : Mr Darcy may perhaps have heard of such a place as Gracechurch Street, but he would hardly think a month's ablution enough to cleanse him from its impurities, were he once to enter it. (Véase también Grosvenor Street en el mismo contexto.)

Gradgrind El apellido de este personaje de Hard Times contiene la palabra "grind" que puede entenderse como trabajo pesado, o como un verbo con el significado de moler, triturar, pulverizar; oprimir o acabar con alguien. Todas estas connotaciones negativas ayudan a hacerse una idea del carácter del personaje.

grammar schools Colegios estatales de enseñanza secundaria, fundados antes o durante el siglo XVI para la enseñanza del latín. Hoy en día quedan pocos, pero antes gozaban de prestigio por su nivel académico, y por sus connotaciones sociales.

Grandison Sir Charles Grandison es el título de una novela en siete volúmenes de Samuel Richardson (1689-1761).

Gravesend Es un puerto en la margen derecha del río Támesis, a unos $20 \mathrm{~km}$. al este del centro de Londres.

gravy browning Colorante para la salsa que acompaña la carne asada.

Gray From Gray that "many a flower is born to blush unseen..." (NOR) Gray, Thomas (1716-1771): poeta inglés, autor de Elegy Written in a Country Churchyard (1751). El fragmento completo es:

Full many a gem of purest ray serene,

The dark unfathomed caves of ocean bear:

Full many a flower is born to blush unseen,

And waste its sweetness on the desert air.

Great Reform Bill En 1867 se aprobó la ley de reforma del sufragio ("Second Reform Act"), que había sido introducida por Disraeli, y que extendió el sufragio al electorado obrero urbano, lo cual significó un aumento de unos dos millones de votantes. 
Green Scientific agriculture, in the form of myxomatosis, has only very recently lost us the Green forever, but the custom itself lapsed in relation to the lapse in sexual more. It is many years since anything but fox or badger cubs tumbled over Donkey's Green on Midsummer's Night. But it was not so in 1867.(FLW) Es un claro en medio de un bosque. Aquí se refiere a la obra Midsummer Night's Dream de Shakespeare en la cual hay un claro que se llama "Donkey's Green" donde la gente bailaba y tenía encuentros sexuales.

Greensleeves Es el título de una balada tradicional inglesa del siglo XVI.

grenadine Una tela hecha de una mezcla de lana y seda, adecuada para el buen tiempo.

Greuze Greuze, Jean Baptiste (1725-1805): pintor francés famoso por sus retratos familiares y pinturas de género. Es autor de El padre leyendo la Biblia a sus hijos (1755) Novia de pueblo (1761) y Devanando lana (1759). Hoy destaca más por sus retratos de personajes políticos, realistas y sin pre- tensiones, como Robespierre y Napoleón, y de niños.

Grimm Grimm, Jacob Ludwig (1785-1863) y Wilhelm Karl Grimm (1786-1859): lingüistas alemanes y recopiladores de cuentos de hadas tradicionales.

Groceries "Ay, bedad! And there's the Groceries sure enough!" cried Mr. Dedalus.(POR) Un bar que también era tienda de ultramarinos. "Bedad" es un intensificador que expresa sorpresa o se usa para dar mayor énfasis.

Grosvenor Square Fortunately in England, at any rate, education produces no effect whatsoever. If it did, it would prove a serious danger to the upper classes, and probably lead to acts of violence in Grosvenor Square. (IMP) Una plaza grande en el oeste de Londres donde se encuentran las embajadas y oficinas diplomáticas. Es una zona residencial de lujo, y en la época de Oscar Wilde no parecía un lugar muy propicio para la violencia. En tiempos más recientes, sin embargo, ha sido un lugar de manifestaciones y protesta 
contra otros países, o contra las relaciones de Gran Bretaña con ciertos países.

Grosvenor Street Una calle del barrio elegante de Mayfair, en el centro de Londres. Los hermanos Bingley (PAP) tienen una casa en esta calle. (Véase también en este contexto

\section{Gracechurch Street.)}

gruel Gachas; esta mezcla de avena cocida y leche o agua se toma sobre todo cuando una persona está débil y necesita reponer fuerzas.

Grundy "What would Mr. Bounderby say" - as if Mr. Bounderby had been Mrs. Grundy (HAT).

Una persona convencional, guardiana de la decencia y las normas de comportamiento victorianas, y que censura toda clase de placer y frivolidad.

Grünewald Grünewald, Matthias (1470/75-1528): pintor alemán, también conocido como Mathis Gothardt Nithardt, famoso por sus escenas religiosas, sobre todo por $L a$ Crucifixión (1515) que se encuentra en el Museo de Unterlinden, Colmar.

Gudrun Un personaje de la mitología nórdica. Forma parte de la leyenda de los Nibelungen.

Guest No es ninguna coincidencia que "Mr Stephen Guest" (MOF) tenga precisamente este apellido y que sea el invitado de la familia Deane, y prometido de Lucy. Así se recalca más su comportamiento inadecuado como invitado y amigo.

Guildford by-pass Guildford es un pueblo al sudoeste de Londres, en el condado de Surrey. El intenso tráfico de esta zona lo rodea por medio de una circunvalación ("bypass").

guimp También escrito "guimpe", este término se refiere a una blusa con el cuello alto que se llevaba debajo de un vestido escotado, o una tela tiesa usada para cubrir los hombros, el cuello y el escote, debajo de un vestido.

guinea Modo de expresar una cantidad equivalente a una libra y un chelín (veintiún che- 
lines). Ya no se usa este sistema, dado que en 1971 se implantó el sistema decimal de libras y peniques nuevos. Una libra actual contiene cien peniques.

Gwyn Gwyn, Nell (1650-1687): actriz inglesa, amante de Carlos II, con quien tuvo dos hijos. Empezó su carrera vendiendo naranjas en las calles de Londres. Fue muy popular como actriz, y una belleza reconocida.

gyppy tummy Expresión usada por los soldados aliados en Egipto ("gyppy" que es una forma coloquial de "Egypt") durante la Segunda Guerra Mundial para describir los trastornos estomacales ("tummy") que sufrían debido a la insalubridad del agua. 


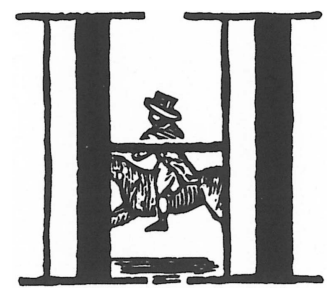

There is no secret so close as that between a rider and his horse.

R.S. Surtees (1805-1864). Mr Sponge's Sporting Tour (1853) 



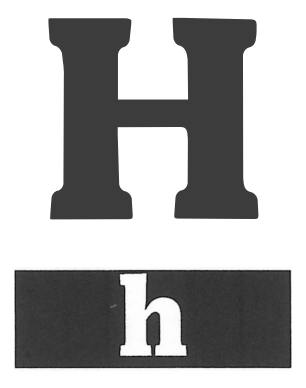

haddock El abadejo es un pescado muy común en Gran Bretaña. Se compra a menudo rebozado y frito con patatas en los fish-and-chip shops.

half His mother absolutely refused to let him have a tailed coat that half, although every other boy of his age had gone into tails already. (MOF) Se refiere a la mitad del año académico, es decir el semestre.

half a crown Una moneda inglesa equivalente a dos chelines y medio (2s $6 \mathrm{~d}$ ). No se usa desde 1971 cuando se introdujo el sistema decimal para la moneda inglesa. También se llamaba "a half crown".
Half-Moon Street Esta calle del barrio lujoso de Mayfair en la zona oeste de Londres estaba de moda como zona residencial para jóvenes solteros en la época de Oscar Wilde. La situación del piso indica el alto nivel social de su dueño (IMP).

Hamadryad Según la mitología griega era una ninfa que vivía en un árbol y moría cuando moría el árbol.

Hammarskjöld Hammarskjöld, Dag (1905-1961): político sueco, secretario general de la O.N.U. durante la guerra fría, y que recibió el Premio Nobel de la Paz en 1961. 
Hampstead Un barrio de la zona norte de Londres, algo alejado del centro.

Handsome Handsome is as handsome does.(MOO) Refrán que significa que uno es tan guapo como sus hechos, es decir, que son los hechos lo que conforman la verdadera belleza o fealdad de las personas.

hang fire Posponer una acción; esperar el momento más adecuado.

Hanover Square Una plaza elegante entre Oxford Street $y$ Regent Street, en el centro de la vida social de Londres en el siglo XIX.

Hareton Este nombre contiene la palabra "hare" que significa liebre.

Harley Street Una calle londinense que sale perpendicularmente de Oxford Street. Tiene fama por ser la calle de las consultas privadas de los cirujanos y especialistas médicos más prestigiosos, y más caros

Harrow Un colegio privado masculino fundado en 1571 . Asisten hijos de la aristocracia y de la clase adinerada. Entre sus ex alumnos se encuentran varios primeros ministros. Véase también Eton.

Harry By the Lord Harry! (HAT) Una exclamación. "Harry" es un eufemismo para el diablo. También se dice "Old Harry".

Harvey Harvey, William (15781657): médico del siglo XVI que describió las circulaciones mayor y menor de la sangre.

Hatfield Un pueblo en el condado de Hertfordshire al norte de Londres. Hatfield House, cerca del pueblo del mismo nombre, es una mansión del siglo XVII, perteneciente a los marqueses de Salisbury. La futura reina Isabel I se crió allí. En ocasiones especiales se celebran recepciones al aire libre en los jardines de la mansión.

Haymarket Una calle de Londres, situada entre Piccadilly y Trafalgar Square, en la cual las prostitutas esperaban a sus clientes ricos, ya que no quedaba lejos del barrio elegante de Mayfair, Pall Mall, los "clubs" de los caballeros, e incluso del palacio real de St. James. Hoy en día, este tipo de actividad se 
ha desplazado ligeramente hacia el norte, al barrio de Soho.

H-Bomb "H-Bomb" es la forma abreviada de "Hydrogen Bomb", la bomba atómica que puso fin a las aspiraciones de Japón en la Segunda Guerra Mundial.

Heathcliff Este nombre consta de dos elementos: "heath" significa un brezal, un terreno baldío, lleno de rocas y vegetación baja, donde el clima es húmedo $\mathrm{y}$ frío, con vientos fuertes. Es el paisaje de Wuthering Heights. El otro elemento es "cliff", que significa acantilado, o peñasco.

Hebrew Hebrew monetary transactions (HAT). Préstamos de un judío, con intereses altos.

Heep He began to wonder if there wasn't something of a Uriah Heep beginning to erupt on the surface of Sam's personality. (FLW) Uriah Heep es el empleado del abogado en David Copperfield de Dickens. Este personaje chantajea a su jefe.
Hendon Un pueblo entre Watford y Londres, al norte de la capital.

Henrietta-Maria style Alusión a la reina Henrietta-Maria (1609-1669), esposa de Carlos I de Inglaterra, hija menor de Enrique IV de Francia. Se casó con Carlos con sólo quince años de edad, y se dice que era menuda, alegre, con el pelo oscuro y rizado, y grandes ojos castaños.

Hertfordshire Un condado al norte de Londres.

highwayman $\mathrm{He}$ rode like a highwayman. (HAT) Un salteador de caminos, un bandido. El personaje en cuestión viajaba, por lo tanto, a caballo, muy deprisa.

hind-leg "To talk the hind leg off a dog": Hablar durante mucho tiempo, aburriendo al interlocutor; hablar por los codos.

hit (below the belt) Literalmente, en el boxeo, significa realizar un golpe ilegal por debajo de la cintura, y por extensión, realizar alguna acción dañina aprovechando la debilidad de alguien. Oscar Wilde modifica la frase idiomática así: ...brute 
reason is quite unbearable. There is something unfair about its use. It is hitting below the intellect. (PDG)

hob Un estante al lado del fuego o la chimenea. Se utilizaba para mantener disponible agua caliente en un hervidor.

\section{Hoffman's Tales Hoffman,} Ernest Theodor Amadeus (1776-1822): escritor alemán, autor de los cuentos fantásticos en los que Jacques Offenbach basó su ópera Los Cuentos de Hoffmann (1880).

Holborn Una zona al nordeste del centro de Londres, que quedaba algo alejada en el siglo XIX. Las hermanas Steele en Sense and Sensibility tenían un alojamiento alquilado en un edificio que se llamaba Bartlett's Buildings de este barrio. Una residencia alquilada en una zona alejada de donde viven los ricos y la gente elegante tenía poco prestigio social.

holly El acebo, y la hiedra, se usan tradicionalmente para dornar la casa en Navidad.

Holy Office El Santo Oficio, la Inquisición.

home civil Cuerpo de funcionarios británicos.
Home Secretary Es el Ministro del Interior, y su sede se llama "Home Office".

Hon. Es la abreviatura de "Honourable", el título que ostenta el hijo o la hija de un vizconde. También se antepone al nombre de un Miembro del Parlamento o "MP".

Honeys Los soldados norteamericanos llamaban así a los tanques "Stuart" de la Segunda Guerra Mundial.

honour bright En el lenguaje coloquial significa de verdad, sinceramente.

Hood, Robin Este personaje, también conocido como "Robin o'Locksley" y "Earl of Huntingdon", era un forajido o proscrito inglés, famoso según la leyenda por su pericia en el tiro con arco, y por robar a los ricos para repartir el dinero entre los pobres. Según las muchas historias, poemas y películas acerca de él, vivió con otros proscritos en el enorme bosque de Sherwood, y se vestían todos de verde para pasar desapercibidos. Probablemente no es más que el fruto de leyendas románticas, pero en la zona central de Inglaterra donde se 
supone que viviría, se convirtió en héroe nacional. Por este motivo, "The Robin Hood" es el nombre de muchos "pubs" en Inglaterra. Los "pubs" reciben su nombre a menudo en relación con acontecimientos o personajes locales curiosos.

Hooker Hooker, Richard (15541600): teólogo inglés cuya obra más importante es The Laws of Ecclesiastical Polity, que fue publicada, tras su muerte, entre 1594 y 1662 . El propósito de la obra fue mostrar las ventajas de la forma episcopal de organización de la Iglesia anglicana frente al presbiterianismo. Hooker defendía que la ley natural es inmutable y eterna, mientras que la ley positiva emanada del Estado y aquellas que afectan a la forma de gobierno pueden alterarse según sea conveniente $o$ necesario. Además, presentó como contraria a la ley natural la interpretación mecánica que los puritanos hacían de la Biblia. Su obra es considerada, además, una obra maestra de la prosa de estilo isabelino.

hoop Un juguete consistente en un aro, que se hacía rodar por medio de un palo, y que era antaño muy popular entre los niños.

Horlicks Marca de una bebida de avena y leche, muy nutritiva, y propia de personas mayores o enfermas.

house Uso dialectal de una palabra estándar. En Yorkshire llaman a la sala principal de la casa "house". Si se dice "come in 'house!" es una invitación no sólo para entrar en la vivienda, sino también para pasar a la sala.

House of Lords Cámara de los Lores. Es la cámara alta del parlamento británico, que también funciona como el tribunal de última apelación dentro de Gran Bretaña.

huckster Es una persona que vende de puerta en puerta, o un vendedor ambulante.

Hume Hume, David (17111776): filósofo e historiador escocés. Rompió con el tradicional recuento cronológico de hazañas y hechos de Estado, e intentó describir las fuerzas económicas e intelectuales que habían tenido importancia en la historia de 
su país. Publicó varios volúmenes de una serie titulada History of Great Britain (1754-1759) que se consideraron títulos clásicos durante muchos años.

Humphreys Humphreys, Noel (1810-1879): escritor y dibujante británico.

Huntley \& Palmers ... the battered, twisted, ruined, tinpot steamboat... She rang under my feet like an empty Huntley \& Palmers biscuit tin. (HOD) Una marca de galletas muy conocida y popular. Se vendían las galletas en cajas grandes y cuadradas de hojalata. El barco parece tan poco resistente como una de estas cajas, que una vez vacías se deforman fácilmente.

Hurlingham El club londinense de polo.

Hussars Un regimiento de caballería del ejército inglés.

huswife Un pequeño costurero para guardar los hilos y agujas.

\section{Hutchinson}

Hutchinson, Colonel John (1615-1664). Luchó en el lado de los parlamentarios (con Cromwell) durante la Guerra Civil inglesa (1642-1645). Fue nombrado teniente coronel y miembro del comité parlamentario por el condado de Nottingham (donde se ambienta la novela Sons and Lovers). Luego fue gobernador de la ciudad de Nottingham. Debido a sus ideas religiosas se alió con los independentistas, y no con los presbiterianos. Actuó como uno de los jueces de Carlos I. Fue elegido miembro de los consejos del "Commonwealth" (1649-1660). Después de la Restauración fue condenado por regicida, pero gracias a sus influencias familiares, se libró de la condena de muerte. Fue encarcelado en la Torre de Londres bajo sospecha de haber fomentado el complot de Yorkshire. Murió en las mazmorras del castillo de Sandown, Kent. Es, por lo tanto, un personaje histórico local para los contemporáneos de Lawrence, una especie de héroe o símbolo para los protestantes de Nottingham.

Huxley As we are a doomed race, chained to a sinking ship (her favourite reading as a girl was Huxley and Tyndall, and 
they were fond of these evolución, así como por el nautical metaphors) .. (DAL) papel del hombre en el univerHuxley, Thomas Henry (1825- so. Fue el abuelo del crítico y 1895): biólogo y profesor de novelista inglés Aldous ciencias naturales. También se Huxley (1894-1963). interesó por la filosofía y la 



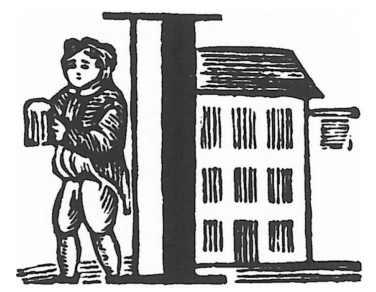

Whoe'er has travelled life's dull round, Where'er his stages may have been, May sigh to think he still has found The warmest welcome, at an inn. W. Shenstone (1714-1763).

Written at an Inn at Henley (1758). 



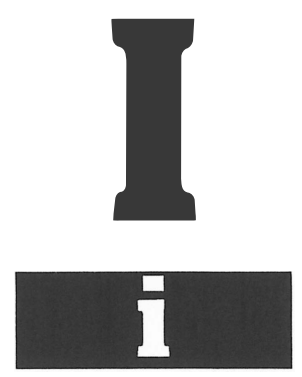

Idylls of the King Título de una serie de doce poemas de Alfred Tennyson (1809-1892) acerca de la leyenda del rey Arturo. Tennyson fue nombrado "Poet Laureate" (el honor de ser el poeta oficial de la corte) por la reina Victoria en 1850 .

ikey "To look ikey": tener una opinión elevada de uno mismo; presumir. Es una forma dialectal del centro/norte de Inglaterra.

inch. Unidad de medida equivalente a $2,5 \mathrm{~cm}$.

income "What is your income?" "Between seven and eight thousand a year." (IMP) Las siete $\mathrm{u}$ ocho mil libras en cuestión constituían unos ingresos muy respetables en la época en la cual escribía Oscar Wilde, ya que unas mil libras al año se consideraban una cantidad adecuada para vivir cómodamente. Un obrero, en cambio, cobraba una libra por semana.

Indian Moon got fifth place in the Indian. (POR) Se refiere al concurso para el cuerpo de funcionarios de la administración británica en la India.

Indian Mutiny Sublevación (1857-58) de soldados nativos de la India al servicio del ejército británico debido al resen- 
timiento contra la política irons in the fire "To have too colonial.

Insolvent Debtor's Court $\mathrm{El}$ tribunal de los deudores insolventes.

Intended There remained only his memory and his Intended. (HOD) Es una forma arcaica para referirse al prometido o a la prometida, y se escribía con mayúscula.

Iron Maiden Un artilugio de tortura medieval que consistía en una caja de hierro en forma de ataúd, forrado con clavos que atravesaban a la víctima. many irons in the fire" significa ocuparse de demasiados asuntos al mismo tiempo.

Italian ... and when you have finished Udolpho, we will read the Italian together. (NOR) Ann Raddiffe (1764-1823) escribió The Italian: or the Confessional of the Black Penitent (1797).

ivy La hiedra, junto con el acebo, se usa para adornar la casa en Navidad. 


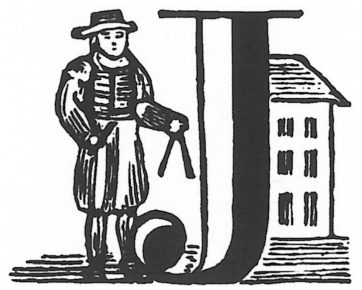

No person who is not a great sculptor or painter can be an architect.

If he is not a sculptor or painter, he can only be a builder.

J. Ruskin (1819-1900).

Lectures on Architecture and Painting (1854). 



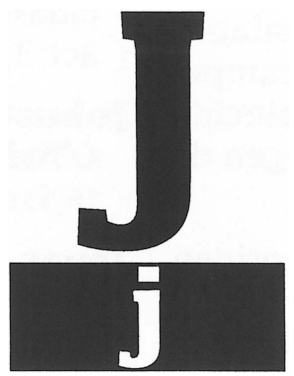

J.P. Es la abreviatura de "Justice of the Peace", que es un magistrado que juzga casos de menor importancia, y decide si un caso debe remitirse a instancias superiores. Tradicionalmente, las personas que ocupaban este puesto eran nombradas por su estatus social y su prestigio local, más que por sus conocimientos jurídicos. Como sugiere el nombre del cargo, su misión era mantener la paz entre los vecinos de una localidad, resolviendo pequeños agravios de la forma más equitativa posible.

Jack the Giant-killer El cuento infantil acerca de Jack y las habas mágicas, de las cuales crece un enorme árbol. Jack sube por el árbol al país del gigante, le roba, se escapa y corta el árbol mientras el gigante desciende, que así se cae y se muere.

jackeen En sentido despectivo, un señorito o habitante de la ciudad, sobre todo de Dublín. Este tipo de persona trataba con condescendencia a los habitantes de las aldeas cuando iba de visita, y exageraba su aprecio de su lengua, costumbres y forma de vida.

Jack-gnat You have the patience of a Jack-gnat with your own brothers and sisters, let alone with a class of children. (RAI) 
Una especie de mosquito. Es decir, que la persona en cuestión no tiene paciencia.

Jakin El apellido de Bob Jakin (MOF) recuerda la palabra "jake", que significa un campesino torpe y tosco. Coincide en gran parte con la imagen de este personaje.

jardinière Palabra de origen francés que se refiere a una maceta de cerámica generalmente grande.

jig saw Una sierra de vaivén, en el contexto de The Caretaker. También significa un rompecabezas, y puede escribirse con o sin guión, así como en una sola palabra.

jingle Un coche de caballos usado como coche de alquiler en Irlanda en el siglo XIX y a principios del siglo XX.

Jock and Day I was thinking we'd scrub Jock and Day, and call ourselves something else. "And jocund day stands tiptoed on the misty mountain tops." (LBA) Es un juego lingüístico entre "Jock and Day" (nombres propios) y "jocund day" (un día alegre, jovial). La cita original es:
Night's candles are burnt out and jocund day

Stands tiptoe on the misty mountain tops.

(Shakespeare: Romeo and Juliet, act 3, sc. 5)

Johnston, Mooney and O'Brian's Una cadena de cafeterías en Irlanda.

Jones Jones, Inigo (1573-1652): arquitecto británico responsable de un gran número de casas solariegas y obras públicas. Entre sus obras más destacadas se encuentran la Queen's House, Greenwich y la plaza de Convent Garden, Londres. Jones también diseñó los decorados de muchas obras de teatro de su época.

Jones, Tom The History of Tom Jones (1749) es una novela de Henry Fielding (1707-1754).

\section{Jorrock's Jaunts and Jollities}

Es el título de una novela de Robert Smith Surtees (18031864). Este autor creó la figura de Mr Jorrocks, uno de los grandes personajes cómicos de la literatura inglesa, cuyo deporte favorito era la caza a caballo del zorro. Esta novela y las crónicas de Soapy 
Sponge se publicaban por entregas y ofrecían una perspectiva satírica de la sociedad de provincias.

Josephus Josephus, Flavius (Josefo, Flavio) (37-98 d.C.): historiador judío, nacido en Jerusalén, de linaje real y sacerdotal. Fue miembro del partido de los fariseos, y también una figura pública. Antes de la sublevación judía contra Roma (66), tuvo buenas relaciones en la corte del emperador Nerón, y le fue concedida la ciudadanía romana. Escribió La Historia de la Guerra Judía y Antigüedades Judías.

Joshua Véase Reynolds, Joshua

jowl Golpear con un palo, o golpear la cabeza contra algo.

jumps Un corpiño que se llevaba debajo del vestido y que hacía las veces de corsé. Se expresaba en plural. 



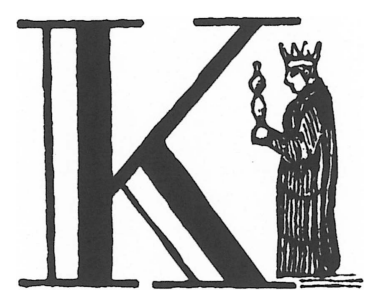

He that plays the king shall be welcome; his majesty shall have tribute of me. W. Shakespeare (1564-1616). Hamlet (1601). 



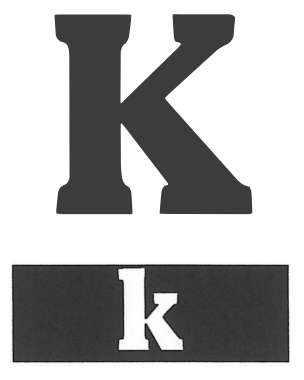

K.C Abreviatura de "King's Counsel", consejero real, abogado de la máxima categoría en el tribunal superior. Es nombrado por el "Lord (High) Chancellor", y tiene el privilegio de llevar una toga de seda negra llamada "silk". Cuando el monarca es una reina, la abreviatura es Q.C. ("Queen's Counsel").

Kenilworth Un pueblo cerca de Coventry, en el centro de Gran Bretaña, conocido por su castillo medieval.

Kenn Este apellido de un clérigo en The Mill on the Floss parece estar relacionado con el verbo "to ken", que significa tener conocimientos, o darse cuenta de algo en el dialecto de Escocia y del norte de Inglaterra.

Kensington Una zona residencial en el oeste de Londres, asociada con la clase media.

Kensington Gardens Un parque de Londres, antiguamente los jardines reales del palacio de Kensington.

Kent Un condado en el sudeste de Inglaterra conocido como el jardín o la huerta de Inglaterra ("the Garden of England") a causa de su producción de frutas y hortalizas, que es posible gracias a su clima benigno.

kettle The kettle of his gift sang with some satire in its note. (JOB) Es una especie de hervi- 
dor de agua con pitorro y asa. Cuando empieza a hervir el agua, el vapor produce un sonido. En inglés se dice que está cantando, o silbando cuando avisa que el agua ya está en su punto para hacer el té. En el caso de la cita, el hervidor está personificado, ya que no sólo canta, sino que incluye un toque de ironía en su tono.

kidney Fellows of the right kidney. (POR) Personas de buena educación y posición social, según el lenguaje coloquial de Dublín.

King and Queen The King and Queen were at the Palace. (DAL) Alusión a Jorge V (18651936) rey de Gran Bretaña desde 1910 hasta 1936. Su esposa fue Mary of Teck (1867-1953). Son los abuelos de la reina actual.

King's scholar Un alumno con beca en el colegio Westminster School, fundado por Enrique VIII. Este centro educativo gozaba de gran prestigio $y$ atraía a los hijos de los poderosos.

kingdom (...) for he was nearly killed - he would not have such another walk for the three kingdoms. (WUH) Los objetos naturales suelen dividirse en tres "reinos": el reino animal, el reino mineral y el reino vegetal. Por lo tanto, la expresión citada significa que el protagonista no repetiría la experiencia por nada del mundo, ni siquiera por los tres reinos juntos.

Kingsley Kingsley, Charles (1819-1875): escritor británico, sacerdote de la Iglesia Anglicana, y profesor de historia de la Universidad de Cambridge. Escribió novelas históricas y obras relacionadas con el sufrimiento de la clase obrera. Su comportamiento era paradójico, dado que le gustaba la caza pero sentía simpatía por los animales, y defendía los derechos del obrero al mismo tiempo que aborrecía a los negros. Es famoso por su obra didáctica infantil The Water Babies (1863).

kirkyard Campo santo. En el inglés estándar sería "churchyard". "Kirk" (iglesia) y "kirkyard" son formas dialectales de Yorkshire y Escocia. 
knivey Forma dialectal del cen- knock about Vagar, desplazartro/norte de Inglaterra. Es un se sin rumbo fijo, o llevar una adjetivo formado de "knive" o vida poco ordenada, en len"knave" que significan un guaje coloquial. hombre poco honrado, sin vergüenza. 



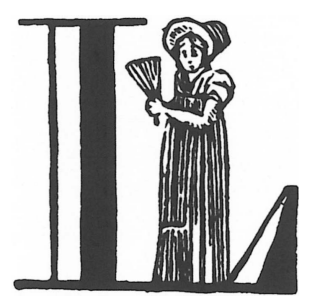

I don't want to talk grammar, I want to talk like a lady. G.B. Shaw (1856-1950). Pygmalion (1916). 



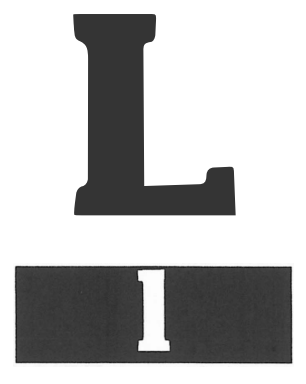

lace-factory ... he became $a$ draughtsman in a lace-factory in Nottingham. (RAI) La ciudad de Nottingham en la zona centro/norte de Inglaterra era famosa por su industria textil, sobre todo por el encaje artesanal, que más tarde también se producía en las fábricas a partir de la Revolución Industrial. El delineante ("draughtsman") era necesario para diseñar los dibujos entramados del encaje producido en las fábricas con la nueva maquinaria.

lamplighter El farolero encendía y apagaba uno por uno los faroles de gas en las calles. Era una figura típica de la época

victoriana. El alumbrado público representó un gran avance tecnológico.

Langtry Langtry, Lillie (18531929): actriz inglesa conocida como Jersey Lily, y considerada muy atractiva. Fue amante del futuro Eduardo VII (hijo mayor de la reina Victoria). Causaba expectación por donde iba tanto por su belleza como por su relación con el príncipe.

Laocoön embrace Laoconte (o Laocoonte) era el nombre de un sacerdote de Troya que, junto con sus dos hijos, fue aplastado por dos enormes serpientes marinas enviadas por Apolo como castigo por 
haberlo desafiado (Virgilio, La Eneida, II, 40-56, 199-231).

lardy-da "Lardy-da" / "lardydardy" / "la-di-da": presumir, darse importancia, en el dialecto del centro/norte de Inglaterra.

Lascar I declare he is that strange acquisition my late neighbour made in his journey to Liverpool - a little Lascar, or an American or Spanish castaway. (WUH). Marinero de las Indias Orientales. Durante los siglos XVIII y XIX Liverpool fue uno de los centros del comercio de esclavos. Por este motivo se sospecha que Heathcliff podría ser de otra raza, quizá hijo de un marinero o un esclavo.

lass Forma dialectal de Escocia $y$ Yorkshire que significa chica.

late (...) the late Mr. Thomas Cardew (...) (IMP) El adverbio late se utiliza para referirse respetuosamente a una persona fallecida: el difunto Sr. Cardew.

Lavater's Physiognomy Lavater, Johann Caspar (1741-1801): filósofo y escritor suizo, cono- cido por el diseño de un sistema que pretendía deducir el carácter y las inclinaciones de una persona a través del estudio de su fisonomía.

Leamington Una ciudad balnearia en Warickshire, en el centro de Gran Bretaña. A finales del siglo XVIII se puso de moda entre la clase alta, y en 1838 la reina Victoria concedió a la ciudad el título de "Royal Leamington Spa". La palabra "Spa" procede del nombre de una pequeña ciudad belga famosa por sus aguas minerales en el siglo XVII.

lees Una forma dialectal de Yorkshire que significa pastos. Forma parte de muchos topónimos de la zona.

lemon platt "Platt" o "plait": Una golosina con sabor a limón, hecha con azúcar cristalizado, y en forma de trenzas.

length "Sit you down," said Tom Brangwen, "an' take a bit off your length." (RAI)

Literalmente, hacerse más corto al sentarse, en lenguaje coloquial. 
Lent El período de cuaresma, durante el cual no se podían presenciar conciertos de música profana, tan sólo música sacra.

\section{Liberal Unionist "Well, I'm} afraid I am a Liberal Unionist." "Oh they count as Tories. They dine with us. (IMP) Los Liberal Unionists se separaron del Partido Liberal en 1886, y se aliaron con el Partido Conservador (Tory). Las dos ideologías son, por lo tanto, cercanas.

Life Guards Un regimiento de gran prestigio dentro del ejército inglés, fundado en 1656. Entre otras funciones, acompaña al monarca en actos oficiales, ya que como su nombre sugiere son sus guardaespaldas oficiales.

Liffey El río que pasa por Dublín. La parte antigua de la ciudad está situada en la orilla sur.

lighting-up time A una hora determinada es obligatorio que los coches enciendan las luces. Varía la hora según el lugar y la estación del año.

Lincoln's Inn Una de las cuatro asociaciones profesionales de abogados en Gran Bretaña.
El conjunto de estas asociaciones se llama "Inns of Court". Todos los abogados deben pertenecer a alguna de ellas. Las otras tres se llaman "Inner Temple", "Middle Temple", y "Gray's Inn". Todas tienen su sede muy cerca de los "Royal Courts of Justice", los tribunales de más alto nivel, en Londres.

Lindisfarne Es una isla en la costa nordeste de Inglaterra (Northumberland) unida a tierra firme durante bajamar (también conocida como Holy Island). Su monasterio fue atacado numerosas veces por los vikingos que buscaban el oro y las piedras preciosas de los objetos del culto. La comunidad religiosa se cansó de estos ataques y decidió buscar un refugio más seguro en Durham. Véase también Northmen.

linoleum squares I'd have teal-blue, copper and parchment linoleum squares. I'd have these colours re-echoed in the walls. (CAR) El linóleo era un tipo de revestimiento para suelos muy empleado en los años 1950-60. Todos los detalles de la descripción de 
la decoración en esta cita reflejan los materiales disponibles y los gustos de la época.

Locke Locke, John (1632-1704): filósofo inglés, que dotó al empirismo de Francis Bacon de una expresión sistemática en An Essay Concerning Human Understanding (1690). Afirmaba que la mente de una persona en el momento del nacimiento es como una tabula rasa, una hoja en blanco sobre la que la experiencia imprime el conocimiento, y no creía en la intuición o teorías de las concepciones innatas.

Lockwood Este apellido de un personaje de Wuthering Heights se descompone en "lock" (cerrar con llave, o una cerradura) y "wood" (bosque o madera).

loo Un juego de cartas en el cual los perdedores pagan una contribución a un fondo común.

Lord Chancellor (Lord High Chancellor) Es el ministro de justicia en Gran Bretaña. También actúa como moderador ("Speaker") en la cámara alta del parlamento ("House of
Lords"). No debe confundirse con Chancellor of the Exchequer.

Lords El famoso campo de críquet, situado en St. John's Wood, en el norte de Londres. En él se celebran partidos nacionales e internacionales, y es la sede de la Asociación Inglesa y Galesa de Críquet. Muchos aficionados lo consideran "la catedral del críquet". No debe confundirse con "the Lords", que es una forma abreviada de "the House of Lords" (la cámara alta del parlamento británico).

Low Church He suited Lyme, a traditionally Low Church congregation, very well (...) and he kept his church free of crucifixes, images, ornaments and all other signs of the Romish cancer. (FLW) Un sector de la Iglesia Anglicana que concede poca importancia a la autoridad de los obispos, que cree en la importancia de la fe y del estudio de los Evangelios, y que rechaza las velas, los adornos y las ceremonias y ritos de la Iglesia Católica compartidos por el sector de su propia Iglesia llamado "High Church". El adjetivo 
"Romish" de la cita es un tér- tribuyeron significativamente mino peyorativo que se aplica a ampliar los conocimientos a la Iglesia Católica. Su efecto de la arqueología y estratigraes aún mayor en este cita, ya fía (el estudio de las capas de que se combina con "cancer". la superficie de la Tierra). Las

Lyell Lyell, Sir Charles (17971875): geólogo escocés cuyos trabajos de clasificación conteorías de Lyell influyeron en el trabajo de su amigo Charles Darwin. 



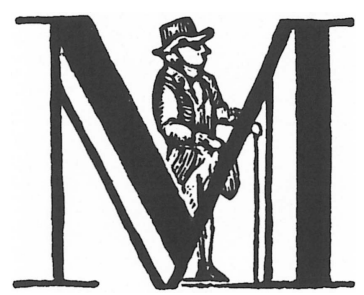

Let me tell you about the very rich. They are different from you and me. F.S. Fitzgerald (1896-1940). All the Sad Young Men (1926). 



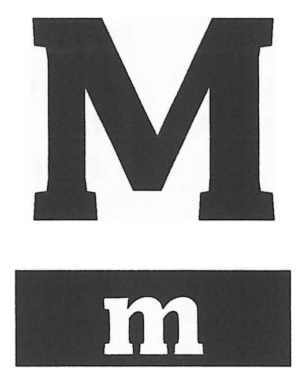

M.F.H. Siglas que corresponden a "Master of Fox Hounds", el encargado de reunir y entrenar los perros de caza para la caza del zorro a caballo en zonas rurales.

M.P. Siglas que corresponden a "Member of Parliament", o diputado en la cámara baja del parlamento británico.

M'Choakumchild Este apellido inventado por Dickens en Hard Times suena como "choke a child": ahogar, estrangular a un niño.

Macaulay Macaulay, Thomas Babington, $1^{\text {st }}$ Baron (18001859): poeta, historiador $y$ político. Publicó los dos pri- meros volúmenes de The History of England en 1848, que alcanzaron un éxito inmediato. Los volúmenes tercero y cuarto de su gran obra fueron publicados en 1855 y obtuvieron una acogida aún mejor que la de los dos anteriores. El quinto y último volumen completo de su obra, que trataba sobre los acontecimientos ocurridos hasta 1702, se publicó en 1861 con carácter póstumo.

Macmillan Macmillan, Harold (1894-1986): político conservador inglés. Fue Primer Ministro entre 1957 y 1963. Mejoró las relaciones entre Gran Bretaña y los demás paí- 
ses, y estimuló el crecimiento económico. Una frase suya se hizo famosa: "You've never had it so good!" (Nunca habían vivido ustedes tan bien como ahora).

mahogany Caoba. Por extensión, una mesa del mismo material.

maisonette Un conjunto de habitaciones, generalmente distribuidas en dos plantas de un edificio más grande, con una entrada individual.

Malthus Malthus, Reverend Thomas R. (1766-1834): sus teorías decían que la población aumenta en progresión geométrica, mientras que la producción de alimentos sólo aumenta en progresión aritmética. Esto haría necesario frenar el crecimiento de la población por medio de la represión moral.

maneen En el dialecto de Dublín, es un joven o adolescente que intenta aparentar ser mayor

manse La casa del sacerdote protestante, que forma parte del sueldo y del puesto. Los sacerdotes de las iglesias protestantes pueden casarse. El tener una casa, generalmente grande, era un mérito a su favor en cuanto a sus perspectivas de matrimonio.

Marchbanks "I get mixed up with all your women. Was she the one all those years older than you?" "Ten years." "Proper little Marchbanks, you are!" (LBA) Eugene Marchbanks es un personaje en la obra de teatro Candida de G.B. Shaw. Tiene 18 años y se enamora de Candida Morell, una mujer casada de 33 años.

mardy Un adjetivo en el dialecto del centro/norte de Inglaterra que significa alguien que protesta siempre, que lloriquea por nada, o que se queja habitualmente.

Maréchal Niel Un tipo de rosa amarilla muy popular en Inglaterra alrededor de 1860 . Se llamó así en honor del Mariscal Adolphe Niel, el ministro de guerra francés.

Margate Tradicional lugar de veraneo en la costa norte de Kent (sudeste de Inglaterra), frecuentado en la época de Virginia Woolf por gente de clase alta. 
Marylebone High Street Una calle en la zona comercial del centro de Londres, entre Regent's Park y Oxford Street.

Marquess of Queensbury El octavo marqués de Queensbury estableció las reglas del boxeo en 1867. Por extensión, el uso de su nombre implica seguir las reglas, o comportarse como caballeros.

mash Hacer té, en el dialecto del centro/norte de Inglaterra. En otras zonas del país el verbo correspondiente suele ser "to brew tea".

mashed-potato men Vendedores de puré de patata montado en rebanadas de pan.

master of ceremonies $\mathrm{El}$ maestro de ceremonias de las salas de reuniones (véase Assembly Rooms) en lugares de veraneo o balnearios como Bath, cumplía la función de presentar a los asistentes a los bailes públicos y reuniones sociales. Sin una presentación formal sería imposible entablar relaciones con desconocidos en los siglos XVIII y XIX.

Matilda En el argot de los soldados aliados de la Segunda
Guerra Mundial era el nombre dado al tanque MKII del ejército británico.

\section{matriculation-examination $\mathrm{El}$} examen de ingreso para poder matricularse en la Universidad de Londres.

Mayfair (May Fair) Una zona residencial londinense donde vivían las clases acomodadas en los siglos XVIII y XIX.

Mayflower Nombre del barco que llevó al primer grupo de colonos puritanos a Norteamérica en 1620 (véase también Plymouth).

Mayhew Mayhew, Henry (18121887): escritor inglés, autor de London Labour and the London Poor (1851-62), un estudio sociológico llevado a cabo entre los vendedores de la calle y los vagabundos de la capital.

McCarthy McCarthy, Joseph (1908-1957): senador estadounidense del Partido Republicano desde 1947 a 1957. Inició una campaña para identificar a miembros del partido comunista en su país, a quienes acusaba de espionaje y actividades dirigidas a socavar la 
democracia. Una de sus tácticas fue establecer el principio de la culpabilidad por asociación ("guilty by association") que consistía en calificar de comunistas a la gente que había conocido o que había estado de acuerdo con un comunista sobre cualquier tema. Fue tachado de demagogo por algunos pero era muy temido por la información confidencial que manejaba acerca de la vida de personajes públicos incluyendo miembros del gobierno. El término "McCarthyism" se utiliza incluso hoy en día (con el significado de caza de brujas) para referirse a una investigación sensacionalista de los miembros de la oposición; o a la descalificación de miembros de la oposición basada en acusaciones poco sostenibles.

McLuhan McLuhan, Marshall, autor de The Gutenberg Galaxy (1962) en el cual se imagina el mundo transformado por la revolución electrónica, y convertido en una aldea global en la cual ya no se leen libros. De su apellido se forma el sustantivo "McLuhanism".
Mechanics' Hall Precursor del "Mechanics' Institute", que constituyó el principio de la formación profesional para miembros de la clase trabajadora. Ofrecían clases nocturnas y cursos de especialización con diploma. Estos institutos fueron desarrollándose, y llegaron a convertirse más tarde en los politécnicos modernos. También tenían actividades de ocio para los matriculados y visitantes.

Mechlin La ciudad de Mechelen, antes Mechlin, en Bélgica, era conocida por su encaje artesanal con dibujos realizados en relieve.

Melbourne Melbourne, William Lamb, $2^{\text {nd }}$ Viscount (1779-1848): político inglés que fue Primer Ministro dos veces. Tenía fama de ser un hombre agradable y honesto; rechazó condecoraciones y promoción dentro de la aristocracia.

Men's Beavers They went in, and while the sleek, well-tied parcels of "Men's Beavers" and "York Tan" were bringing down and displaying on the counter (...) (EMA) Son guantes de caballero hechos de piel de 
castor. (Nótese la forma verbal: modo activo were bringing down and displaying en lugar del pasivo moderno "were being brought down and displayed".) "York Tan" es otro tipo de guante, de cuero teñido de color marrón claro.

mend La expresión "mend the fire" significa colocar más carbón o leña en la chimenea para que vuelva a arder el fuego.

Menton Una ciudad en la Costa Azul de Francia.

Merchant-Taylors' Un colegio privado muy antiguo, fundado por los miembros de un gremio medieval londinense.

merino Una tela de lana de buena calidad, adecuada para los días más fríos.

mess tin Recipiente de hojalata que se utiliza en el comedor de los soldados ("mess hall") o en maniobras cuando tienen que comer a la intemperie.

Methodism Un grupo de evangelistas, bajo la influencia de Charles y John Wesley, que abandonaron la Iglesia Anglicana en el siglo XVIII, y fundaron este grupo religioso. Eran estrictos y metódicos en sus rezos (de ahí su nombre) y no permitían adornos en sus capillas. Tuvieron mucho éxito entre las clases bajas, sobre todo en las zonas urbanas e industriales.

methylated spirits Alcohol desnaturalizado para encender un hornillo o estufa.

mews Originalmente eran varios establos en fila detrás de las casas de los ricos, donde se guardaban los caballos y carruajes. En el piso de arriba vivían los cocheros y mozos que cuidaban los caballos. Cuando el coche de caballos cayó en desuso, estos establos fueron convertidos en casas, pequeñas pero muy céntricas y caras, propias de los jóvenes elegantes de las clases emergentes.

Michaelmas La festividad de San Miguel, el 29 de septiembre. Desde la Edad Media los "quarter days" han marcado el comienzo de cada cuarta parte del año (trimestre). Los pagos correspondientes a los intereses y los alquileres se realizaban en estos días, y muchos contratos de trabajo empezaban o terminaban en estas fechas. Tradicionalmente, se celebraban ferias para festejar 
estos días especiales, y los criados y jornaleros que querían cambiar de empleo acudían a la feria para buscar un patrón nuevo. Los nombres de estos "quarter days" se tomaron del calendario eclesiástico, y en Inglaterra y Gales correspondían a: 25 de marzo ("Lady Day" o Anunciación de la Vírgen), 24 de junio (San Juan o solsticio de verano), 29 de septiembre (San Miguel), y 25 de diciembre (Navidad).

Midland Railway Una línea y compañía de ferrocarril que unía los centros de población del centro y norte de Inglaterra a partir de la Revolución Industrial.

mild-and-soda "Mild" es un tipo de cerveza inglesa con un sabor suave, y se puede mezclar con otras bebidas como sifón.

Mile End Waste Un mercadillo al aire libre en la zona este de Londres.

milk bar Una cafetería o mostrador donde se venden leche, helados y bebidas no alcohólicas.

Mill Mill, John Stuart (18061873): filósofo liberal y diputado del parlamento británico. Hizo campaña a favor del voto femenino, defendió los dere- chos de la mujer y la igualdad para hombres y mujeres, lo cual constituyó un hito para su época. Entre sus numerosos escritos destacan Principles of Poltical Economy (1848), The Subjection of Women (1869) y Autobiography (1873).

Millais Millais, Sir John Everett (1829-1896): un miembro original del grupo de pintores británicos llamados prerrafaelistas. Pintó temas de la historia inglesa e italiana, de Shakespeare y de la Biblia, utilizando una delineación escrupulosa y detalles realistas. También pintó acuarelas de paisajes escoceses y temas sentimentales. Entre sus obras destacan Christ in the House of his Parents (1850), Ophelia (1852) y The Blind Girl (1856).

Miller Miller, Hugh (18021856): geólogo escocés cuyos trabajos acerca de la historia de la geología consiguieron atraer el interés del gran público.

Milton Milton, John (16081674): poeta inglés, autor de Paradise Lost (1667) y Paradise Regained (1671). También escribió panfletos políticos apoyando al parlamento en contra del rey, y en defensa de 
la libertad religiosa y de prensa.

\section{Mitford Mitford, Nancy} Freeman (1904-1973): hija del segundo Lord Redesdale, y autora inglesa de novelas acerca de las familias acomodadas. Entre sus obras más conocidas están The Pursuit of Love (1945) y Love in a Cold Climate (1949). En 1956 escribió Noblesse Oblige: an enquiry into the identifiable characteristics of the English aristocracy, en el cual utilizó los términos "U" y "Non-U", acuñados dos años antes por el lingüista Alan S. C. Ross, para describir la forma de hablar y el comportamiento aceptables o inaceptables, respectivamente, entre los miembros de la clase alta. A partir de la publicación de esta obra, estos términos, que eran abreviaturas de "upper class" y "non-upper class", fueron empleados por lingüistas, sociólogos y otros escritores para clasificar las costumbres sociolingüísticas de los hablantes aspirantes a pertenecer a la alta sociedad.

Mod En la década de los 1960 los "Mods" eran adolescentes que vestían levitas y llevaban el pelo corto, y que se enfrentaban a sus rivales los "Rockers" que eran motoristas de pelo largo y con chaquetas de cuero.

Model T Ford Uno de los primeros coches fabricados por la empresa americana Ford entre 1908 y 1927. Fue, además, el primer coche fabricado en serie. Tenía un precio asequible y su nombre popular era "Tin Lizzie". Se dice que Ford bromeaba con que se podía encargar este coche en cualquier color, con tal que fuera el negro. Se fabricaron unos quince millones de este modelo emblemático, que posteriormente fue sustituido por el "Model A".

moiety (second) (POR) Un documento que notifica que se deben las tasas municipales para la segunda mitad del año.

Monk Matthew Gregory Lewis (1775-1818) escribió The Monk en 1796. Esta novela gótica, una mezcla extravagante de elementos supernaturales, terror y detalles escabrosos, tuvo gran éxito en el momento de su publicación, y gracias a 
su fama el autor ganó el sobrenombre "Monk Lewis".

Monkey Brand Una marca de jabón de cocina, en cuyo anuncio se veía un mono que se miraba reflejado en una sartén reluciente. "Monkey Brand" se usaba como frase hecha en los años 1920-30, a menudo para referirse a alguien con una cara fea.

Monkshood Una planta con flores venenosas (aconitum napellus).

Monmouth To the west sombre grey cliffs (...) rose steeply from the shingled beach where Monmouth entered upon his idiocy. (FLW) Monmouth, James Scott, $1^{\text {st }}$ Duke of Monmouth (1649-1685): era el hijo ilegítimo mayor de Carlos II de Inglaterra. Mientras estaba exiliado en Holanda, un grupo de radicales le animó a invadir Inglaterra. Desembarcó en Lyme en 1685 con tan sólo 80 seguidores, esperando encontrar apoyo entre los afines a los Whigs (presbiterianos escoceses). Consiguió reunir unos 3.000 soldados entre el pueblo, pero fue derrotado y ejecutado. La "idiotez" de la cita es, por lo tanto, este intento de invasión con tan pocos medios.

Moore Moore, Henry (18981986): escultor británico conocido sobre todo por sus esculturas semiabstractas de figuras humanas. Está considerado como el escultor británico más importante del siglo XX. Su obra ha ejercido una fuerte influencia sobre la escultura figurativa contemporánea. Sus esculturas de figuras humanas de gran tamaño hechas de piedra, madera o bronce, con líneas curvas y suaves se conciben como una parte integral del lugar en el cual se sitúa la obra.

Moorgate Street Una calle al este de la zona central de Londres.

Moors Páramos, brezales, grandes extensiones sin cultivar donde sólo se encuentra una vegetación baja. Son lugares solitarios, con un clima inhóspito en invierno. En verano, sin embargo, el color violeta del brezo recubre las montañas y embellece este paisaje agreste.

Morland Morland, George (1763-1804): pintor inglés que popularizó la imagen bucólica 
del campesino feliz, de la vida sencilla de las personas corrientes. Fue uno de los maestros de la pintura de género, de paisajes y de animales.

Morning Post Un periódico de tendencia conservadora que ya no se publica. En su momento incluía los anuncios de los compromisos, matrimonios, nacimientos, fallecimientos y vida social de la alta sociedad londinense. Si un compromiso venía anunciado en este periódico, se podía considerar oficial.

morning-room Las casas de la alta sociedad tenían una sala de estar para recibir las visitas por la mañana. Por la tarde y por la noche los dueños recibirían en otras estancias de la casa.

Morris Morris, William (18341896): poeta, artista, diseñador y decorador británico. Fue uno de los primeros socialistas, y llevó a cabo campañas contra las consecuencias negativas de la Revolución Industrial. Se conoce sobre todo por los muebles que diseñó y por su estilo de deco- ración de interiores. Muchos de sus dibujos para el papel pintado y los textiles aún se reproducen y se emplean hoy en la decoración moderna. Entre estos dibujos detallados, simétricos y de colores suaves basados en la naturaleza destacan The Strawberry Thief, Honeysuckle, Pimpernel 86 , e Iris.

morris-dancing Un baile tradicional inglés. Lo realizan grupos de hombres vestidos de blanco, con cascabeles atados a las piernas, palos y pañuelos.

Mother Hubbard Una rima infantil cuenta la historia de esta mujer:

Old Mother Hubbard, Went to the cupboard To get her poor dog a bone. But when she got there The cupboard was bare And so the poor dog had none.

motto There's an English family with a charming Italian motto. What will be, will be. (HAT) El lema italiano mencionado en esta cita es "Che sera, sera", y pertenecía a la familia de Lord Russell, Primer Ministro de Gran Bretaña en dos ocasiones 
(1846-1852 y 1865-1866), y muy amigo de Dickens.

Mudie Mudie, Charles Edward (1818-1890) Fundador de una biblioteca pública (Mudie's Lending Library) en Londres. En 1842 empezó a prestar libros por un penique, y el negocio creció tanto que abrió un local más grande, y sucursales en Birmingham $y$ Manchester. Tuvo éxito porque hizo publicidad de su of erta, $y$ porque se esforzó en conseguir los primeros ejemplares de los libros nuevos más populares, a menudo en grandes cantidades. Consiguió contar con unos 25.000 suscriptores, y su biblioteca se convirtió en una especie de institución nacional. Las novelas en tres volúmenes que se prestaban fueron muy populares entre los lectores victorianos, y sobre todo entre las mujeres.

muffin Panecillo con mantequilla servido caliente como merienda.

muffineer Azucarero en forma de vaso con una tapa con agujeros. Se usaba para dosificar el azúcar que se echaba en los postres o específicamente en los "muffins".

mules Then Daphne's feet, in mules, clip-clopped off across the landing. (DOH) Babuchas. "Mule" también significa "mula", así que el verbo "clip-clop" una representación onomatopéyica del andar de un caballo o una mula - juega con este segundo significado.

mullioned window Una ventana dividida en parteluces.

Musgrove, Luisa Luisa Musgrove sufrió un accidente en las escaleras del paseo marítimo ("The Cobb") en Lyme Regis. (Véase Persuasion, Capítulo 12.) En The French Lieutenant's Woman, Fowles menciona la novela de Jane Austen al referirse a estas escaleras y las protagonistas respectivas de su novela y de la novela de Austen.

muster-roll Una lista oficial de los soldados alistados, los tripulantes de un barco, o los colaboradores de un hombre de negocios.

mystery play Una obra teatral representada en la calle en la Edad Media, basada en histo- 
rias de la Biblia o en la vida de desde Australia para intentar los santos. controlar y reducir de forma "natural" la población de conejos en Gran Bretaña en los años 1950-1960. 



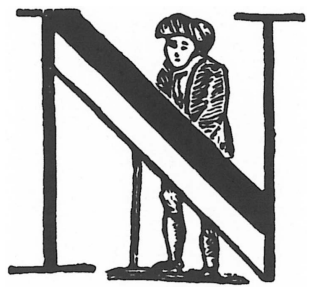

Spurn not the nobly born

With love affected,

Nor treat with virtuous scorn

The well-connected.

W.S. Gilbert (1836-1911). Iolanthe (1882). 



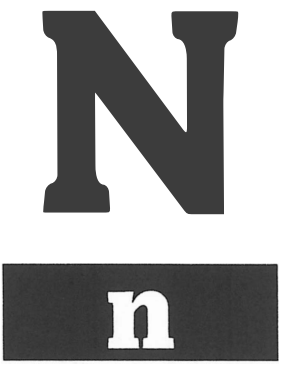

N.B Además de ser la abreviatura de "nota bene" (tomar buena nota, en latín), Oscar Wilde la usa como la abreviatura de "North Britain", para referirse a Escocia. Este término ya no se usa para denominar a Escocia, que aunque sigue formando parte del Reino Unido, ostenta un alto grado de autonomía y el orgullo de ser una nación.

N.W. Abreviatura de "North West" (noroeste), en el contexto de los distritos postales de Londres. Los habitantes de Londres asociaban las abreviaturas tales como W1 ("West one"), SW1, ("South West one") WC1, ("West Central one") y sus correspondientes barrios con la elegancia y las clases acomodadas. En cambio, en los distritos del este (EC2, "East Central two", etc) y sudeste (SE1, "South East one", etc) de la capital vivía la gente que se dedicaba al comercio, y eran barrios más populares e incluso pobres. (Véase Cheapside.)

NAAFI Siglas que corresponden a "The Navy, Army and Air Force Institutes", organización que administra comedores, tiendas, instalaciones recreativas, etc. para el personal militar en Gran Bretaña y en las bases militares británicas que existen en el extranjero. 
nabob Un oficial o gobernador musulmán en el imperio mogol (1526), o una persona que regresó a Europa de la India después de hacerse rico.

Nag's Head Es el nombre de un "pub" famoso en el centro de Londres.

Narragansett El lenguaje del pueblo indio de Norteamérica del mismo nombre.

National Gallery El museo nacional de pintura de Londres, situado en Trafalgar Square. Contiene la colección permanente más importante de Gran Bretaña.

netting Una especie de encaje hecho en forma de red. Era un trabajo manual realizado por las señoras durante los siglos XVIII y XIX para llenar sus horas libres de otras ocupaciones de tipo social.

netting-box Un costurero para guardar los hilos y las agujas del encaje ("netting") que las señoras de los siglos XVIII y XIX realizaban para entretenerse.

New Statesman Semanario de reconocido prestigio interna- cional de contenido político y literario, fundado en 1913 y publicado en Londres, y que cuenta entre sus colaboradores con los escritores más destacados del país.

News El boletín de noticias en la televisión, y en otros tiempos en la radio.Tradicionalmente el boletín de las nueve de la noche era de más audiencia.

News of the World Este periódico británico sensacionalista cuenta los detalles de todos los escándalos, la vida de los famosos, además de noticias acerca de los deportes. Es el periódico de mayor tirada en Gran Bretaña. A pesar de su nombre, contiene muy pocas noticias mundiales.

nick En el lenguaje coloquial "in the nick" significa estar en la cárcel.

Nick (Owd/Old) Una forma de referirse al diablo. "Owd Nick" es "Old Nick" en el dialecto del norte de Inglaterra.

nick-nack vendor Vendedor de artículos pequeños de decoración de poco valor y escasa utilidad. 
Nightingale Nightingale, Florence (1820-1910): reformista de la sanidad. Viajó a Crimea en 1854 donde organizó la atención médica para los heridos. Allí se creó la leyenda de "la Dama de la Lamparita" que atendía a los enfermos de noche. De vuelta a Londres aprovechó su éxito para reformar los servicios sanitarios del ejército, la arquitectura hospitalaria, la formación de enfermeras, y el sistema sanitario en general. Elevó el estatus de la profesión de enfermera, desprestigiada hasta entonces, y la convirtió en una vocación honrosa. Se la consideró un ejemplo para las mujeres durante varias décadas.

night-rail Es un término arcaico que significa camisón.

niminy-piminy Remilgado, estirado, esnob, refinado hasta la exageración.

North Circular Una carretera (la A406) que rodea la zona norte de Londres.

North Wiltshire Un condado situado en el sudoeste de Inglaterra. Es famoso por una variedad de queso que lleva el mismo nombre que el condado.

Northmen Los Northmen o Norsemen eran los vikingos. Los monjes que sufrían los ataques y saqueos de los vikingos en sus monasterios rezaban: "From the wrath of the Northmen, O Lord deliver us!" (¡Que Dios nos libre de la ira de los vikingos!)

Norton Norton, Caroline (18081877): escritora y reformista, se casó a los 19 años con George Norton, quien la maltrató y la acusó de adulterio con Lord Melbourne, Primer Ministro en esa época. En el juicio no se la encontró culpable pero Norton sigió maltratándola, impidiéndole el acceso a sus hijos pequeños, e intentando hacerse con sus ganancias procedentes de la literatura.

not much cop Una expresión idiomática, usada en el lenguaje coloquial, que significa que algo tiene poco valor, que no está en buen estado o que no tiene utilidad.

Notting Hill Gate Barrio bohemio y cosmopolita de Londres con un mercado al aire libre 
muy popular en la calle habitantes de origen caribeño Portobello Road. Hoy en día es de la zona. conocido por su fiesta celebrada en agosto por los muchos 


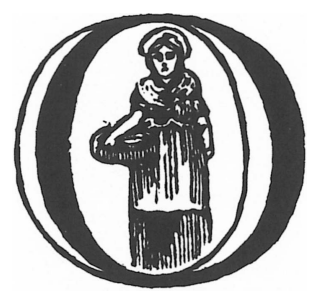

It's a wery remarkable circumstance ... that poverty and oysters always seem to go together.

C. Dickens (1812-1870) Pickwick Papers (1837). 



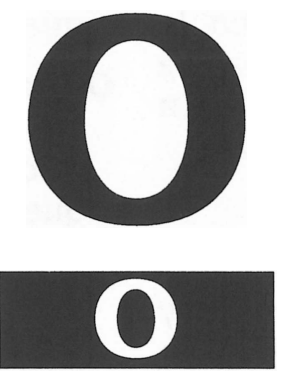

oak leaves Detalles en bronce o plata con forma de hojas y bellotas de roble que se añaden a una condecoración básica para indicar un mérito adicional.

odour (bad) Expresión idiomática que significa que alguien o algo está mal considerado.

Old Harry Es una manera de referirse al diablo.

Old King Cole Es el protagonista de una rima infantil:

Old King Cole was a merry old soul

And a merry old soul was he. He called for his pipe

And he called for his bowl And he called for his fiddlers three.
Old woman Es un personaje de una rima infantil:

There was an old woman

Who lived in a shoe, She had so many children, She didn't know what to do.

omnibus Un autobús tirado por caballos.

Once seen ... never remembered El dicho original es "Once seen, never forgotten", pero Oscar Wilde lo modifica para burlarse de la clase social en la cual se mueve: ... one of those characteristic British faces, that once seen, are never remembered. (PDG)

oriel Una especie de mirador o balcón cerrado en la fachada 
de un edificio, similar a una galería.

osier Es una especie de sauce.

oubliette Una mazmorra que sólo tiene una entrada en la parte superior. Las víctimas se dejaban allí olvidadas. (En francés "oublier" es olvidar.)

Owd Nick Véase Nick.

Oxbridge Esta palabra es una mezcla de Oxford y Cambridge, y se emplea para referirse informalmente a las universidades de estas dos ciudades, en contraste con el resto de las universidades británicas.
Oxford Street Es una calle comercial dentro de la zona cosmopolita del West End londinense. Desde el siglo pasado es una calle de gran movimiento de peatones y tráfico.

Oxonian Untruthful! My nephew Algernon? Impossible! He is an Oxonian. (IMP) Es una persona que se ha licenciado en la universidad de Oxford (lo cual no es realmente ninguna garantía de honradez). Oscar Wilde se burla en este fragmento de los prejuicios de la clase alta. 


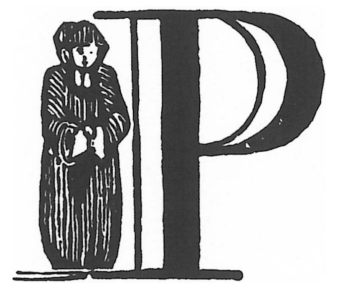

As I take my shoes from the shoemaker, and my coat from the tailor, so I take my religion from the priest. O. Goldsmith (1730-1774).

In James Boswell Life of Samuel Johnson (1773). 


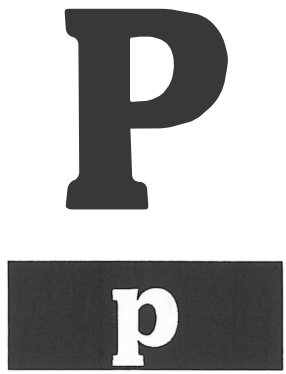

Paine Paine, Thomas (1737-1809): emigró a Filadelfia en 1774, donde escribió Common Sense (1776) en el cual recomendaba cortar los lazos con Gran Bretaña. En Francia escribió The Rights of Man (I y II) y The Age of Reason (I y II). Sin embargo no apoyó la ejecución del rey Luis XVI, y estuvo a punto de ser ejecutado también. En 1802 regresó a Estados Unidos.

paisley Es una tela de lana o algodón con un diseño de figuras abstractas, consistentes en formas como plumas o lágrimas con un extremo curvado, muy utilizada tradicionalmente en la decoración en Gran Bretaña. El diseño se popularizó en el siglo XIX porque las fábricas textiles y de confección de la ciudad de Paisley en Escocia introdujeron el diseño que tenía su origen en la India.

palanquin Especie de andas usadas en Oriente para llevar en ellas a las personas importantes.

Pall Mall Una calle londinense situada en el barrio elegante de St. James, cerca del palacio real.

Palmer Palmer, Samuel (18051881): pintor de paisajes pastorales que ofrecen una visión de la Inglaterra rural sin pro- 
blemas sociales, en paz y armonía. A los 14 años expuso tres paisajes en la academia ("Royal Academy"), y empezó a relacionarse con otros artistas, entre los cuales se encontraba William Blake, que tendría una influencia notable en su producción. Entre sus obras destacan los paisajes como Scene from Lee, North Devon, y las ilustraciones para obras de Milton, como The Dell of Comus.

Palmerin of England Alusión a una serie de libros de caballería que aparecen a principios del siglo XVI, siendo el más importante Palmerín de Inglaterra (1547-1548), escrito en portugués por Franciso de Morais.

pandybat Un cinturón de cuero reforzado, utilizado para los castigos físicos en los colegios de principios del siglo $X X$.

pantalettes Pantalones largos para llevar debajo de la falda en la moda victoriana. Se ajustaban en los bajos con un lazo alrededor del tobillo.

pantomime Es una especie de obra de teatro infantil con música, baile y humor repre- sentada en Navidades en Gran Bretaña. Las obras se basan en cuentos tradicionales (Jack and the Beanstalk, Aladin, Cinderella), y el héroe, Principal Boy, es una mujer joven disfrazada. La heroína se llama "Principal Girl", y generalmente hay una mujer vieja, fea y exagerada pero graciosa ("Dame") que en realidad es un hombre disfrazado. El espectáculo cuenta con la participación activa del público (cantando, contestando preguntas o adivinanzas, etc.), y aparte de las representaciones hechas con actores y cómicos profesionales, muchos pueblos pequeños organizan uno de estos espectáculos con actores aficionados y con fines benéficos.

pantoufle "En pantoufles" es una expresión de origen francés que significa estar en zapatillas.

parish ... to save a sister and her children from the parish. (MOF) Las parroquias tenían la obligación de cuidar de los pobres, enfermos y desamparados, según una serie de leyes ("Poor Laws") introducidas en tiempos de Isabel I, y 
modificadas en siglos posteriores. Esta ayuda benéfica tenía su contrapartida, dado que los receptores de la ayuda de la parroquia debían realizar trabajos más o menos duros en agradecimiento por la supervivencia. Los que carecían de hogar propio ingresarían en la institución correspondiente, ("workhouse") cuyas características conocemos gracias a Dickens. Por este motivo, era deseable "salvar" a los familiares de la "parroquia”, y sus consecuencias físicas, económicas y sociales.

parish oven Una boca muy grande y voraz (uso dialectal del centro/norte de Inglaterra). Por extensión, alguien que tiene muchísima hambre.

Parley (Peter) Pseudónimo de al menos siete autores del siglo XIX que publicaron libros infantiles. Uno de dichos autores fue William Martin (18011867) que publicó Peter Parley's Annual en 1840, imitando una obra con el mismo título publicado en 1838 por el norteamericano Samuel Griswold Goodrich (17931860). parliamentary En el siglo XIX este término se aplicaba a un tren de pasajeros, con tarifa reducida según una ley del parlamento ("Act of Parliament"). Así que viajar en un "parliamentary" era la forma más barata de trasladarse para la gente humilde.

parlour Sala de estar. Es un término y un concepto desconocido para los habitantes de Yorkshire (véase Wuthering Heights), más bien propio de sus vecinos del sur del país. Véase también la explicación en house.

Pascal's Pensées Es una colección de apuntes varios escritos por el matemático, físico y filósofo francés Blaise Pascal (1623-1662). Sus escritos versan sobre la religión, la filosofía y la ética, y compartía la opinión jansenista en cuanto a la salvación del hombre por la gracia divina como única posibilidad para salvar a un ser tan depravado como el hombre.

Passchendaele La malograda campaña militar de Passchendaele (Bélgica), también conocida como la batalla de Ypres, 
durante la Primera Guerra Mundial, que comenzó el 31 de julio de 1917 y contó con la participación de tropas inglesas. Se trataba de impedir un posible ataque alemán a Francia después de la batalla en Somme, pero fue un fracaso, resultando en la muerte de 260.000 soldados británicos.

Patmos Una isla en el mar Egeo en la cual, según el Apocalipsis, San Juan tuvo su visión de los acontecimientos que se producirán en los últimos días del mundo.

pattened La palabra "patten" significa zueco, y el adjetivo correspondiente "pattened" se usa para indicar que una persona lleva zuecos.

Peel Peel, Robert (1788-1850): político y estadista británico, fue Primer Ministro de 1834 a 1835 , y de 1841 a 1846 , y entre otros logros, se le recuerda como impulsor de la reforma de las leyes criminales, y la creación de la policía metropolitana de Londres (1829). De hecho, su apellido fue usado para designar al cuerpo de policía que creó, ("Peelers") y su nombre de pila en diminutivo ("Bob") dio lugar al apodo casi cariñoso ("Bobby/Bobbies") para los recién estrenados policías. $\mathrm{Mr}$ Peel's late conduct on the Catholic Question (MID) es una alusión a la campaña de Peel a favor de la libertad de culto para los católicos, que culminó en la Ley de Emancipación Católica ("Act of Parliament" 1829). Su actitud moderada le procuró muchos enemigos dentro de su propio partido Conservador.

peep-show Una atracción de feria en la que se pagaba por ver imágenes obscenas a través de un aparato parecido a un telescopio, con una ranura para las monedas.

Penistone Crag Es una formación rocosa en medio del páramo en el oeste de Yorkshire. La leyenda cuenta que en sus cuevas vivían seres sobrenaturales.

Pennines Los montes Peninos ("Pennine Chain Mountains") forman una cordillera que atraviesa la parte norte de Inglaterra en dirección nortesur, por lo cual se la conoce como la espina dorsal de 
Inglaterra ("the backbone of England").

penny In for a penny in for a pound (MOC) Este dicho popular significa que si uno decide implicarse en un asunto, es mejor aceptar todas las consecuencias y llegar hasta el final.

penny-gaff Un teatro de variedad de muy baja calidad.

penthouse Un apartamento de lujo en el último piso de un edificio alto, ofreciendo, por lo tanto, vistas panorámicas.

periwinkle Un caracol de mar.

\section{Peter Parley's tales Véase Parley.}

\section{Peter Piper Véase Piper, Peter}

pew-opener Una persona empleada por la iglesia para abrir la sección de asientos privados de las personas ricas o importantes.

physic Una dosis de medicina, o un tratamiento médico arcaico, generalmente algo desagradable.

Piccadilly Una calle céntrica de Londres, con comercios y gran movimiento de personas $y$ vehículos.
Pickwick Papers Fue una de las primeras obras de Dickens. La novela apareció mensualmente en una revista desde abril de 1836 hasta noviembre de 1837, y en el mismo año se publicó como libro.

Pierre Pierre Glendinning es el protagonista de Pierre, or the Ambiguities de Herman Melville, escrito en 1852.

Pimlico Una zona al sudoeste del centro histórico de Londres.

Pimm's No 1 Marca de una bebida alcohólica, hecha de ginebra. Su nombre completo es Pimm's Number One Cup. Suele beberse mezclada con gaseosa, hielo y trozos de fruta y se toma en verano en actos o reuniones elegantes. Está considerada una bebida propia de las clases altas.

Piper, Peter Es el protagonista de un trabalenguas infantil muy conocido

Peter Piper picked a peck of pickled pepper.

A peck of pickled pepper Peter Piper picked.

If Peter Piper picked a peck of pickled pepper, 
Where's the peck of pickled pepper Peter Piper picked?

Pisgah Mount Desde el Monte Nebo, y la cima del Pasga, Moisés vio la Tierra Prometida (Deuteronomio 34:1).

pit La parte de un teatro donde se sientan los músicos, generalmente delante del escenario y en un nivel más bajo.

Pitt Pitt, William (1759-1806): Primer Ministro de Gran Bretaña desde 1783 a 1801 . Entre otros aspectos es conocido por su política fiscal, y sus reformas económicas y comerciales.

Pivart El apellido de este personaje de The Mill on the Floss se parece a "pivot", que significa eje, o elemento central. El argumento de la novela se centra en un primer momento en los litigios contra esta persona.

plain Irish En el lenguaje coloquial este término peyorativo significa una mezcla de falta de lógica e inteligencia. Se observa esta actitud en los chistes de irlandeses contados por los ingleses, que desprecian a los irlandeses por sim- ples y poco desarrollados. La expresión "plain Irish" implica que no hay quien entienda el asunto en cuestión.

plucked En lenguaje coloquial significa que alguien ha suspendido un examen.

plum pudding Un postre tradicional navideño, hecho de frutos secos, bañado en coñac, y servido caliente en la comida de navidad.

plus-fours Pantalones holgados y de media pierna, típicos en los años 1920 como prenda de los jugadores de golf y para los cazadores de clase alta.

Plymouth Un famoso grupo de colonos, los "Pilgrim Fathers", salió de este puerto en la costa sur de Gran Bretaña y fundó una colonia con el mismo nombre en Norteamérica en 1620. Habían huido buscando un lugar donde practicar su religión libremente. (Véanse también Mayflower, y vessel.)

poached eggs Huevos escalfados, es decir, cocidos en agua sin la cáscara.

Pocahontas Una mujer nativa de Norteamérica, hija del jefe 
de la tribu de los Powhatan, que salvó la vida del capitán John Smith cuando su padre estaba a punto de matarlo. Posteriormente, Pocahontas se casó con otro colono, John Rolfe, y se fue a vivir a Inglaterra, donde murió de viruela (1595?-1617).

\section{pocketful of posies Es una} rima y juego infantil, que tiene su origen en la Edad Media y que describe los síntomas de la peste (marcas circulares y de color rosa; estornudos; desmayos) y la costumbre de llevar un ramillete de hierbas aromáticas para protegerse de la enfermedad y disimular el mal olor de los cadáveres:

Ring a ring o'roses, A pocketful of posies, A-tishoo! A-tishoo!

We all fall down.

polony Salchichas parcialmente cocidas, hechas de carne de caballo o de cerdo.

Pope Pope, Alexander (16881744): poeta inglés, autor de ensayos críticos y traducciones de obras clásicas. La primera vez que atrajo la atención del público fue en 1709 con sus Pastorals En 1711, publicó su Essay on Criticism, una exposición de los cánones del gusto. Su poema más famoso, The Rape of the Lock (1712) le consolidó como escritor. En 1713 publicó Windsor Forest, obra de poco interés y acogida sin grandes entusiasmos, por lo que decidió dedicarse a la traducción. Tradujo en verso la Iliada (1715-1720) y la Odisea (17251726). Estas traducciones le proporcionaron estabilidad económica. En 1725 también publicó una edición de las obras de Shakespeare

popery Catolicismo y todo lo relacionado con los ritos y creencias, usado como término despectivo por alguien protestante y contrario a la libertad de culto.

pork-pie hat Un sombrero pequeño de ala estrecha. Se llama así porque tiene el mismo formato que una especie de pastel de carne.

porridge Gachas de avena, cocidas en agua y leche. Es un alimento típico de zonas frías. La expresión "Keep your breath to cool your porridge" signifi- 
ca que una persona no debe hablar de más, sino sólo lo justo.

Port Said Es un puerto que se encuentra en la entrada del Canal de Suez. En 1956 Gran Bretaña y Francia mandaron barcos y tropas a la zona cuando Egipto declaró que iba a nacionalizar el canal. La ONU se opuso a esta intervención y ese mismo año las tropas fueron repatriadas. Se interpretó como una derrota para Gran Bretaña, y una señal de la pérdida de su poder e influencia en el mundo.

Portman Square Una plaza elegante al norte de Oxford Street, en el centro de Londres.

Presbyterianism Una forma de organización no jerárquica adoptada por la Iglesia ("Kirk") de Escocia.

\section{Priestley Priestley, John} Boynton (1894 -1984): autor inglés conocido también por sus emisiones radiofónicas durante la Segunda Guerra Mundial. Entre sus obras destacan When We Are Married (1938), An Inspector Calls (1947) y The Good
Companions (1929). Su estilo radical le reportó fama.

Prince Consort El título creado especialmente para el marido de la reina Victoria de Inglaterra. Como ella era la soberana, su marido, el príncipe Alberto Saxe-Coburg (18191861) ostentaba este título para elevarlo de rango.

Prior Prior, Matthew (16641721): secretario del embajador británico en Holanda, ayudó a negociar el Tratado de Utrecht (conocido como "Matt's Peace"). Es conocido por sus poemas, epigramas y piezas familiares.

prof En el argot de Dublín es el capitán del equipo de críquet.

promenade concert En el siglo XIX los conciertos de música tenían lugar en una sala que carecía de asientos. Los asistentes escuchaban la música mientras paseaban ("to promenade" significa pasear) con sus amistades, charlaban, fumaban, etc. De esta expresión se deriva la abreviatura "The Proms", que son los conciertos de música clásica que tienen lugar actualmente en el Royal Albert Hall de Londres cada 
verano desde hace más de un siglo. En estos conciertos aún hay una zona sin asientos donde los más jóvenes entusiastas escuchan, muestran su aprecio y participan activamente en ciertas piezas tradicionales.

\section{public house Establecimiento} donde se sirven y consumen bebidas alcohólicas además de comidas sencillas. Hoy en día el uso ha impuesto el apócope "pub".

\section{public school Expresión que se} utiliza para describir cualquiera de las prestigiosas escuelas de internado privadas en Gran Bretaña. Estas escuelas of recen estudios tradicionales $y$ una preparación para la universidad, e incluyen entre su alumnado a los hijos de la realeza, la aristocracia y los miembros de la clase alta.

pulamiter Una persona que se queja de todo, que lloriquea por nada en el dialecto del centro/norte de Inglaterra.
Pullet Una de las tías de Maggie en The Mill on the Floss tiene este apellido tan descriptivo: significa una gallina joven.

punch Una mezcla de "whisky" (escocés) o "whiskey" (irlandés), agua caliente, azúcar y zumo de limón.

Punch (pleased as) "To be pleased as Punch" significa estar muy satisfecho. Punch es uno de los protagonistas de una representación tradicional de marionetas ("Punch and Judy Show") que se presencia al aire libre, y que cuenta con la participación del público infantil.

purple of commerce La expresión "born to the purple" significa nacer dentro de una familia real o una clase alta y privilegiada. Por lo tanto, "the purple of commerce" (IMP) se refiere a los niveles más elevados de las finanzas y los negocios.

Putney Un barrio al sudoeste de Londres. 



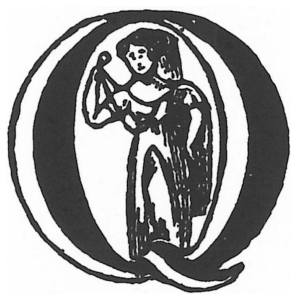

I am your anointed Queen.

I will never be by violence constrained to do anything.

Elizabeth I (1533-1603).

Speech to Members of Parliament,

5 th November 1566. 



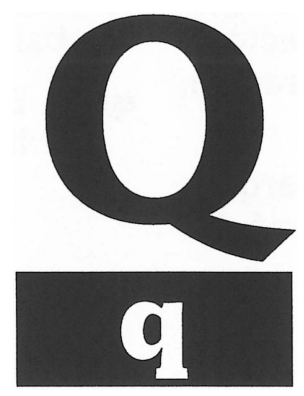

quad Abreviatura de "quadrangle", el patio interior de un colegio mayor, sobre todo con referencia a las Universidades de Oxford o Cambridge.

quadrille Un juego de cartas muy popular durante los siglos XVII y XVIII. Por lo tanto, en la época en la cual se ambientan las obras de Jane Austen se consideraba pasado de moda. La pobre señora Bates en Emma era muy mayor y "almost past everything but tea and quadrille".

quahaug Un tipo de almeja americana.

\section{Queen's Highness ... the} Golden Hind returning with her round flanks full of treasure, to be visited by the Queen's Highness ... (HOD). Dado que el "Golden Hind" (ciervo dorado) era el barco de Drake, la reina a la cual se refiere la cita es Isabel I.

Queen-Anne (house, etc.) There she met a wonderful family of girls, living in a large, old, Queen-Anne house whose lawns sloped to the river. (RAI) Es frecuente la clasificación de los estilos arquitectónicos según el nombre del soberano que reinaba en esa época. Por lo tanto, esta casa se construyó a principios del siglo XVIII, cuando reinaba Ana (1702-1714), hija de Jaime 
II. Igualmente existen los adje- reglas del boxeo en 1867. Por tivos Elizabethan (Isabel I), extensión, se relaciona su Jacobean (Jaime I y II), Georgian nombre con el juego limpio de (Jorge III y IV), Regency, Victorian, acuerdo con las normas, o el y Edwardian (Eduardo VII) apli- comportamiento propio de un cados a estilos arquitectóni- caballero.

cos o a muebles, decoración, quid En argot es sinónimo de etc.

Queensbury El octavo Marqués una libra esterlina. de Queensbury estableció las 


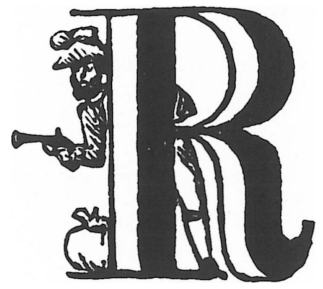

A fair exchange is no robbery.

Traditional proverb first traced to 1546 as Chaunge be no robbry for the changed case. J. Heywood (1497-1580). Dialogue of Proverbs. 



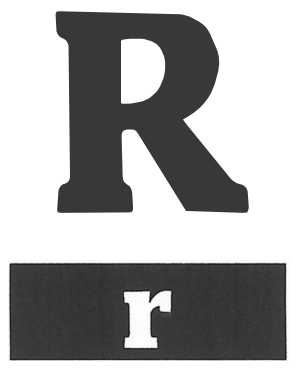

Radical Member of Parliament Miembro de un sector extremista del partido liberal británico durante el siglo XIX.

Radical papers Periódicos de ideología progresista y reformista del siglo XIX.

RAF Siglas que corresponden a "Royal Air Force" (el ejército del aire británico).

Ranelagh En la época de Virginia Woolf era la sede londinense de un famoso club de polo.

Récamier attitude ... on the sofa in a Récamier attitude... $(\mathrm{DOH})$ Alusión a un retrato pintado en 1800 de Madame Récamier (1777-1849), dama francesa célebre por su belleza que durante el período del Directorio y del Primer Imperio era anfitriona de la sociedad más selecta de su tiempo. En el retrato de Jacques-Louis David (17481825) la dama se recuesta coquetamente sobre un diván.

red brick It was a town of red brick, or of brick that would have been red if the smoke and ashes had allowed it; (...) It was a town of machinery and tall chimneys .. (HAT) "Red brick": ladrillo. Este material más nuevo y más barato se usó para la construcción rápida de los tiempos modernos de la Revolución Industrial, en con- 
traste con materiales nobles como la piedra utilizada en "Stone Lodge". En esta época se fundaron las "red brick universities" en las ciudades industriales del norte. Estas instituciones carecen de las tradiciones seculares y de los edificios históricos de lugares tales como Oxford o Cambridge. Se asocian con las carreras técnicas impulsadas por la Revolución Industrial.

\section{Red Lion Véase Black Horse}

redden Encender (una pipa, etc.)

Regency terraces Hilera de edificios de fachada blanca característicos del estilo regencia, construidos durante el período de 1790 a 1830 , y diseñados por los arquitectos ingleses John Nash y Decimus Burton. (Véase también

\section{Queen-Anne.)}

Regent's Park Parque en el norte de Londres desarrollado por John Nash durante la regencia (1810-1820) de Jorge, Príncipe de Gales, futuro Jorge IV. El mecenas de Nash era el propio regente, de ahí el nombre del parque. Está rodeado de mansiones y edificios de época diseñados por el mismo arquitecto.

regimentals Es el uniforme militar, sobre todo el uniforme de gala.

Reynolds... the gilt rim of the Sir Joshua picture... (DAL). Es una alusión a Sir Joshua Reynolds (1723-1792), pintor inglés, primer presidente de la Academia Real de Arte. Se especializó en retratos de personajes famosos en poses románticas, y fue el retratista oficial de la corte. Entre sus obras destacan Lady Cockburn and her Three Eldest Sons (1773), y Lord Heathfield of Gibraltar (1788). Estimuló la valoración de los retratos por encima de los paisajes.

riding-habit Traje de montar para una señora.

right as the mail En el lenguaje coloquial significa que algo $o$ alguien se encuentra en perfecto estado.

Robbe-Grillet Robbe-Grillet, Alain: escritor francés nacido en Brest en 1922. Propugna el "objetivismo literario", ya que en su obra el autor no interviene con comentario alguno 
sobre los personajes o la situación, y es fiel reflejo del "nouveau roman" de la década de 1950. Entre sus novelas cabe destacar Las gomas (1953), El mirón (1955), En el laberinto (1959) y Topología de una ciudad fantasma (1976).

Robertson Robertson, William (1721-1793): historiador cuyos trabajos siguen la línea en cuanto a estilo y profundidad de las obras de Hume.

Robin, Christopher Protagonista de la serie de cuentos infantiles del escritor inglés A.A. Milne (1882-1956) que narran las aventuras del niño Christopher con un oso llamado Winnie-the-Pooh, y otros personajes animales de fantasía. El niño no es nada travieso y resuelve los problemas de sus amigos animales. Es un personaje sencillo y casi demasiado bueno para ser de verdad, aunque el autor se basó en su propio hijo para crearlo. Si a alguien es comparado con Christopher Robin, la implicación puede ser que es demasiado bueno, inocente o inverosímil.

Robin Hood Véase Hood, Robin.
Roger de Coverley ${ }^{1}$ Un baile popular tradicional ("country dance") en Inglaterra.

Roger de Coverley ${ }^{2}$ Este nombre fue el seudónimo utilizado por Richard Steele y Joseph Addison en los primeros ejemplares de la revista The Spectator. De Coverley se presentaba como un caballero inglés adinerado del campo.

Roland Véase Chanson de Roland

Romance of the Forest Es el título de una novela gótica de Ann Radcliffe escrita en 1791.

romanist Un término peyorativo para designar a alguien a favor de promocionar la Iglesia católica en Inglaterra.

Romish Es un adjetivo peyorativo que se refiere a la religión católica y el poder de Roma y el Papa.

Rommel Rommel, Erwin (18911944): general alemán al mando de las fuerzas alemanas en el norte de Africa durante la Segunda Guerra Mundial. Su astucia le mereció el apodo de "el zorro del 
desierto". Fue derrotado por su contrincante, el general inglés Montgomery ("Monty").

Rosetti, Christina Rossetti, Christina Georgina (18301894): poetisa cuyas obras incluyen poemas de fantasía, versos para niños, baladas, poemas de amor, sonetos y poesía religiosa. Gran parte de su obra refleja una sensación de melancolía. Dos de sus poemas mejor conocidos son Uphill y A Birthday (1861). Era hermana de Dante Gabriel y William Michael Rossetti.

\section{Rossetti, Dante Gabriel}

Rossetti, Dante Gabriel (18281882): poeta, pintor y cofundador del Movimiento PreRafaelita (1848). Era hermano de Christina y William Michael Rosetti. Una colección de sus poemas apareció en 1911 , editada por su hermano.

Rotarian/ Rotary "The Rotary Club" (o "The Rotarian Association") es una sociedad internacional fundada en 1905 en Chicago que promueve proyectos que impulsan el civismo y cuyo lema es "servicio". Funciona como una organización de hombres de negocios que tra- bajan juntos por el bien de la comunidad, generalmente recaudando fondos para obras de caridad. El nombre de la asociación se debe a la costumbre de sus miembros, llamados "Rotarians", de reunirse por turnos en la casa de cada uno.

round robin Una carta que recoge las opiniones o quejas de un grupo de personas, firmada por las mismas y presentada a las autoridades correspondientes. Se llama "round" porque sus firmantes escriben sus nombres siguiendo un círculo para que no se sepa quién ha sido el primer firmante y posible instigador.

rout-cakes Pastelitos dulces que se solían tomar en las recepciones y fiestas en el siglo XVIII. "Rout" significaba una gran reunión vespertina.

\section{Royal Horticultural Society} Real Sociedad de Horticultura: una organización británica de amantes de los jardines que organiza cada año la famosa exposición de flores de Chelsea. Esta sociedad tiene connotaciones de clase mediaalta. 
Royal Personage $A$ Royal Personage was about to pass through the borough on his course west, to inaugurate an immense engineering work ... the corporation of Casterbridge ... wished to express its sense of the great services he had rendered to agricultural science and economics... (MOC) Este personaje podría ser Alberto, Príncipe Consorte de la reina Victoria (1819-1861). (Véase

Prince Consort.) Mostró gran interés en promocionar las letras, las ciencias y los avances tecnológicos, culminando en la celebración de la Gran Exposición de 1851 (véase Crystal Palace). Al principio de la novela, Hardy sitúa la acción así: One evening of late summer, before the nineteenth century had reached one-third of its span ... Esto implica que nos situamos alrededor del año 1830, y cuando la ciudad recibe la visita del ilustre personaje han pasado unos veinte años, de forma que nos encontramos alrededor del año 1850 , lo cual coincide con la biografía de Alberto.
RSC Siglas de la "Royal Shakespeare Company", que representa el teatro clásico.

Rubicon Nombre de un río que formaba la frontera entre la provincia ocupada por Julio César en Galia, e Italia. En el año 49 a.C. al cruzar César este río, estalló la guerra civil en la cual él salió vencedor. La expresión "to cross the Rubicon" significa tomar una decisión importante o hacer algo decisivo para el futuro inmediato.

rugger Existen dos tipos de rugby: "Rugby Union" y "Rugby League", cada uno con sus reglas de juego. El primero también se llama "rugger", y se dice que fue inventado en el colegio privado de Rugby en 1823. Siempre se ha asociado con las clases medias y altas, mientras el "Rugby League" se desarrolló entre la clase obrera.

Rules Es el nombre de un famoso y elegante restaurante de Londres.

Rumpelmeyer's Es un salón de té, en Londres, famoso por sus dulces exquisitos. 
rush (rush hour) La hora punta en las ciudades británicas (hacia las 5 o 6 de la tarde) coincidiendo con la salida de los oficinistas y el cierre de los comercios.

rush mats Salvamanteles de mimbre.

Ruskin Ruskin, John (18191900): escritor, crítico de arte y reformista británico, que ejerció una importante influencia en los gustos de los intelectuales victorianos.

Apoyaba la emancipación de los obreros industriales, y denunció sus condiciones de vida, así como la política económica materialista. Ruskin es conocido ante todo por sus estudios de arquitectura y sus implicaciones históricas y sociales, como se refleja en The Seven Lamps of Architecture (1849) y The Stones of Venice (1851-1853). 


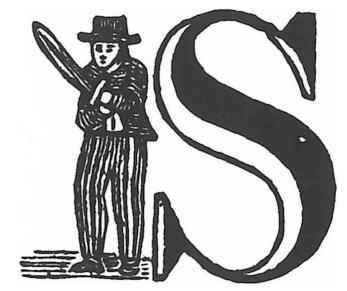

Ah, make the most of what we yet may spend, Before we too into the dust descend.

E. Fitzgerald (1809-83).

The Rubáiyát of Omar Khayyám (1859). 



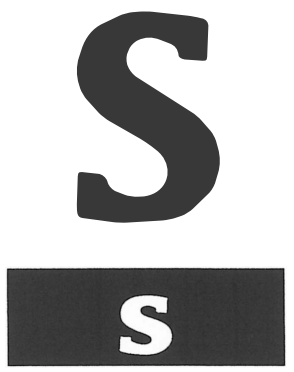

S.W Véase N.W.

Sacco and Vanzetti Nicola Sacco (1891-1927) y Bartolomeo Vanzetti (18871927) fueron unos anarquistas estadounidenses de origen italiano que en los años 1920 fueron juzgados y sentenciados a muerte por robo y dos asesinatos en un polémico juicio. Muchos consideraron que hubo irregularidades en el juicio y que en realidad fueron condenados por sus ideas políticas y no por las pruebas reunidas contra ellos. Su caso atrajo la atención internacional.

Sackville Street Una calle perpendicular a Piccadilly, en Londres.
Sade Sade, Marquis de (17401814): escritor francés cuya visión peculiar de la sexualidad dio lugar al término "sadismo" (consiguir placer a través del sufrimiento de los demás).

salaam Hacer zalemas para dar la bienvenida a alguien.

Saladin Saladino I, sultán ayubí de Egipto y Siria (1138-1193). Tenía fama de ser muy astuto.

salt "To be worth one's salt" significa ser buen trabajador, y merecer lo que se gana.

Salvation Army Un movimiento religioso fundado en 1865 , organizado de forma semimilitar, que realiza labores evangelizadoras, y que ayuda 
a los pobres y marginados. Sus miembros llevan uniforme y organizan actos religiosos públicos. Tiene un código de conducta muy estricto.

\section{saveloy Véase polony.}

Scarborough Pequeña ciudad costera en el este de Yorkshire, que era un lugar de veraneo muy popular entre las clases medias y altas durante el siglo XIX.

scarlet woman Es una mujer promiscua o adúltera.

\section{Schliemann}

Schliemann, Heinrich (1822-1890): arqueólogo alemán, descubridor de los restos de la antigua Troya.

Scotland Yard Era el nombre de la calle donde se ubicaba la sede de la Policía Metropolitana de Londres. Ahora sus oficinas se encuentran en un edificio nuevo llamado "New Scotland Yard".

Scott Scott, Sir Walter (17711832): escritor escocés de poesía, y autor de novelas histórico-románticas. Publicó The Lay of the Last Minstrel en 1805, The Lady of the Lake en 1810 , y sus novelas más populares incluyen: Waverley (1814), Rob Roy (1817), The Heart of Midlothian (1818) e Ivanhoe (1819).
Season Desde primavera hasta finales del verano, hasta bien entrado el siglo $\mathrm{XX}$, la alta sociedad de las grandes ciudades se dedicaba a asistir a las reuniones sociales, bailes, cenas, etc. y esta época se llamaba "the Season". Fuera de esta temporadà, descansaban para recuperar fuerzas para la siguiente temporada social.

secularism El secularismo fue un movimiento promovido por George Jacob Holyoake alrededor de 1850. Se basaba en una moralidad inspirada en hacer el bien sin relacionarse con una religión determinada.

send (to Australia) El "exilio" en las colonias, como Australia, se utilizaba como una manera de reformar a los jóvenes difíciles o rebeldes de buenas familias, ayudándoles a desarrollar un carácter más adecuado. Además, solían hacer fortuna al mismo tiempo.

send down' ${ }^{1}$ La expresión "to be sent down (from university)" significa ser suspendido o expulsado de la universidad por mal comportamiento.

send down ${ }^{2}$ En las reuniones formales los invitados se reunían en la sala de estar en la 
primera planta, y bajaban al comedor para cenar en la planta baja. Cada caballero debía acompañar a una dama hasta el comedor y sentarse a su izquierda en la cena. Si había más damas que caballeros un miembro de la familia o un viejo amigo acompañaría a dos damas. Si había demasiados hombres, los miembros de la familia no acompañarían a ninguna señora. Por esta razón, en The Importance of Being Earnest Algernon se queja así: ... Whenever I do dine there I am always treated as a member of the family, and sent down with either no woman at all, or two. (IMP: Act I)

Serpentine Un lago artificial en Hyde Park, el parque más grande del centro de Londres.

settle Un banco de madera con un respaldo alto y apoyabrazos.

settle... hash En lenguaje coloquial "to settle somebody's hash" significa hacer callar, acabar con alguien, o hacer que esté sumiso.

Seven Dials Un distrito del centro de Londres, donde hasta el siglo XVIII había un cruce de siete calles. Este distrito tenía fama de ser pobre y base de operaciones de pequeños ladrones.

shantung Un tipo de seda china, con la superficie ligeramente rugosa.

Shelley Shelley, P.B. (17921822): poeta romántico inglés, ateo y anarquista. Es autor de Ode to the West Wind (1819), To a Skylark (1819) y Prometheus Unbound (1820). También tradujo al inglés obras de griego, latín, español, alemán, italiano $y$ algunos fragmentos de árabe.

Sheperd's Bush Un distrito popular del oeste de Londres.

Sheridan Sheridan, Richard Brinsley (1751-1816): escritor y político nacido en Dublín, autor de The Rivals (1773), y The School for Scandal (1777).

shilling Un chelín, ahora equivalente a cinco peniques. Es una moneda que no se usa desde 1971 cuando se introdujo el sistema decimal. Una libra actual equivale a cien peniques.

shilly-shallying Titubeos, vacilaciones. 
shindy Un disturbio, alboroto o tumulto, que se asocia con las clases bajas y estados de embriaguez.

Shoreditch Una zona dentro del centro histórico de Londres.

shower En el lenguaje coloquial, es un grupo de personas incompetentes o inútiles.

shufti En el lenguaje coloquial de los militares "to take a shufti" significa echar un vistazo. Se empezó a utilizar esta expresión en los años 1940, en plena Segunda Guerra Mundial, y proviene de la palabra árabe šafa que significa intentar ver.

Sidcup Pueblo en el límite sudeste de la zona metropolitana de Londres.

sideboard drawers Los cajones de un aparador.

side-saddle Silla de montar a la amazona.

sidewalk Es la palabra norteamericana que significa acera y que se expresa como "pavement" en el inglés británico.

\section{Sin Véase City of Sin}

Sing a song of sixpence Es una rima y canción infantil: Sing a song of sixpence,
A pocketful of rye, Four and twenty blackbirds Baked in a pie, When the pie was opened, The birds began to sing, Wasn't that a dainty dish To set before a king!

The king was in his counting house, Counting out his money, The queen was in the parlour, Eating bread and honey, The maid was in the garden, Hanging out the clothes, When down came a blackbird And pecked off her nose.

\section{sixty-four dollar (question)} "But why should he have married you, feeling as he did about everything?" "That is the famous American question you know, the sixty-four dollar one!" (LBA) En los años 1950 había un concurso de televisión en Estados Unidos titulado The $\$ 64000$ Question en el cual había que responder una serie de preguntas de dificultad progresiva. La cuantía del premio aumentaba en progresión geométrica desde $\$ 1(\$ 2$, $\$ 4, \$ 8, \$ 16)$ y luego redondeando las cantidades hasta llegar a los $\$ 64.000$, lo cual significaba un grado de dificultad considerable. El formato de concurso se calcó en Gran Bretaña en los años 1950 y 
1960, sustituyendo libras por dólares, pero la frase "the sixty-four dollar question" se incorporó al lenguaje coloquial para significar una pregunta muy difícil, casi imposible de contestar, ya que casi ningún concursante conseguía llegar al final de la serie de preguntas. Nótese que aunque el título del concurso se refería a los $\$ 64000$, la frase idiomática quedó simplificada en sólo \$64.

\section{Skilly Véase Char Bydis.}

skimmington Una procesión que tenía por objeto ridiculizar a una esposa gruñona y mandona, o un cónyuge infiel. Un grupo de vecinos paseaba por las calles de la localidad con unas efigies de los protagonistas, golpeando cacerolas y cantando versos alusivos.

\section{skimmity-ride Véase skim- mington.}

Skulker El nombre de este perro en Wuthering Heights parece relacionarse con el verbo "to skulk", que significa esconderse, escurrir el bulto.

slave-trade $O h !$ My dear, human flesh! You quite shock me; if you mean a fling at the slave-trade, I assure you $\mathrm{Mr}$.
Suckling was always rather a friend to the abolition. (EMA) A principios del siglo XIX el comercio de esclavos todavía era muy común, especialmente en Gran Bretaña. En 1807, sin embargo, poco antes de que Jane Austen escribiera Emma, el parlamento británico aprobó una ley que hacía ilegal tanto el transporte de esclavos en los barcos británicos, como la importación de esclavos por parte de las colonias británicas.

Slim Jim Una golosina de melcocha y coco, en tiras largas y delgadas.

slip ... Tom Brangwen, who was best man, coming up the garden path most elegant in cutaway coat and white slip and spats. (RAI) Es un jersey sin mangas.

Smith Smith, Adam (17231790): economista y filósofo británico, cuyo tratado An Inquiry into the Nature and Causes of the Wealth of Nations, más conocida por su nombre abreviado de The Wealth of Nations (1776), constituyó el primer intento de analizar los determinantes del capital y el desarrollo históri- 
co de la industria y el comercio entre los países europeos, lo que permitió crear la base de la moderna ciencia de la economía.

Smith Smith, William (17691839): geólogo e ingeniero británico que hizo progresar la estratigrafía al descubrir los estratos de Inglaterra y Gales y representarlos en el primer mapa geológico preciso.

smock Una prenda, parecida a una camisa larga, usada en el pasado por las personas que se dedicaban a las tareas agrícolas. Se asocia principalmente con la zona sudoeste de Inglaterra, y con cuadros idílicos de pastores y sus rebaños.

smoking jacket Una chaqueta de seda o pana que se utilizaba en momentos informales, o mientras se fumaba para que el humo no impregnara la otra ropa. Era una prenda con asociaciones de lujo, utilizada por las clases altas.

smoking-room Una sala en las casas de los ricos a la cual los caballeros se retiraban para fumar después de cenar, ostensiblemente para no molestar a las damas con el humo, pero también para que los hombres pudiesen hablar de temas no aptos para los oídos de las damas.

snood Una cinta para atar el moño.

Soanesque Adjetivo derivado del apellido de Sir John Soanes (1753-1837), el arquitecto que diseñó el edificio del Banco de Inglaterra en 1788. El museo Sir John Soanes se encuentra en Lincoln Inn's Fields, Londres, y contiene su colección de cuadros y antigüedades.

Soapy Sponge Las crónicas de Soapy Sponge, de Robert William Surtees se publicaban por entregas y ofrecían una perspectiva satírica de la sociedad de provincias en la primera mitad del siglo XIX. (Véase también Jorrock's Jaunts and Jollities.)

Somme Alusión a una serie de batallas que tuvieron lugar durante la Primera Guerra Mundial desde el 1 de julio de 1916 en Somme, en el norte de Francia, donde la infantería británica fue derrotada por las tropas alemanas. Lo que se conoce como la ofensiva del 
Somme duró 4 meses y las bajas británicas superaron las 400.000 personas, las francesas 195.000 y las alemanas 650.000 .

song "To take / sell something for a song" significa comprar /vender algo muy barato.

Southey Southey, Robert (17741843): poeta británico perteneciente al grupo de los poetas asociados con la región de los lagos en el noroeste de Inglaterra. También escribió obras de historia como The Life of Nelson (1813) y The History of the Peninsular War (1823-1832).

\section{south-western leg ...the} underside of England's outstretched south-western leg. La "pierna" en cuestión es la península formada por tres condados: Cornualles, Devon y Dorset.

sovereign Una moneda de oro que valía una libra esterlina, y que ya no se usa. En la época de su uso representaba una cantidad considerable para una persona humilde.

spats Son polainas, hechas de tela o cuero, que cubrían el tobillo y la pierna hasta la rodilla.
Spectator The Spectator era una publicación periódica (1711-14) sucesor de The Tatler (1709-11), que publicaba opiniones en forma de ensayos a través de los miembros de un club ficticio llamado "Spectator Club". (Véase Roger de Coverley ${ }^{2}$.)

spencer Una chaqueta entallada de señora que sólo llegaba hasta la cintura.

spir She rather dreaded than sought for the first view of that well-known spire which would announce her within twenty miles of home. (NOR) Se trata de la aguja de la torre de la catedral de Salisbury, la más alta de Gran Bretaña. Como la catedral está situada en una zona llana, es visible desde bastante distancia.

sporran Es una especie de monedero hecho de cuero que un escocés lleva colgando de la cintura delante de la falda escocesa o "kilt". En The Importance of Being Earnest, Oscar Wilde inventa una casa solariega en Escocia con este poco verosímil nombre.

sportsman En los siglos XVIII y XIX este término se utilizaba para referirse a los practicantes de los deportes de los caballeros de clase media y 
alta: la caza del zorro a caballo, la caza con escopeta y la pesca.

spud Es una pala delgada que se utiliza para cortar las raíces de las malas hierbas.

St. George Es el patrono de Inglaterra (pero no del Reino Unido). La leyenda cuenta que mató a un terrible dragón para salvar a una dama, pero su vida es poco conocida, y es difícil distinguir la realidad de la leyenda.

St. James Sede de la corte real desde 1697 a 1837 . Está situado al oeste del centro de Londres donde la corte se estableció para aprovecharse del terreno más seco y saludable, además de evitar los vientos prevalecientes que soplaban de oeste a este, dejando en el este, por lo tanto, todos los malos olores y humos de las chimeneas. Las personas que querían buscar favores reales, o que querían presentar a sus familiares en sociedad eran asiduos en el Palacio de St. James. Hoy en día el soberano ya no preside su corte allí, pero los nuevos embajadores de otros países presentan sus credenciales en esta sede, y oficialmente su nombramiento es como embajador en la Corte de St. James.
St. James Park Un famoso parque londinense situado entre Piccadilly y el palacio real de Buckingham. Al norte de este parque se concentran los "clubs" exclusivos masculinos, cuyos socios son aristócratas y personajes destacados de la política y de los negocios.

St. John's Wood Una zona de Londres situada en el lado oeste de Regent's Park.

St. Pancras Una estación en Londres, desde la cual salen trenes para el centro del país (Midlands).

stalls La sección de asientos en la planta baja de un teatro.

starving/starved El significado moderno es "muriendo de hambre", literal o figuradamente, pero en el siglo XIX, y todavía en el dialecto del norte de Inglaterra, se usa para decir que se tiene mucho frío.

Stern Gang Un grupo sionista fundado en 1940 por Abraham Stern (1907-1942) que operaba en Palestina. Llevaron a cabo varios ataques contra personal militar británico en Palestina, además de instalaciones estratégicas como campos de aviación y estaciones de tren. 
Sterne Sterne, Laurence (17131768): escritor inglés, autor de Tristram Shandy.

stewpond Un estanque artificial donde se crían peces para el consumo. Era habitual en las casas grandes de la clase acomodada en los siglos XVIII y XIX.

Stilton cheese Un queso con vetas azules originario del pueblo homónimo en el condado de Cambridge. Los gastrónomos aprecian su sabor fuerte característico.

stone Then he got fever, and had to be carried in a hammock swung under a pole. As he weighed sixteen stone I had no end of rows with the carriers. (HOD) Es una medida de peso imperial usado en Gran Bretaña, pero no en Estados Unidos, donde expresan el peso corporal en libras ("pounds"). Equivale a 6'3 kilos, de modo que una persona de dieciséis "stone" pesa unos 100 kilos. Así se comprenden las quejas de los porteadores en la cita. La forma es invariable en singular y plural.

Stonehenge Monumento ritual prehistórico situado en la llanura de Salisbury, al sudoeste de Inglaterra, fechado entre los últimos períodos del neolí- tico (finales de la edad de piedra) y los primeros de la edad de bronce. Aunque se desconoce con exactitud su funcionalidad, es muy probable que hubiera sido un lugar de reunión o un centro religioso relacionado con la observación astronómica.

stove-pipe hat Una chistera.

Strand Una calle ancha que sale en dirección este de la plaza de Trafalgar, en Londres.

stuff Material, u objetos varios, sin especificar.

Sturm and Drang Movimiento literario alemán de finales del siglo XVIII que se caracterizaba por obras de acción trepidante y sentimentalismo que retratan al individuo que se rebela contra la sociedad. El movimiento adopta como nombre el título de una obra de teatro, Sturm und Drang de Friedrich von Klinger (1776).

Stygian domain Es el entorno de la laguna Estigia, que era la entrada del infierno en la mitología griega. El viejo barquero Caronte transportaba las almas de los muertos por el agua hasta las puertas del mundo subterráneo.

succession-house Es un invernadero para el cultivo de las plantas delicadas. 
Suffragette Las sufragistas eran partidarias del movimiento feminista que pedía el derecho al voto para las mujeres a principios del siglo XX. Las británicas no consiguieron el voto hasta 1918.

suit En el contexto legal es un pleito.

summut En el dialecto del norte de Inglaterra significa algo ("something").

Sunday papers Los periódicos de formato grande ("broadsheets") son serios, con artículos apropiados para aquellos con inquietudes intelectuales, mientras los de formato pequeño ("tabloids") son populares, con una proporción mayor de material gráfico y noticias más cortas y más fáciles de leer.

Sussex Condado en la costa sur de Inglaterra, lindando con el Canal de la Mancha.

sweal away Hacer desaparecer, hacer que se consuma algún mal físico. Es una forma dialectal del centro/norte de Inglaterra.

swingboats Una atracción en las ferias, como un columpio para dos o más personas, en forma de barquito. 


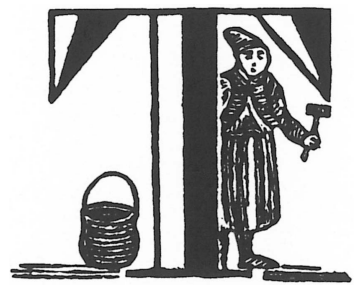

Tinker, tailor, soldier, sailor, Rich man, poor man, Beggar man, thief.

Traditional children's fortune-telling rhyme. 



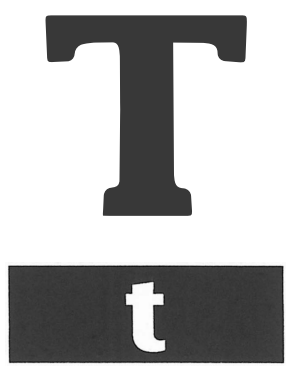

tart A parte de ser un dulce, en el lenguaje coloquial es una prostituta.

Tatler Revista publicada en Londres entre 1709 y 1711 por Sir Richard Steele cuyo contenido consistía en ensayos, poesía, relatos cortos y noticias. Hoy en día existe una revista mensual con el mismo nombre que informa acerca de la vida de personajes ricos y famosos y acontecimientos sociales.

Tauchnitz novels Christian Berhard Tauchnitz (18161895) fundó una editorial en Leipzig con la que comenzó la publicación de más de cinco mil volúmenes de la serie The
Tauchnitz Collection of British and American Authors. Era una reimpresión económica de obras relevantes de autores británicos y americanos muy popular entre los viajeros por el formato pequeño y además por el precio asequible.

Taylor Taylor, Jeremy (16131667): capellán de Carlos I de Inglaterra. Fue hecho prisionero en la derrota de los monárquicos durante la Guerra Civil, se retiró a Gales a escribir, y después de la Restauración fue nombrado obispo de Down y Connor. Su fama se debe la sencillez y al mismo tiempo al esplendor de su estilo. Sus obras más destacadas son The 
Rule and Exercise of Holy Living (1650), The Rule and Exercise of Holy Dying (1651), The Liberty of Prophesying (1647), Eniautos (una serie de sermones para el año litúrgico) 1653, y The Golden Grove (1655), un manual de rezos diarios.

tea Aparte del nombre de la infusión tan popular tradicionalmente entre los británicos, esta palabra también engloba la merienda ligera o incluso más consistente que se toma junto con el té: emparedados, galletas, bizcocho, bollitos rellenos, etc.

tea-cake Es un bollito dulce con uvas pasas, tostado, y untado con mantequilla. Acompaña el té.

teetotal La abstinencia de tomar alcohol. Su origen está en un discurso pronunciado en 1833 por Richard Turner, un obrero del norte de Inglaterra, que utilizó el término como una forma enfática de propagar el rechazo total del alcohol y sus efectos nocivos entre los obreros.

temperance beverage Una bebida no alcohólica. Una aso- ciación llamada "Temperance Movement" hizo campaña durante el siglo XIX para que la gente dejara de beber alcohol, ya que sus miembros creían que el alcoholismo tenía efectos negativos no sólo en el individuo, sino también para la sociedad en general.

Temple Una zona de Londres, junto a la "City", donde tradicionalmente los abogados tenían sus bufetes llamados "chambers in the Temple".

Terror El nombre del barco que acompañó al Erebus. (Véase Franklin.)

Tess Es la protagonista de la novela Tess of the d'Urbervilles de Thomas Hardy, escrita en 1891. La novela se desarrolla en el antiguo reino de Wessex, hoy el sudoeste de Inglaterra, y describe la vida difícil y triste de una mujer joven.

Thatcher Thatcher, Margaret (1925): la primera mujer británica que ocupó el cargo de Primer Ministro, desde 1979 hasta 1991. De ideología conservadora, fue creadora de una escuela de pensamiento político y económico ("Thatcherism"). Su mandato 
se caracterizó por la privatización de la economía, y por una serie de leyes para controlar los sindicatos. Su apodo era "La dama de Hierro" ("the Iron Lady").

thimble-rig Un truco de feria que se realiza con tres vasos y un objeto pequeño que se traslada tan rápidamente de debajo de un vaso a otro, que el espectador se engaña al intentar adivinar, apostando, dónde se encuentra. Los que se dedican a este truco se llaman "thimble-riggers."

Thirty-Nine Articles Es una lista de los artículos de la fe establecida tras la creación de la Iglesia de Inglaterra (Anglicana) en 1571. Su doctrina expone las creencias de la Iglesia Anglicana, y los sacerdotes y novicios tienen que jurar fidelidad a sus principios.

Thomson Thomson, James (1700-48): poeta escocés, autor de The Seasons, (1746) que contiene un fragmento parafraseado en Northanger Abbey, de Jane Austen. El fragmento de Thomson es: Delightful task! To rear the tender thought,

To teach the young idea how to shoot.

(Spring, line 1 152).

Jane Austen lo recuerda como: It is a delightful task to teach the young idea how to shoot.

Three is company... You don't seem to realize, that in married life three is company and two is none. (IMP) El dicho debía ser: "Two is company, three is none", o "Two is company, three is a crowd". Equivale a la expresión: $\mathrm{Ni}$ amor ni señoría quieren compañía.

Throttler El verbo "to throttle" significa estrangular o ahogar. El perro que lleva este nombre en Wuthering Heights parece bastante peligroso.

Thrushcross Grange El nombre de esta casona y finca en Wuthering Heights tiene las características fonéticas de muchos topónimos del norte de Inglaterra: una abundancia de sonidos fricativos, como en lugares tales como Braithwaite, Thornthwaite Forest, Watendlath, Skidby, Withernsea, Skipton, o Crosthwaite 
tight-Jeff "To be on the tightjeff" significa estar en la cuerda floja, estar en una situación difícil.

Times The Times es un periódico británico prestigioso e influyente, que se publicó por primera vez en 1785 , con el nombre de The Daily Universal Register. Aunque es independiente, se considera que representa las opiniones y actitudes de la clase media y la derecha. La sección de las cartas al director sobre temas o acontecimientos de actualidad es un foro importante para la expresión de la opinión pública en Gran Bretaña. No debe confundirse su nombre con la revista semanal norteamericana Time.

Tin-Pan-Alley Expresión que se utilizaba para referirse al distrito donde se concentraban los compositores y editores de música popular en Nueva York. También se utiliza para referirse al conjunto de éstos, aunque la expresión ha caído en desuso. En Moontiger Penelope Lively hace un juego semántico: The only clear spaces are the tracks along which wind the occasional line of trucks or armoured cars, the "Tin-Pan Alleys" defined by petrol cans. Se refiere a una especie de callejón ("alley") hecho de latas de gasolina y peroles de hojalata.

tippet Una pequeña capa o estola hecha de lana, o de piel, para poner alrededor de los hombros. Formaba parte del atuendo femenino en los siglos XVIII y XIX.

TLS Siglas que corresponden al Times Literary Supplement, el suplemento semanal publicado por el periódico británico The Times, y fundado en 1902. La calidad de sus reportajes sobre temas literarios se reconoce internacionalmente.

tokay Vino dulce de la zona de Tokaj, en Hungría. Tradicionalmente procedía de los viñedos del propio emperador austríaco.

toffee Un dulce hecho de mantequilla y azúcar que se calientan, y una vez disueltos se dejan enfriar en una bandeja poco honda. Una vez que se haya solidificado, se corta en cuadraditos.

top Es un trompo. 
toper Una persona aficionada a las bebidas alcohólicas.

Tory (plural Tories) Nombre diminutivo de los miembros del partido conservador británico.

toss-pot Bebedor empedernido.

town Hasta el siglo XIX, Londres era "la ciudad". Si alguien decía "I'm going up to town", no podía tratarse de otro lugar que Londres. Las familias acomodadas tenían una residencia en el campo, y otra en la capital. Si alguien estaba "in town", se sabía que residía temporalmente en casa londinense.

transported En el siglo XIX los ladrones y malhechores eran "transportados" a la fuerza a la colonia penal establecida en Sydney, Australia, para descongestionar las prisiones británicas. También los hijos difíciles o rebeldes de las clases altas eran enviados a Australia para que la experiencia les ayudara a desarrollar un carácter más adecuado, pero en este último caso se decía que sus familias los "enviaban" a Australia ("send").
Treasury Bench Es el banco delantero en la Cámara de los Comunes (la cámara baja del parlamento), donde se sientan los ministros, el primer ministro y otros cargos importantes.

Trevor-Roper Trevor-Roper, Hugh (1914): historiador británico, especialista en temas relacionados con la Segunda Guerra Mundial, y la época isabelina.

tricot Una prenda de lana o similar; un jersey o suéter. Procede del verbo francés "tricoter" (calcetar).

tricoteuse Palabra francesa que significa, literalmente, una mujer que calceta. Se usaba para referirse a las mujeres que calcetaban mientras asistían a las ejecuciones durante la Revolución Francesa. Por extensión se aplica a las mujeres que disfrutan contemplando la violencia o escenas desagradables.

trivet as right as a trivet (IMP). El soporte para la tetera se llama "trivet", y tiene que ser estable para que no caiga la tetera. La frase significa que 
todo en general está bien, o que una persona se encuentra bien de salud.

trot round En lenguaje coloquial significa ir a dar una vuelta, pasar por un sitio, hacer una visita.

tube En los taxis antiguos y en los coches de lujo con chófer había un tubo que hacía las veces de amplificador, para comunicarse con el pasajero en el asiento de atrás dado que les separaba un cristal.

tucker Era un trozo de encaje o tela para llenar el escote de un vestido. También forma parte de la expresión "one's best bib and tucker", que significa vestirse con la mejor ropa que se tiene, de punta en blanco.

Tullabeg En este pueblo irlandés se encuentra el noviciado de los jesuitas.

Tunbridge Wells Una ciudad en Kent (sudeste de Inglaterra) con fama de ser elegante, frecuentada por la gente rica $y$ conservadora. También se conoce por su balneario.

tuppence Es la representación gráfica de la forma hablada de "two-pence". Es una cantidad muy pequeña, y, por lo tanto, si alguien no vale ni dos peniques, es una persona de muy poco valor.

tureen Una sopera o fuente para servir legumbres, verduras, etc.

turf-coloured "Turf" es la turba, que se encuentra en abundancia en Irlanda. Se corta en bloques, se seca y se usa como si fuera carbón para calentarse y cocinar. Es de color marrón oscuro.

turnpike Una carretera con barrera de portazgo, o peaje.

Twinkle, twinkle little star Es una rima y canción infantil: Twinkle, twinkle little star, How I wonder what you are. Up above the world so high, Like a diamond in the sky, Twinkle, twinkle little star, How I wonder what you are.

twitchel Es un pasillo o camino estrecho entre muros o setos. Es una forma arcaica.

Twittermiss Esta palabra es una mezcla de "twitter" (piar, gorjear) y "miss" (señorita). El conjunto significa una niña o joven demasiado habladora, y 
que habla, además, de cosas insignificantes.

Tyndall Tyndall, John (18201893): físico británico, conocido por su estudio sobre los coloides, que pronunció un famoso discurso en 1874 sobre la relación entre la ciencia y la teología, y que dio lugar a una gran controversia. 



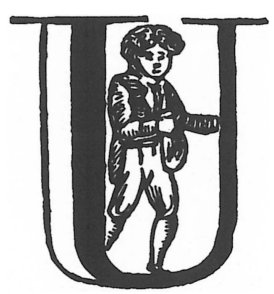

Neither a borrower, nor a lender be. W. Shakespeare (1564-1616). Hamlet (1601). 



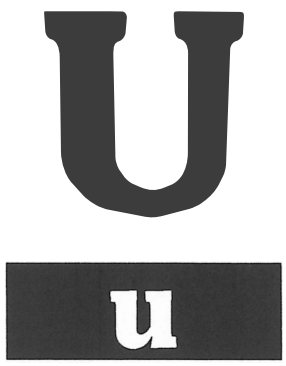

Udolpho The Mysteries of Udolpho (1794) es una novela gótica de Ann Radcliffe (17641823).

ulster Con mayúscula, este término es sinónimo de Irlanda del Norte, parte del Reino Unido. Con minúscula, se refiere a un abrigo largo y holgado de caballero, hecho de una tela gruesa, con un cinturón en la espalda, confeccionado y vendido originalmente en el Ulster durante el siglo XIX. No era una prenda de calidad, ni tenía gran estilo. Por este motivo, Dorian Gray reprende a su amigo Hallward así: "What a way for a fashionable painter to travel! A

Gladstone bag, and an ulster!" (PDG)

Union Jack Así se llama la bandera británica, ya que simboliza la unión política de los países cuyas banderas individuales la componen. Es la suma de las banderas de San Jorge (Inglaterra), San Andrés (Escocia) y San Patricio (Irlanda del Norte). El único componente del Reino Unido que no tiene representación en la bandera es el Principado de Gales, que tiene, sin embargo, sus propios símbolos (San David y una bandera verde $y$ blanca con un dragón en el centro). La razón es que Gales fue incorporado a la corona 
británica varios siglos antes que las demás naciones por medio de una ley ("Act of Union", 1536). Escocia se unió a Inglaterra en 1707 por medio de otra ley similar, y se diseñó una bandera consistente en la cruz blanca y el fondo azul de San Andrés, con la cruz roja de San Jorge encima. Irlanda se unió en 1801 , y la actual bandera británica que incorpora la cruz roja de San Patricio data de esta fecha.

\section{Unitarian Church Doctrina} religiosa que afirma la personalidad única de Dios, en contraste con la doctrina trinitaria que se basa en la Santísima Trinidad.

up (to town) La preposición "up" se usa para ir a la capital y "down" se emplea para ir al campo desde Londres, o a la segunda residencia campestre de la gente adinerada. Sin embargo, esto sólo es válido en el contexto de la clase media/alta en el sur de Inglaterra, ya que los habitan- tes del norte tienen otra visión de la geografía. Para éstos, "up" se emplea para dirigirse al norte, "down" es para ir hacia el sur. Así que los habitantes del norte/centro dirían "move up north", "go down south", "travel down to London", etc.

\section{Upper Grosvenor Street Es} una calle en el barrio residencial de Mayfair en el oeste de la zona central de Londres, muy cerca de Hyde Park. Es la sección oeste de la calle Grosvenor, que atraviesa la plaza del mismo nombre.

Upper Rooms Salas de reunión social en el primer piso de un edificio público. La gente más selecta frecuentaba estas salas superiores en lugares elegantes como Bath que gozaban de mucha popularidad en los siglos XVIII y XIX, no sólo como balnearios, sino como lugares de diversión y donde los matrimonios podían concertarse. 


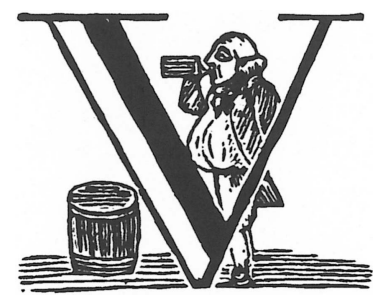

\section{$\mathbf{O}$, for a draught of vintage!}

J. Keats (1795-1821). Ode to a Nightingale (1820). 



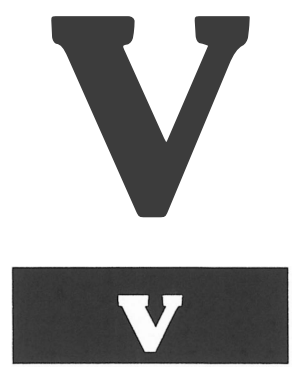

Valley of the Dolls Why Mrs Poultney should have been an inhabitant of the Victorian valley of the dolls we need not inquire (...) (FLW) Se refiere al argumento de la novela Valley of the Dolls, de Jacqueline Susann, acerca de la corrupción, los escándalos, el mundo de los artistas de cine y la drogadicción de los famosos entre 1960 y 1970 . El tema del efecto de las drogas es lo que une esta novela, que vendió 19 millones de ejemplares pero que tiene escaso valor literario, con los sedantes que tomaba la Sra. Poultney en The French Lieutenant's Woman.

Vanzetti Véase Sacco.
Vaughan Williams Vaughan Williams, Ralph (1872-1958): compositor inglés conocido por sus arreglos musicales que incluyen piezas tradicionales inglesas. Se sintió atraído e influenciado por la música de la época de los Tudor, y su trabajo sugiere la vida rural y el paisaje inglés. Sus piezas cortas más famosas incluyen Fantasia on a Theme by Thomas Tallis (1910) y The Lark Ascending (1914). También compuso operas y música para el cine.

Vessel And that most interesting arrival of all, a creaking top-heavy vessel named from an English hedgerow, cram- 
med with pots and pans, fishhooks, muskets, butter, meal and pig-headed, idealistic, ambitious, foolhardy people nosing its way into the embracing arm of Cape Cod. (MOO) Alusión al primer grupo de colonos británicos que llegó a las costas de Massachusetts en 1620 en el barco "Mayflower", cuyo nombre es el de un seto de espino ("hedgerow") con flores blancas, muy típico del paisaje inglés. (Véanse también Mayflower y Plymouth.)

Vicar of Wakefield Véase Wakefield.
Victoria Station La estación de Victoria es una terminal ferroviaria muy importante. De allí salen trenes de la capital para la zona sur y sudeste del país.

Vingt-un Un juego de cartas, también conocido como "Pontoon" o "Blackjack", en el cual el valor total de las dos cartas repartidas a cada jugador no debe sobrepasar los veintiún puntos. Procede del francés "vingt-et-un".

Vinolia Era una marca de limpiacristales. 


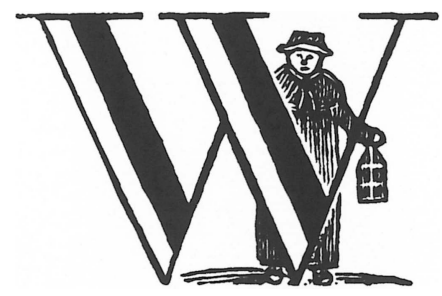

Watchman, what of the night?

Watchman, what of the night?

The watchman said, The morning cometh, and also the night.

Isiah, ch. 21 , v.11. 


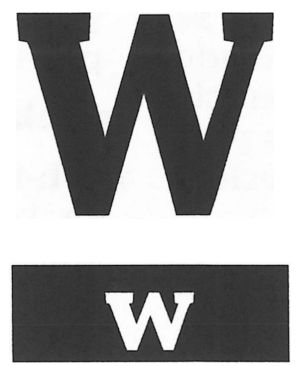

W1, SW1, SW3, W8 We'd set out from headquarters in Poplar, and carry out our raids on the enemy in W1, SW1, SW3, and W8. (LBA) Son distritos postales de Londres, correspondientes a las residencias de las clases más acomodadas, contra las cuales los protagonistas de la obra de John Osborne llevan a cabo una especie de guerra. "Poplar" era un distrito londinense que en 1965 se incorporó al nuevo distrito llamado Tower Hamlets.

Wakefield The Vicar of Wakefield (1766): una novela sentimental de Oliver Goldsmith. Es una de las obras de ficción más populares de la lengua inglesa.
Wampanaug Palabra en narragansett, lenguaje del pueblo indio de Norteamérica del mismo nombre, cuyo equivalente en inglés es "wampum", que significa cuentas de conchas ensartadas en collares o hilos que los indios norteamericanos utilizaban como adorno o moneda de cambio.

War Este sustantivo, escrito con mayúscula, se utilizaba para referirse a la Primera Guerra Mundial (1914-1918) durante el tiempo transcurrido desde su conclusión hasta el inicio de la Segunda Guerra Mundial (1939-1945). A veces se llamaba la Gran Guerra para distinguirla de otras guerras de la historia. La gente en el período de entreguerras tenía la 
esperanza de que la humanidad viviría en paz y evitaría un conflicto similar, y por lo tanto no podían imaginarse otra guerra en el futuro inmediato. Por este motivo, se usaba el artículo determinado para nombrar algo que parecía único, y la "W" mayúscula para darle la importancia merecida.

war in Spain Se refiere a la Guerra Civil española, en la cual muchos voluntarios británicos y de otras nacionalidades se ofrecieron para luchar en el bando Republicano.

warming-pan Es un objeto metálico plano y redondo, con un mango que se llenaba de brasas y que se usaba antiguamente para calentar la cama. La expresión "as flat as a warming-pan" significa que uno es novato o inexperimentado.

Warwickshire Es un mineral con la fórmula $\left.(\mathrm{MgFe})_{3} \mathrm{Ti}_{(\mathrm{BO}}\right)_{3}$ que se encuentra en el condado de Warwickshire, en el centro de Inglaterra.

wash one's clean linen... The amount of women in London who flirt with their own husbands in perfectly scandal ous. It looks so bad. It is simply washing one's clean linen in public. (IMP) La expresión suele ser "wash one's dirty linen in public", es decir, exponer públicamente los secretos y escándalos, o airear los trapos sucios.

washboard Es el zócalo.

wash-tub Una especie de tina en la cual se lavaba la ropa antes de la invención de las lavadoras.

water The furniture was all sent round by water. (SAS) Desde Sussex en el sudeste de Inglaterra hasta Exeter en el condado de Devon la ruta más fácil para transportar las mercancías, debido al estado de las carreteras a principios del siglo XIX, era por mar, navegando hacia el oeste por el Canal de la Mancha. Como Devon está situado en la península de Devon y Cornualles, con una costa sur y una costa norte, era factible mandar las mercancías o los muebles de la mudanza, según la cita, navegando hacia el oeste por el Canal de la Mancha y girando hacia el norte por el Canal de San Jorge, para descargar en la costa norte del condado. 
Watford Una población pequeña al norte de Londres.

wax "To get into a wax" significa ponerse de mal humor, o enfadarse. Es una forma arcaica.

Wedgwood La porcelana fina de la fábrica del inglés Josiah Wedgwood era muy popular en el siglo XVIII. Sobre un fondo azul pálido se reproducían en relieve blanco temas y decoración de la Grecia clásica. Como consecuencia de su popularidad, la frase "Wedgwood blue" ha quedado como una forma de describir este tono exacto de azul.

weeded /weeds Son el adjetivo y sustantivo, respectivamente, correspondientes a la ropa negra de luto, sobre todo de una viuda.

weeper Un velo negro que las mujeres llevaban en el sombrero, o una cinta negra para el sombrero de los hombres como señal de luto. Cuanto más aparatoso el velo, más pena se atribuía a la mujer portadora.

Wellington Arthur Wellesley, $1^{\text {st }}$ Duke of Wellington (17691852): general y político de gran prestigio, famoso sobre todo por su papel en la guerra en la Península Ibérica (18081814), y en la derrota de Napoleón en Waterloo (1815).

Wembley Una zona del noroeste de Londres, famosa por su estadio.

West Dorset Gazette Dorset está en la costa sur de Inglaterra. Los periódicos provinciales como el West Dorset Gazette dan información local acerca de la cartelera y la agenda cultural además de dar noticias acerca de bodas o fallecimientos en la zona, pero, en cambio, ofrecen muy poca información acerca de acontecimientos nacionales o internacionales. Si se menciona este tipo de periódico, la implicación es que sus lectores tienen pocas inquietudes de tipo intelectual.

West End Es una zona céntrica de Londres donde se encuentran los teatros, cines y grandes almacenes, así como "pubs" y restaurantes. De noche, cuando cierran los teatros y comercios, todavía hay mucha gente en la calle, inclu- 
yendo a quienes ejercen la prostitución.

West Ham Un barrio popular al este de la "City" (zona financiera) de Londres.

Westminster Una zona en el centro de Londres donde se encuentran los edificios del parlamento. Se usa como sinónimo de parlamento y gobierno.

Westminster School Un colegio londinense fundado por Enrique VIII, de gran prestigio, que atraía a los hijos de los poderosos.

Weymouth Una ciudad en la costa sudoeste de Inglaterra, muy popular entre las clases media y alta a finales del siglo XVIII y principios del XIX. Se hacía vida social mientras se veraneaba en este tipo de ciudades costeras o balnearios como Bath.

whipperty-snapping Es una expresión en el lenguaje coloquial del centro/norte de Inglaterra que significa ser impertinente o presuntuoso, haciendo mucho ruido por poca cosa.

Whitechapel Un barrio de clase baja en el este de Londres, asociado con alcohólicos, prostitutas y ladrones. También se asocia con los asesinatos de "Jack the Ripper".

Whitehall La calle de Londres donde se hallan las oficinas de los distintos departamentos del gobierno británico. "Whitehall" es sinónimo del poder del gobierno central.

Whitsuntide Es la semana que empieza por el Domingo de Pentecostés, que es el séptimo domingo después del Domingo de Resurrección.

\section{Whittington}

Whittington,

Richard (Dick) (1358-1423): según la leyenda, era un joven londinense triste y pobre que trabajaba en la cocina de un mercader rico. Cuando se hartó, se marchó de la capital, desilusionado con sus perspectivas de futuro. De repente creyó oír que las campanadas de la iglesia de Bow le decían "Turn again Whittington, thrice Lord Mayor of London" (Da la vuelta Whittington, tres veces Alcalde de Londres). Hizo caso, y al poco tiempo se enriqueció, y llegó a convertirse en alcalde. En realidad, era hijo de un mercader acomodado, y se hizo rico trabajando 
para el gremio de los merceros. Llegó a ser alcalde de Londres no tres, sino cuatro veces, llevó a cabo obras benéficas, y mandó construir asilos para los pobres, un colegio y una biblioteca. La leyenda dio lugar al personaje del espectáculo teatral infantil llamado Pantomime.

whittle En el dialecto del centro/norte de Inglaterra significa preocuparse, o lamentarse por algo difícil de arreglar.

Whole Duty of Man Una obra piadosa publicada en 1658 por Richard Allestree, capellán del rey Carlos II. Analiza y comenta los deberes del hombre con respecto a Dios y a los demás hombres.

\section{Wilberforce}

Wilberforce,

William (1759-1833): filántropo evangélico inglés y figura destacada en la campaña a favor del abolicionismo, que se originó en Inglaterra a partir de 1780, cuando Wilberforce y la secta Clapham, un grupo de adinerados evangelistas anglicanos, iniciaron una campaña contra el comercio de esclavos africanos. Los cuáqueros ingleses
("Quakers") solicitaron al Parlamento la abolición de la esclavitud en 1783 .

Willis's Alrededor de 1890 era un conocido restaurante londinense en la zona elegante de St. James.

Wilton carpet Una alfombra gruesa de lana, de gran calidad, fabricada en Wilton, Wiltshire, en el sur de Inglaterra.

window-bay Una ventana construida hacia fuera, con tres lados. En las casas antiguas solía aprovecharse para albergar un banco en el hueco. También se llama "baywindow".

Windsor (House of) En 1917 el rey Jorge $\mathrm{V}$ de Inglaterra sustituyó el apellido de la familia real británica, que era SaxeCoburg-Gotha, por el nombre de la casa de Windsor debido al fuerte sentimiento anti-alemán durante la Primera Guerra Mundial (1914-18).

Windsor chair Una silla de madera con el respaldo en forma de semicírculo.

Windsor Terrace Una calle en una zona residencial en el nor- 
deste de Londres. La palabra "terrace" indica una hilera de casas adosadas.

Women's Guild Precursor del "Women's Institute" (W.I.) que fue fundado en 1915. Es una organización cuyo objetivo es mejorar y fomentar las perspectivas de las mujeres de zonas rurales. Organiza actividades formativas, culturales y sociales.

\section{Women's Social and Political} Union Una asociación fundada por Emmeline Pankhurst en 1903 para presionar a las autoridades y ganar el derecho al voto para las mujeres.

\section{Woolwich Arsenal El}

"Woolwich Royal Arsenal" de Londres fue un polvorín desde la época de los Tudor hastal966.

Woolworth's Es una cadena de tiendas que venden una gran variedad de productos de poca calidad a bajo precio. work Cuando las señoras acomodadas de los siglos XVIII y XIX hablaban de su "trabajo", se referían a la costura y el bordado ("needlework") como entretenimientos, y no como fuente de ingresos.

worrit/worrited Una forma arcaica y coloquial del verbo "to worry/worried".

Wuthering Heights El título de esta novela y nombre de la casa invita a apreciar ciertas connotaciones. "Wuthering", del verbo "to wuther", es una palabra que sólo existe en el dialecto de Yorkshire, y describe el ruido que hace una mezcla de viento, lluvia y tormentas mientras choca contra las partes salientes de la casa, o entre las rocas del paisaje. El segundo término, "Heights", significa cimas, cumbres o cerros. El conjunto es un lugar inhóspito, al menos en los oscuros días de invierno. 


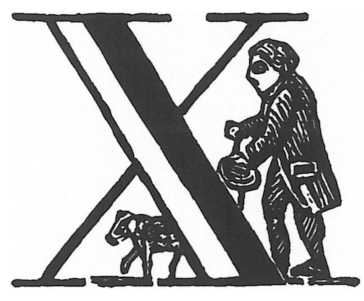

Anyone who has ever struggled with poverty knows how extremely expensive it is to be poor.

J. Baldwin (1924-1987).

Nobody Knows My Name (1961).

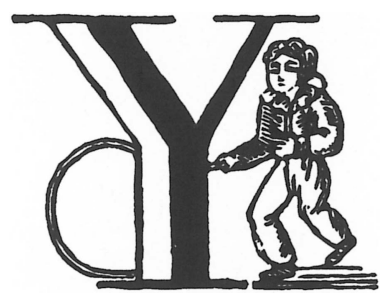

If youth knew; if age could. H. Estienne (1531-1598). Les Prémices (1594).

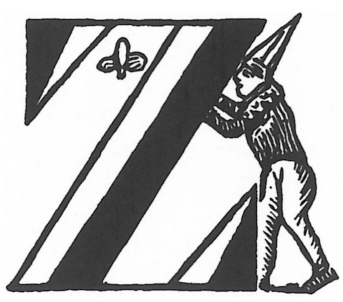

A fool and his money are soon parted.

W. Shenstone (1714-1763).

Works (1764). 



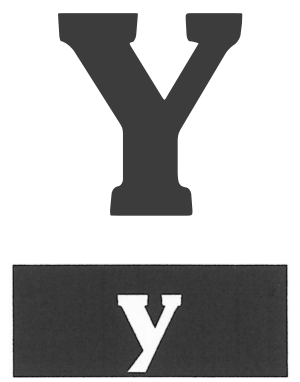

Yellow (en los mapas del York tan El color marrón del siglo XIX) Véase colours of cuero teñido, que se utilizaba the rainbow

Yellow candidate Véase Blue (editor). para confeccionar guantes $y$ calzado en los siglos XVIII y XIX. 



\section{BIBLIOGRAFÍA}

Automobile Association. 1982. Road Atlas of Great Britain. London: St.Michael/AA.

Babcock Gove, P. (ed.) 1961. Webster's Third New International Dictionary of the English Language Unabridged. Cologne: Könemann / Merriam Webster.

Benito, F. \& P. Benito. 2000. London Map. London: Bensons. Cannon, J. (ed) 1997. Oxford Companion to British History. Oxford: O.U.P.

Cohen, J.M. \& M.J. Cohen. 1995. Penguin Dictionary of Twentieth-Century Quotations. London: Penguin.

Cohen, J.M. \& M.J. Cohen. 1996. New Penguin Dictionary of Quotations. London: Penguin.

Concise Oxford Dictionary (Tenth Edition). CD-Rom. 2000. Oxford: Oxford University Press.

Crowther, J. (ed.)1999. Oxford Guide to British and American Culture. Oxford: O.U.P.

Dale, R. \& S. Puttick. 1999. Wordsworth Dictionary of Abbreviations \& Acronyms. Hertfordshire: Wordsworth Editions.

Davis, D. 1997. A Guide to Parliament. London: Penguin / BBC Worldwide Ltd.

Drabble, M. 1993. Concise Oxford Companion to English Literature. Oxford: O.U.P.

Egerton, J. 1998. The British School. London: National Gallery Publications.

Enciclopedia Microsoft Encarta 99. 1993-1998. Microsoft Corporation. 
Gloag, J. 19962000 Years of England. London: Bracken Books.

Gomez, M. 2000. Essential Constable. Bath: Parragon.

Green, J. 1999. Penguin Slang Thesaurus. London: Penguin.

Grimal, P. 1991. Dictionary of Classical Mythology. London: Penguin

Holder, R. 1995. A Dictionary of Euphemisms. Oxford: O.U.P.

Hurtley, J.A. et al. 1996. Diccionario cultural e histórico de Irlanda. Barcelona: Ariel.

Hogan, R. (ed.) 1996. Dictionary of Irish Literature. London: Aldwych.

Kearney, H. 1989. The British Isles: A History of Four Nations. Cambridge: C.U.P.

Marr, A. 2000. The Day Britain Died. London: Profile Books.

Marwick, A. 1996. The Penguin Social History of Britain. British Society since 1945. London: Penguin.

McDowall, D. 1989. An Illustrated History of Britain. Harlow, Essex: Longman.

Mitchinson, J. 2000. British Greats. London: Cassell.

Partington, A. 1996. Oxford Dictionary of Quotations. Oxford: O.U.P.

Partridge, E. 1993. A Dictionary of Catch Phrases from the Sixteenth Century to the Present Day. London: Routledge.

Paxman, J. 1999. The English: A Portrait of a People. London: Penguin.

Payton, G. 1992. Penguin Dictionary of Proper Names. London: Penguin

Rees, N. 1992. Dictionary of Popular Phrases. London: Bloomsbury Publishing

Room, A. 1985. Concise Dictionary of Modern Place-Names in Great Britain and Ireland. Oxford: O.U.P.

Room, A. 1990. An A to Z of British Life. Oxford: O.U.P. 
Simpson, J. 1993. Concise Oxford Dictionary of Proverbs. Oxford: O.U.P.

Storry, M. \& P. Childs. 1997. British Cultural Identities. London: Routledge.

Summers, D. 1992. Longman Dictionary of English Language and Culture. Harlow, Essex: Longman.

Dictionary of National Biography, Compact Edition. Vols. I and II. 1975. Oxford: Oxford University Press.

Yapp, N. 2000. The British Millennium: 1,000 years of Incident and Achievement. Cologne: Könemann. 



\section{ÍNDICE DE CLAVES}

Las entradas de este Diccionario proceden de las siguientes obras. Muchas entradas incorporan la cita original para que se entienda el contexto, y entre paréntesis aparece la clave correspondiente al título de cada obra:

$\begin{array}{lll}\text { BRR } & \text { Brideshead Revisited } & \text { Evelyn Waugh } \\ \text { CAR } & \text { The Caretaker } & \text { Harold Pinter } \\ \text { DAL } & \text { Mrs Dalloway } & \text { Virginia Woolf } \\ \text { DOH } & \text { Death of the Heart } & \text { Elizabeth Bowen } \\ \text { EMA } & \text { Emma } & \text { Jane Austen } \\ \text { FLW } & \text { The French Lieutenant's Woman } & \text { John Fowles } \\ \text { HAT } & \text { Hard Times } & \text { Charles Dickens } \\ \text { HOD } & \text { Heart of Darkness } & \text { Joseph Conrad } \\ \text { IMP } & \text { The Importance of Being Earnest } & \text { Oscar Wilde } \\ \text { JOB } & \text { Jude the Obscure } & \text { Thomas Hardy } \\ \text { LBA } & \text { Look Back in Anger } & \text { John Osborne } \\ \text { LCC } & \text { Love in a Cold Climate } & \text { Nancy Mitford } \\ \text { MAJ } & \text { Major Barbara } & \text { George Bernard Shaw } \\ \text { MID } & \text { Middlemarch } & \text { George Eliot } \\ \text { MOC } & \text { The Mayor of Casterbridge } & \text { Thomas Hardy } \\ \text { MOF } & \text { The Mill on the Floss } & \text { George Eliot } \\ \text { MOO } & \text { Moon Tiger } & \text { Penelope Lively } \\ \text { MSQ } & \text { Monsignor Quixote } & \text { Graham Greene } \\ \text { NOR } & \text { Northanger Abbey } & \text { Jane Austen } \\ \text { PAP } & \text { Pride and Prejudice } & \text { Jane Austen } \\ \text { PDG } & \text { The Picture of Dorian Gray } & \text { Oscar Wilde } \\ \text { POR } & \text { A Portrait of the Artist as a Young Man } & \text { James Joyce } \\ \text { PYG } & \text { Pygmalion } & \text { George Bernard Shaw } \\ \text { RAI } & \text { The Rainbow } & \text { D.H. Lawrence } \\ \text { ROS } & \text { Rosencrantz and Guildenstern are Dead } & \text { Tom Stoppard } \\ \text { SAL } & \text { Sons and Lovers } & \text { D.H. Lawrence } \\ \text { SAS } & \text { Sense and Sensibility } & \text { Jane Austen } \\ \text { WUH } & \text { Wuthering Heights } & \text { Emily Brontë } \\ & & \\ & & \end{array}$




\section{ÍNDICE TEMÁTICO}

\section{Abreviaturas y acrónimos}
ATS
G.H.Q.
N.W.
B.A.
$\mathrm{G}$ and $\mathrm{S}$
NAAFI
C.O.
Hon.
RAF
C.O.'s HQ
J.P.
RSC
CND
K.C.
S.W.
D.D.
M.F.H.
TLS
ENSA
M.P.
F.O.
N.B.
W1, SW1, SW3, W8

\section{Comidas, bebidas, costumbres y enseres asociados}

$\begin{array}{lll}\text { Apple dumplings } & \text { Dine } & \text { Muffineer } \\ \text { Apple jelly } & \text { Dripping } & \text { Periwinkle } \\ \text { Arrow-root } & \text { Dripping pan } & \text { Pimm's N 1 } \\ \text { Beet-root } & \text { Drisheens } & \text { Plum pudding } \\ \text { Bisurated Magnesia } & \text { Eno's } & \text { Poached eggs } \\ \text { Blue Vinny } & \text { Fish-and-chip shop } & \text { Polony } \\ \text { Book (butler's) } & \text { Fortnum's } & \text { Porridge } \\ \text { Brioche } & \text { Galantine } & \text { Punch } \\ \text { Broth } & \text { Gingerbread } & \text { Quahaung } \\ \text { Butterscotch } & \text { Gogonzola } & \text { Rout-cakes } \\ \text { Castro } & \text { Gravy browning } & \text { Rules } \\ \text { Cellery (celery) } & \text { Gruel } & \text { Rumplemeyer's } \\ \text { Champers } & \text { Gyppy tummy } & \text { Rush mats } \\ \text { Chany } & \text { Haddock } & \text { Saveloy } \\ \text { Chicken in aspic } & \text { Horlicks } & \text { Slim Jim } \\ \text { Continental (breakfast) } & \text { Huntley and Palmers } & \text { Stilton cheese } \\ \text { Cosy } & \text { Kettle } & \text { Tea } \\ \text { Cream cracker } & \text { Lemon plait } & \text { Tea-cake } \\ \text { Crown Derby } & \text { Mashed-potato man } & \text { Toakay } \\ \text { Crumpet } & \text { Mess tin } & \text { Toffee } \\ \text { Cucumber sanwich } & \text { Mild-and-soda } & \text { Tureen } \\ \text { Cuppa } & \text { Milk bar } & \\ \text { Damson cheese } & \text { Muffin } & \end{array}$




\section{Enseñanza}

$\begin{array}{lll}\text { All Souls } & \text { Half } & \text { Public school } \\ \text { Bachelor of Arts } & \text { Harrow } & \text { Quad } \\ \text { Cambridge Tripos } & \text { King's scholar } & \text { Red brick } \\ \text { Don } & \text { Matriculation-examination } & \text { Westminster School } \\ \text { Enter (to be entered) } & \text { Merchant-Taylors' } & \\ \text { Eton } & \text { Oxbridge } & \\ \text { Grammar school } & \text { Oxonian } & \end{array}$

\section{Acontecimientos históricos, batallas, y el ámbito militar}

Agincourt
Alamo
Armada
Army Lists
Austerlitz
Bayeux Tapestry
Black Hole of Calcutta
Black Watch
Colonial
Colours $\left(\mathrm{C} 19^{\text {th }}\right.$ maps)
Dark Ages
Depression

Edgehill
Fleet
Furlough
Gold Rush
Golden Hind
H-Bomb
Honeys
Hussars
Indian Mutiny
Iron Maiden
Life Guards
Matildas

Mayflower
Northmen
Passchendaele
Port Said
Regimentals
Rubicon
Slave-trade
Somme
Terror
Vessel
War
War in Spain

5. Ocio: juegos, espectáculos, deportes, aficiones, lugares de reunión

$\begin{array}{lll}\text { Arrange (music) } & \text { Blind-hookey } & \text { Coconut man } \\ \text { Assembly Rooms } & \text { Box } & \text { Commerce (cards) } \\ \text { Astley's } & \text { Box Brownie } & \text { Covert } \\ \text { Athenaeum } & \text { Boy Scouts } & \text { Cricket } \\ \text { Aunt Sally } & \text { Bridge } & \text { Curzon } \\ \text { Battledores and } & \text { British Opera } & \text { Dress circle } \\ \text { shuttlecocks } & \text { Broadwood's (piano) } & \text { Empire } \\ \text { Beckenham Reserves } & \text { Café Royal } & \text { Field sports } \\ \text { Black Horse } & \text { Cat's cradle } & \text { Fifteen } \\ \text { Black twist } & \text { Club } & \text { Flanagan and Allen }\end{array}$




$\begin{array}{lll}\text { Gallery } & \text { Nag's Head } & \text { Sportsman } \\ \text { Girl Guides } & \text { Netting } & \text { Stalls } \\ \text { Glee } & \text { Pantomime } & \text { Swingboats } \\ \text { Glee-men } & \text { Peep-show } & \text { Thimble-rig } \\ \text { Greensleeves } & \text { Penny-gaff } & \text { Top } \\ \text { Hoop } & \text { Pit } & \text { Upper Rooms } \\ \text { Hurlingham } & \text { Promenade concert } & \text { Vingt-un } \\ \text { Johnston, Mooney, \& } & \text { Public house } & \text { Willis's } \\ \quad \text { O'Brian's } & \text { Quadrille } & \text { Women's Guild } \\ \text { Loo } & \text { Red lion } & \text { Work } \\ \text { Lords } & \text { Rotarian/Rotary Club } \\ \text { Master of ceremonies } & \text { Royal Horticultural } \\ \text { Mechanics'Hall } & \text { Society } \\ \text { Morris-dancing } & \text { Rugger } & \\ & & \end{array}$

\section{Edificios, calles, barrios, ciudades y condados.}

$\begin{array}{lll}\text { Albany } & \text { Co-op } & \text { Guildford by-pass } \\ \text { Aldgate } & \text { Clifton } & \text { Half-Moon Street } \\ \text { Almack's } & \text { Conduit Street } & \text { Hampstead } \\ \text { Angel } & \text { Crystal Palace } & \text { Hanover Square } \\ \text { Ascot } & \text { Dartmoor } & \text { Harley Street } \\ \text { Barnet } & \text { Deal } & \text { Hatfield } \\ \text { Bath } & \text { Derbyshire } & \text { Haymarket } \\ \text { Bayswater } & \text { Devonshire } & \text { Hendon } \\ \text { Bedford Square } & \text { Dresden } & \text { Hertfordshire } \\ \text { Bedlam } & \text { Drury Lane } & \text { Holborn } \\ \text { Belgrave Square } & \text { Epping } & \text { Kenilworth } \\ \text { Berkley Square } & \text { Epsom } & \text { Kensington } \\ \text { Blenheim } & \text { Erewash Valley } & \text { Kensington Gardens } \\ \text { Bloomsbury } & \text { Exeter } & \text { Kent } \\ \text { Bond Street } & \text { Exmoor } & \text { Leamington } \\ \text { Bournemouth } & \text { Finsbury Park } & \text { Lindisfarne } \\ \text { Box Hill } & \text { Finsbury Pavement } & \text { Margate } \\ \text { Buckingham } & \text { Fulham } & \text { Marleybone High } \\ \text { Burford Church } & \text { Gervase Park } & \text { Street } \\ \text { Camden Town } & \text { Gower Street } & \text { Mayfair (May Fair) } \\ \text { Cheapside } & \text { Gracechurch Street } & \text { Menton } \\ \text { City of Sin } & \text { Gravesend } & \text { Mile End Waste } \\ \text { Clane } & \text { Grosvenor Square } & \text { Moorgate Street } \\ \text { Clapham } & \text { Grosvenor Street } & \text { North Wiltshire }\end{array}$




$\begin{array}{lll}\text { Notting Hill Gate } & \text { Shoreditch } & \text { Street } \\ \text { Oxford Street } & \text { Sidcup } & \text { Victoria Station } \\ \text { Pall Mall } & \text { Sin } & \text { Watford } \\ \text { Piccadilly } & \text { Spire } & \text { Wembley } \\ \text { Pimlico } & \text { St. James Park } & \text { West End } \\ \text { Plymouth } & \text { St. John's Wood } & \text { West Ham } \\ \text { Portman Square } & \text { St. Pancras } & \text { Westminster } \\ \text { Putney } & \text { Stonehenge } & \text { Weymouth } \\ \text { Ranelagh } & \text { Strand } & \text { Whitechapel } \\ \text { Regent's Park } & \text { Sussex } & \text { Windsor Terrace } \\ \text { Sackville Street } & \text { Town } & \text { Woolwich Arsenal } \\ \text { Scarborough } & \text { Tullabeg } & \text { Woolworth's } \\ \text { Scotland Yard } & \text { Tunbridge Wells } & \\ \text { Seven Dials } & \text { Up (to town) } & \\ \text { Shepherd's Bush } & \text { Upper Grosvenor } & \\ & & \end{array}$

\section{Nombres propios en la ficción: connotaciones y ono- matopeya}

$\begin{array}{lll}\text { Bounderby } & \text { Guest } & \text { Pivart } \\ \text { Coketown } & \text { Hareton } & \text { Pullet, Mrs } \\ \text { Dean } & \text { Heathcliff } & \text { Skulker } \\ \text { Deane } & \text { Jakin } & \text { Throttler } \\ \text { Earnshaw } & \text { Kenn } & \text { Thrushcross Grange } \\ \text { Glegg, Mr and Mrs } & \text { Lockwood } & \text { Wuthering Heights } \\ \text { Gradgrind } & \text { M'Choakumchild } & \end{array}$

\section{Personajes en la ficción y la leyenda}

$\begin{array}{lll}\text { Baronne d'Almane } & \text { Christopher Robin } & \text { Marchbanks, Eugene } \\ \text { Bennet girls } & \text { Fauntleroy, Little Lord } & \text { Musgrove, Luisa } \\ \text { Blimp } & \text { Gilpin, John } & \text { Palmerin of England } \\ \text { Blue Beard } & \text { Grundy, Mrs } & \text { Pierre } \\ \text { Bracknell, Lady } & \text { Gudrun } & \text { Robin Hood } \\ \text { Britannia } & \text { Heep } & \text { Soapy Sponge } \\ \text { Button, William } & \text { Hood, Robin } & \text { St. George } \\ \text { Chinless wonder } & \text { Jack the Giant-killer } & \text { Tess }\end{array}$




\section{Personajes históricos}

Agricola, Gnaeus I. Alfred the Great Amadis of Gaul Arden, Elizabeth Asquith, Herbert $\mathrm{H}$. Asquith, Margot Beau Brummel Bismark, Otto von Bowdler, Thomas Brummel, George B. Caesar, Julius

Churchill, Winston

Cook, James

Davy, Humphry

Disraeli, Benjamin

Drake, Francis

Dulles, John F.

Franklin, John

Galbraith, John K.

German Jew
Gladstone, William E. Gosse, Philip H.

Gwyn, Nell

Hammarskjöld, Dag

Harvey, William

Hutchinson, John

Jones, Inigo

Josephus, Flavius

King and Queen

Langtry, Lillie

Lyell, Charles

Macmillan, Harold

Maréchal Niel

Marquess of

Queensbury

McCarthy, Joseph

Melbourne, William

Mill, John

Miller, Hugh

Monmouth, James
Nightingale, Florence

Paine, Thomas

Peel, Robert

Pitt, William

Pocahontas

Prince Consort

Queen's Highness

Rommel, Erwin

Royal Personage

Sacco, Nicola

Sade, Marquis de

Saladin I

Schliemann, Heinrich

Stern Gang

Thatcher, Margaret

Vanzetti, Bartolomeo

Wellington, Arthur

Whittington, Dick

Wilberforce, William

\section{Artes plásticas y compositores}

Brown, Ford Madox

Constable, John

Cramer, Johann B.

Greuze, Jean B.

Grünewald, Matthias
Millais, John

Moore, Henry

Morland, George

Morris, William

Palmer, Samuel
Récamier (attitude)

Reynolds, Joshua

Vaughan Williams, Ralph

\section{Vestimenta, moda y complementos}

Beaver fur
Blazer
Blue (washing)
Bonnet
Broadcloth
Brook's
Camargo petticoat

Chausable

Chevaux-de-frise

Coif

Coty

Crape

Craped

Crinoline
Dishabille

Disrobe

Dress

Dundrearies

Flannels

Gibson Girl

Gladstone bag 
Grenadine

Guimp

Henrietta-Maria style

Jumps

Mechlin

Men's Beavers

Merino

Mod

Mules

Night-rail
Pantalettes

Pantoufles

Pattened

Plus-fours

Pork-pie hat

Riding-habit

Shantung

Slip

Smock

Smoking jacket
Snood

Spats

Spencer

Sporran

Stove-pipe hat

Tippet

Tricot

Tucker

Ulster

York tan

\section{Prensa}

Bath paper

Boy's Own Paper

Country Life

Daily Telegraph

Evening Standard
Morning Post

New Statesman

News

News of the World

Radical papers
Spectator

Sunday papers

Tattler

Times

West Dorset Gazette

\section{Mitología y fuentes bíblicas}

Bacchante

Bellerophon

Coptic Goddess
Erebus

Hamadryad

Laocoön embrace
Patmos

Pisgah Mount

Stygian domain

\section{Grupos políticos, administración del estado, monarquía y derecho}

$\begin{array}{lll}\text { Admiralty } & \text { County Council } & \text { Home civil } \\ \text { Bar } & \text { Court of Common Law } & \text { Home Secretary } \\ \text { Bench } & \text { Dieu et mon droit } & \text { House of Lords } \\ \text { Blue (editor) } & \text { Doctors' Commons } & \text { Indian } \\ \text { Blue books } & \text { Entailed } & \text { Insolvent Debtor's } \\ \text { Chancellor of the } & \text { Exchequer } & \text { court } \\ \quad \text { Exchequer } & \text { Excise-rod } & \text { Jack (Union) } \\ \text { Chartists } & \text { General Election } & \text { Liberal Unionist } \\ \text { Communist Manifesto } & \text { God Save the Queen } & \text { Lincoln's Inn } \\ \text { Coroner's Inquest } & \text { Great Reform Bill } & \text { Lord Chancellor }\end{array}$


Moiety

Parish

Radical Member of

Parliament

St. James

Suffragette
Suit

Temple

Tory (Tories)

Transported

Treasury Bench

Union Jack
Windsor (House of)

Whitehall

Women's Social and

Political Union

Yellow candidate

\section{Refranes, proverbios y rimas}

Ave...Morituri te salutant

By hook or by crook

Call a spade

Chip of better quality

Crumpled horn

Divorces/marriages

Familiarity breeds contempt

Finger in the pie

Handsome is...
Hind-leg (talk)

Hit below the (belt)

Irons in the fire

Mother Hubbard

Old King Cole

Old Woman

Once seen ...

Peter Piper

Pocketful of posies

Punch (pleased as)
Salt (worth)

Sing a song of sixpence

Song (buy/sell)

Three is company

Twinkle, twinkle little star

Wash one's clean linen in public

\section{Conceptos relacionados con la religión}

$\begin{array}{lll}\text { Almighty } & \text { Dissenter } & \text { Popery } \\ \text { Anabaptist } & \text { Evensong } & \text { Presbyterianism } \\ \text { Anglican } & \text { Friends (Society of) } & \text { Romanist } \\ \text { Beads } & \text { Grace } & \text { Romish } \\ \text { Bishop } & \text { Holy Office } & \text { Salvation Army } \\ \text { Calvinism } & \text { Low Church } & \text { Secularism } \\ \text { Chapel-goers } & \text { Methodism } & \text { Thirty-Nine Articles } \\ \text { Congregationalist } & \text { Pew-opener } & \text { Unitarian Church }\end{array}$

\section{Profesiones e indicadores de rango social}

$\begin{array}{lll}\text { Apothecary } & \text { Draughtsman } & \text { Nabob } \\ \text { Cheap Jack } & \text { Funds } & \text { Nick-nack vendor } \\ \text { Chemist } & \text { Huckster } & \text { Oak leaves } \\ \text { Collier } & \text { Income } & \\ \text { Colliery-manager } & \text { Lamplighter } & \end{array}$




\section{Unidades de medida}

Bob

Brown

Dollar (half crown)

Farthing

Florin
Guinea

Half a crown

Inch

Penny

Quid
Shilling

Sovereign

Stone

\section{Arquitectura, vivienda, muebles y decoración}

Antimacassar
Apartment
Bath chair
Blackout curtains
Boss
Bow window
Brown Holland
Buckram
Canterbury (case)
Chesterfield (sofa)
Chintz
Chippendale
Cloak-room
Clothes horse
Convenience
Dormer window
Drugget

Electrolux
Fauteuil
Hob
House
Huswife
Jardinière
Linoleum squares
Mahogany
Maisonette
Manse
Mews
Morning-room
Mullioned window
Netting-box
Oriel
Paisley
Parlour

Penthouse

Queen-Anne (house)

Regency terraces

Settle

Sideboard drawers

Smoking-room

Soanesque

Stewpond

Succession-house

Vinolia

Washboard

Wash-tub

Wedgwood

Wilton carpet

Window-bay

Windsor chair

\section{Literatura: títulos, alusiones y géneros}

Agnostic writings
Anglo Saxon Chronicle
Becky Sharp
Belinda
Brief Lives
Camilla
Cecilia
Chanson de Roland,
Char Bydis
(Charybdis)
Children of the Abbey
Comus
Dombey and Son

Elegant Extracts

Fear no more

Grandison, Sir Charles

Green (Donkey's)

Idylls of the King

Italian

Jock and Day

Jorrock's Jaunts and Jollities

Lavater's Physiognomy

Monk

Motto (family)

Mystery play
Pascal's Pensées

Peter Parley's Tales

Pickwick Papers

Romance of the Forest

Skilly (Scylla)

Sturm and Drang

Tauchnitz novels

Tom Jones

Udolpho

Valley of the Dolls

Vicar of Wakefield

Whole Duty of Man 


\section{Autores}

Andersen, Hans C. Aubrey, John

Baedeker, Karl

Bard (Shakespeare)

Barthes, Roland

Bentham, Jeremy

Berkeley, George

Berkleyan

Bossuet, Jacques

Boswell, James

Bourget, Paul-Charles

Bradlaugh, Charles

Burke, Edmund

Childe, Vere Gordon

Coverley, Roger de

Cowper, William

Eliot, T.S.

Elton, Charles

Glyn, Elinor

Godwin, William

Goldsmith, Oliver
Goodrich, Samuel G.

Gray, Thomas

Grimm, J.L. and W.K.

Hooker, Richard

Hume, David

Humphreys, Noel

Huxley, Thomas

Kingsley, Charles

Locke, John

Macaulay, Thomas

Malthus, Thomas

Martin, William

Mayhew, Henry

McLuhan, Marshall

Milton, John

Mitford, Nancy

Norton, Caroline

Parley, Peter

Pascal, Balise

Pope, Alexander

Priestley, John
Prior, Matthew Robbe-Grillet, Alain

Robertson, William

Roger de Coverley

Rosetti, Christina

Rosetti, Dante G.

Ruskin, John

Scott, Walter

Shelley, P.B.

Sheridan, Richard

Smith, Adam

Smith, William

Southey, Robert

Sterne, Laurence

Taylor, Jeremy

Thomson, James

Trevor-Roper, Hugh

Tyndall, John

\section{Léxico: lenguaje coloquial, usos idiomáticos y for- mas dialectales}

Bad odour

Badly

Bairn

Bake

Bally

Banditti

Barkled

Barm-man

Beastly

Bide

Bijou

Billy-o

Blinking

Bluddy

Blue moon

Bobby-dazzler
Brat

Brew

Bunkum

Butty

Cant lass

Cap (set one's)

Chaps

Chucker-out

Cod (to)

Compos mentis

Constitutional (take one's)

Coomb

Demi-monde

Dewlaps

Eyeties
Faucet

Fox

Frame

Frame off

Frisson

Frowsty

Fuzz-ball

Gaberlunzie

Gabey

Gallivant

George (by)

Gooseberry

Hang fire

Harry

Hebrew transactions

Honour bright 
Ikey

Jackeen

Jack-gnat

Jowl

Kidney

Kingdom (three)

Kirkyard

Knivey

Knock about

Lardy-da

Lass

Late

Lees

Length

Maneen

Mardy

Mash

Mend

Narragansett

Nick (in the)
Nick (Owd, Old)

Niminy-piminy

Not much cop

Old Harry

Parish oven

Plain Irish

Plucked

Prof

Pulamiter

Purple of commerce

Redden

Right as the mail

Salaam

Settle one's hash

Shilly-shallying

Shindy

Shower (bunch)

Shufti

Side-saddle

Sidewalk
Sixty-four dollar question

Starved

Starving

Stuff

Summut

Sweal away

Tight-Jeff (be on the)

Trivet (right as)

Tuppence (not worth)

Tricoteuse

Trot round

Twittermiss

Wampanaug

Warming-pan (flat as)

Wax

Whipperty-snapping

Whittle

Worrit/worrited

\section{Bibliotecas y museos}

Ashmolean Museum

Bodleian (library)
Free Library

Mudie (lending library)

\section{Costumbres y normas sociales}

Australia
Best man
Botany Bay
Chaperon
Come of age
Court Guides
Duenna
Foster sister
Groceries
Holly
Intended

Ivy

Lent

Michaelmas

Round robin

Rush

Scarlet woman

Season

Send (to Australia)

Send down

Skimmington

Skimmity-ride
Tart

Teetotal

Temperance beverage

Toper

Toss-pot

Whitsunstide

Broad hems

Funeral

Weeded

Weeds

Weeper 


\section{Transporte y comunicaciones}

Bridle-path

Brighton Line

Fly

Highwayman

Jingle
Lighting-up time

Midland Railway

Model T Ford

North Circular

Omnibus
Palanquin

Parliamentary (train)

Tube (pipe)

Turnpike

Twitchel

\section{Rasgos del paisaje y flora}

Barrow

Blue Lias

Boghole

Cader Idris

Gorse

Liffey

\section{Miscelánea}

Monkshood

Moors

Osier

Penistone Crag

Pennines

Serpentine
South-western leg Turf-coloured

Warwickshire (mineral)

Water (sent by water)

\begin{abstract}
Brasso
Engine-house

Jig saw

Lace-factory

Lascar
\end{abstract}

\author{
Methylated spirits \\ Monkey Brand \\ Muster-roll \\ Myxomatosis \\ Oubliette
}

Pandybat

Physic

Spud

Tin-Pan-Alley 


\section{ÍNDICE ALFABÉTICO}

A

Admiralty

Agincourt

Agnostic writings

Agrícola, Gnaeus I.

Alamo

Albany

Aldgate

Alfred the Great

All Souls

Almack's

Almighty

Amadis of Gaul

Anabaptist

Andersen, Hans C.

Angel

Anglican

Anglo Saxon Chronicle

Antimacassar

Apartment

Apothecary

Apple dumplings

Apple jelly

Arden, Elizabeth

Armada

Army Lists

Arrange (music)

Arrow-root

Ascot

Ashmolean Museum

Asquith, Herbert Henry

Asquith, Margot

Assembly Rooms

Astley's

Athenaeum

ATS

Aubrey, John

Aunt Sally

Austerlitz

Australia

Ave...Morituri te salutant

B

B.A.

Bacchante
Bachelor of Arts

Bad odour

Badly

Baedeker

Bairn

Bake

Bally

Banditti

Bar

Bard

Barkled

Barm-man

Barnet

Baronne d'Almane

Barrow

Barthes, Roland

Bath

Bath chair

Bath paper

Battledores and shuttlecocks

Bayeux Tapestry

Bayswater

Beads

Beastly

Beau Brummel

Beaver fur

Beckenham Reserves

Becky Sharp

Bedf ord Square

Bedlam

Beet-root

Belgrave Square

Belinda

Bellerophon

Bench

Bennet girls

Bentham, Jeremy

Berkley Square

Berkleyan

Best man

Bide

Bijou

Billy-o

Bishop

Bismark, Otto von
Bisurated Magnesia

Black Hole of Calcutta

Black Horse

Black twist

Black Watch

Blackout curtains

Blazer

Blenheim

Blimp (Colonel)

Blind-hookey

Blinking

Bloomsbury

Bluddy

Blue (washing)

Blue (editor)

Blue Beard

Blue books

Blue Lias

Blue moon

Blue Vinny

Bob

Bobby-dazzler

Bodleian

Boghole

Bond Street

Bonnet

Book

Boss

Bossuet, Jacques

Boswell, James

Botany Bay

Bounderby

Bourget

Bournemouth

Bow window

Bowdler

Box

Box Brownie

Box Hill

Boy Scouts

Boy's Own Paper

Bracknell, Lady

Bradlaugh, Charles

Brasso

Brat 
Brew

Bridge

Bridle-path

Brief Lives

Brighton Line

Brioche

Britannia

British Opera

Broad hems

Broadcloth

Broadwood's

Brook's

Broth

Brown

Brown Holland

Brown, Ford Madox

Brummel, George B.

Buckingham

Buckram

Bunkum

Burford Church

Burke, Edmund

Butterscotch

Button, William

Butty

By hook or by crook

C

C.O.

C.O.'s HQ

Cader Idris

Caesar, Julius

Café Royal

Call a spade

Calvinism

Camargo petticoat

Cambridge Tripos

Camden Town

Camilla

Cant lass

Canterbury

Cap (set one's)

Castor

Cat's cradle

Cecilia

Cellery (celery)

Champers
Chancellor of the

Exchequer

Chanson de Roland

Chany

Chapel-goers

Chaperon

Chaps

Char Bydis

Chartists

Chausable

Cheap Jack

Cheapside

Chemist

Chesterfield

Chevaux-de-frise

Chicken in aspic

Childe, Vere Gordon

Children of the Abbey

Chinless wonder

Chintz

Chip of better quality

Chippendale

Christopher Robin

Chucker-out

Churchill, Winston

City of Sin

Clane

Clapham

Clifton

Cloak-room

Clothes horse

Club

CND

Coconut man

Cod

Coif

Coketown

Collier

Colliery-manager

Colonial

Colours

Come of age

Commerce

Communist Manifesto

Compos mentis

Comus

Conduit Street
Congregationalist

Constable, John

Constitutional

Continental

Convenience

Cook, James

Coomb

Co-op

Coptic Goddess

Coroner's Inquest

Cosy

Coty

Country Life

County Council

Court Guides

Court of Common Law

Coverley, Roger de

Covert

Cowper, William

Cramer, Johann B.

Crape

Craped

Cream cracker

Cricket

Crinoline

Crown Derby

Crumpet

Crumpled horn

Crystal Palace

Cucumber sandwich

Cuppa

Curzon

D

D.D.

Daily Telegraph

Damson cheese

Dark Ages

Dartmoor

Davy, Humphry

Deal

Dean

Deane

Demi-monde

Depression

Derbyshire

Devonshire 
Dewlaps

Dieu et mon droit

Dine

Dishabille

Disraeli, Benjamin

Disrobe

Dissenter

Divorces

Doctors' Commons

Dollar (half-crown)

Dombey and Son

Don

Dormer window

Drake, Francis

Draughtsman

Dresden

Dress

Dress circle

Dripping

Dripping pan

Drisheens

Drugget

Drury Lane

Duenna

Dulles, John F.

Dundrearies

\section{E}

Earnshaw

Edgehill

Electrolux

Elegant Extracts

Eliot, T.S.

Elton, Charles

Empire

Engine-house

Eno's

ENSA

Entailed

Enter (to be entered)

Epping

Epsom

Erebus

Erewash Valley

Eton

Evening Standard

Evensong
Exchequer

Excise-rod

Exeter

Exmoor

Eyeties

F

F.O.

Familiarity

Farthing

Faucet

Fauntleroy, Little Lord

Fauteuil

Fear no more

Field sports

Fifteen

Finger in the pie

Finsbury Park

Finsbury Pavement

Fish-and-chip shop

Flanagan and Allen

Flannels

Fleet

Florin

Fly

Fortnum's

Foster sister

Fox

Frame

Frame off

Franklin, John

Free Library

Friends (Society of)

Frisson

Frowsty

Fulham

Funds

Funeral

Furlough

Fuzz-ball

G

G.H.Q.

$G$ and $S$

Gaberlunzie

Gabey

Galantine
Galbraith, John K.

Gallery

Gallivant

General Election

George (by)

German Jew

Gervase Park

Gibson Girl

Gilpin, John

Gingerbread

Girl Guides

Gladstone bag

Gladstone, William E.

Glee

Glee-men

Glegg, Mr and Mrs

Glyn, Elinor

God Save the Queen

Godwin, William

Gold Rush

Golden Hind

Goldsmith, Oliver

Gooseberry

Gorgonzola

Gorse

Gosse, Philip H.

Gower Street

Grace

Gracechurch Street

Gradgrind

Grammar school

Grandison, Sir Charles

Gravesend

Gravy browning

Gray, Thomas

Great Reform Bill

Green

Greensleeves

Grenadine

Greuze, Jean B.

Grimm, J.L. and W.K.

Groceries

Grosvenor Square

Grosvenor Street

Gruel

Grundy, Mrs

Grünewald, Matthias 


\author{
Gudrun \\ Guest \\ Guildford by-pass \\ Guimp \\ Guinea \\ Gwyn, Nell \\ Gyppy tummy
}

\section{H}

Haddock

Half

Half a crown

Half-Moon Street

Hamadryad

Hammarskjöld, Dag

Hampstead

Handsome

Hang fire

Hanover Square

Hareton

Harley Street

Harrow

Harry

Harvey, William

Hatfield

Haymarket

$\mathrm{H}$-Bomb

Heathcliff

Hebrew

Heep

Hendon

Henrietta-Maria style

Hertfordshire

Highwayman

Hind-leg

Hit

Hob

Hoffman's Tales

Holborn

Holly

Holy Office

Home civil

Home Secretary

Hon.

Honeys

Honour bright

Hood, Robin
Hooker, Richard

Hoop

Horlicks

House

House of Lords

Huckster

Hume, David

Humphreys, Noel

Huntley and Palmers

Hurlingham

Hussars

Huswife

Hutchinson, John

Huxley, Thomas

\section{I}

Idylls of the King

Ikey

Inch

Income

Indian

Indian Mutiny

Insolvent Debtor's Court

Intended

Iron Maiden

Irons in the fire

Italian

Ivy

\section{J}

J.P.

Jack (Union)

Jack the Giant-killer

Jackeen

Jack-gnat

Jakin

Jardinière

Jig saw

Jingle

Jock and Day

Johnston, Mooney, and

O'Brian's

Jones, Inigo

Jones, Tom

Jorrock's Jaunts and Jollities

Josephus, Flavius
Joshua

Jowl

Jumps

K

K.C.

Kenilworth

Kenn

Kensington

Kensington Gardens

Kent

Kettle

Kidney

King and Queen

King's scholar

Kingdom

Kingsley, Charles

Kirkyard

Knivey

Knock about

L

Lace-factory

Lamplighter

Langtry, Lillie

Laocoön embrace

Lardy-da

Lascar

Lass

Late

Lavater's Physiognomy

Leamington

Lees

Lemon plait

Length

Lent

Liberal Unionist

Life Guards

Liffey

Lighting-up time

Lincoln's Inn

Lindisfarne

Linoleum squares

Locke, John

Lockwood

Loo

Lord Chancellor 
Lords

Low Church

Lyell, Charles

\section{M}

M.F.H.

M.P.

M'Choakumchild

Macaulay, Thomas

Macmillan, Harold

Mahogany

Maisonette

Malthus, Thomas

Maneen

Manse

Marchbanks, Eugene

Mardy

Maréchal Niel

Margate

Marleybone High Street

Marquess of Queensbury

Mash

Mashed-potato man

Master of ceremonies

Matilda

Matriculation-examination

Mayfair (May Fair)

Mayflower

Mayhew, Henry

McCarthy, Joseph

McLuhan, Marshall

Mechanics' Hall

Mechlin

Melbourne, William

Men's Beavers

Mend

Menton

Merchant-Taylors'

Merino

Mess tin

Methodism

Methylated spirits

Mews

Michaelmas

Midland Railway

Mild-and-soda
Mile End Waste

Milk bar

Mill, John

Millais, John

Miller, Hugh

Milton, John

Mitford, Nancy

Mod

Model T Ford

Moiety

Monk

Monkey Brand

Monkshood

Monmouth, James

Moore, Henry

Moorgate Street

Moors

Morland, George

Morning Post

Morning-room

Morris, William

Morris-dancing

Mother Hubbard

Motto

Mudie

Muffin

Muffineer

Mules

Mullioned window

Musgrove, Luisa

Muster-roll

Mystery play

Myxomatosis

N

N.B.

N.W.

NAAFI

Nabob

Nag's Head

Narragansett

National Gallery

Netting

Netting-box

New Statesman

News

News of the World
Nick

Nick (Owd, Old)

Nick-nack vendor

Nightingale, Florence

Night-rail

Niminy-piminy

North Circular

North Wiltshire

Northmen

Norton, Caroline

Not much cop

Notting Hill Gate

O

Oak leaves

Odour (bad)

Old Harry

Old King Cole

Old Woman

Omnibus

Once seen ...

Oriel

Osier

Oubliette

Owd Nick

Oxbridge

Oxford Street

Oxonian

$\mathbf{P}$

Paine, Thomas

Paisley

Palanquin

Pall Mall

Palmer, Samuel

Palmerin of England

Pandybat

Pantalettes

Pantomime

Pantoufles

Parish

Parish oven

Parley, Peter

Parliamentary

Parlour

Pascal, Blaise

Pascal's Pensées 
Passchendaele

Patmos

Pattened

Peel, Robert

Peep-show

Penistone Crag

Pennines

Penny

Penny-gaff

Penthouse

Periwinkle

Peter Parley's Tales

Peter Piper

Pew-opener

Physic

Piccadilly

Pickwick Papers

Pierre

Pimlico

Pimm's $N^{0} 1$

Piper, Peter

Pisgah Mount

Pit

Pitt, William

Pivart

Plain Irish

Plucked

Plum pudding

Plus-fours

Plymouth

Poached eggs

Pocahontas

Pocketful of posies

Polony

Pope, Alexander

Popery

Pork-pie hat

Porridge

Port Said

Portman Square

Presbyterianism

Priestly, John

Prince Consort

Prior, Matthew

Prof

Promenade concert

Public house
Public school

Pulamiter

Pullet, Mrs

Punch

Punch (pleased as)

Purple of commerce

Putney

Q

Quad

Quadrille

Quahaug

Queen's Highness

Queen-Anne (house)

Queensbury

Quid

$\mathbf{R}$

Radical Member of Parliament

Radical papers

RAF

Ranelagh

Récamier attitude

Red brick

Red lion

Redden

Regency terraces

Regent's Park

Regimentals

Reynolds, Joshua

Riding-habit

Right as the mail

Robbe-Grillet, Alain

Robertson, William

Robin Hood

Robin, Christopher

Roger de Coverley

Romance of the Forest

Romanist

Romish

Rommel, Erwin

Rosetti, Christina

Rosetti, Dante G.

Rotarian

Rotary Club

Round robin
Rout-cakes

Royal Horticultural Society

Royal Personage

RSC

Rubicon

Rugger

Rules

Rumpelmeyer's

Rush

Rush mats

Ruskin, John

\section{S}

S.W.

Sacco (and Vanzetti)

Sackville Street

Sade, Marquis de

Salaam

Saladin I

Salt

Salvation Army

Saveloy

Scarborough

Scarlet woman

Schliemann, Heinrich

Scotland Yard

Scott, Walter

Season

Secularism

Send (to Australia)

Send down

Serpentine

Settle

Settle one's hash

Seven Dials

Shantung

Shelley, P.B.

Shepherd's Bush

Sheridan, Richard

Shilling

Shilly-shallying

Shindy

Shoreditch

Shower

Shufti

Sidcup 


\begin{tabular}{|c|c|c|}
\hline Sideboard drawers & Strand & Tricoteuse \\
\hline Side-saddle & Stuff & Trivet \\
\hline Sidewalk & Sturm and Drang & Trot round \\
\hline $\operatorname{Sin}$ & Stygian domain & Tube \\
\hline Sing a song of sixpence & Succession-house & Tucker \\
\hline Sixty-four dollar question & Suffragette & Tullabeg \\
\hline Skilly & Suit & Tunbridge Wells \\
\hline Skimmington & Summut & Tuppence \\
\hline Skimmity-ride & Sunday papers & Tureen \\
\hline Skulker & Sussex & Turf-coloured \\
\hline Slave-trade & Sweal away & Turnpike \\
\hline Slim Jim & Swingboats & Twinkle, twinkle little \\
\hline Slip & & star \\
\hline Smith, Adam & $\mathbf{T}$ & Twitchel \\
\hline Smith, William & Tart & Twittermiss \\
\hline Smock & Tattler & Tyndall, John \\
\hline Smoking jacket & Tauchnitz novels & \\
\hline Smoking-room & Taylor, Jeremy & $\mathbf{U}$ \\
\hline Snood & Tea & Udolpho \\
\hline Soanesque & Tea-cake & Ulster \\
\hline Soapy Sponge & Teetotal & Union Jack \\
\hline Somme & Temperance beverage & Unitarian Church \\
\hline Song & Temple & Up (to town) \\
\hline Southey, Robert & Terror & Upper Grosvenor Street \\
\hline South-western leg & Tess & Upper Rooms \\
\hline Sovereign & Thatcher, Margaret & \\
\hline Spats & Thimble-rig & $\mathbf{V}$ \\
\hline Spectator & Thirty-Nine Articles & Valley of the Dolls \\
\hline Spencer & Thomson, James & Vanzetti \\
\hline Spire & Three is company & Vaughan Williams, Ralph \\
\hline Sporran & Throttler & Vessel \\
\hline Sportsman & Thrushcross Grange & Vicar of Wakefield \\
\hline Spud & Tight-Jeff & Victoria Station \\
\hline St. George & Times & Vingt-un \\
\hline St. James & Tin-Pan-Alley & Vinolia \\
\hline St. James Park & Tippet & \\
\hline St. John's Wood & TLS & $\mathbf{W}$ \\
\hline St. Pancras & Toakay & W1, SW1, SW3, W8 \\
\hline Stalls & Toffee & Wakefield \\
\hline Starved & Top & Wampanaug \\
\hline Starving & Toper & War \\
\hline Stern Gang & Tory (Tories) & War in Spain \\
\hline Sterne, Laurence & Toss-pot & Warming-pan \\
\hline Stewpond & Town & Warwickshire \\
\hline Stilton cheese & Transported & Wash one's clean linen in \\
\hline Stone & Treasury Bench & public \\
\hline Stonehenge & Trevor-Roper, Hugh & Washboard \\
\hline Stove-pipe hat & Tricot & Wash-tub \\
\hline
\end{tabular}


Water (sent by water)

Watford

Wax

Wedgwood

Weeded

Weeds

Weeper

Wellington, Arthur

Wembley

West Dorset Gazette

West End

West Ham

Westminster

Westminster School

Weymouth

Whipperty-snapping
Whitechapel

Whitehall

Whitsunstide

Whittington, Dick

Whittle

Whole Duty of Man

Wilberforce, William

Willis's

Wilton carpet

Window-bay

Windsor (House of)

Windsor chair

Windsor Terrace

Women's Guild

Women's Social and

Political Union
Woolwich Arsenal

Woolworth's

Work

Worrit/worrited

Wuthering Heights

Y

Yellow (maps)

Yellow candidate

York tan 


\section{A PICTURE ALPHABET}

(A nineteenth-century anonymous poem accompanying the original wood-cuts used to separate each alphabetical section of this Dictionary.)

A was an archer who shot at a frog;

$B$ was a butcher, who had a great dog;

C was a captain, all covered with lace;

D was a drunkard, and had a red face;

E was an esquire, with pride on his brow;

$\mathrm{F}$ was a farmer, and followed the plough;

$\mathrm{G}$ was a gamester, who had but ill-luck;

$\mathrm{H}$ was a hunter, and hunted a buck;

I was an innkeeper, who loved to carouse;

$\mathrm{J}$ was a joiner, and built up a house;

$\mathrm{K}$ was King William, once governed the land;

L was a lady, who had a white hand;

$M$ was a miser, and hoarded up gold;

$\mathrm{N}$ was a nobleman, gallant and bold;

O was an oyster girl, and went about town;

$P$ was a parson, and wore a black gown;

$Q$ was a queen, who wore a silk slip;

$\mathrm{R}$ was a robber, and wanted a whip;

$S$ was a sailor, and spent all he got;

$\mathrm{T}$ was a tinker, and mended a pot;

U was a usurer, a miserable elf;

V was a vintner, who drank all himself;

$W$ was a watchman, and guarded the door;

$\mathrm{X}$ was expensive, and so became poor;

$Y$ was a youth, that did not love school;

$Z$ was a zany, a poor harmless fool. 

¿Dónde se encuentra tradicionalmente Aunt Sally? ¿Qué tipo de persona es el Colonel Blimp? ¿El término dollar siempre se emplea pârâa referirse a la moneda norteamericana? ¿A quién se alude con el término peyorativo Eyeties? Si el lector de la literatura inglesa de los siglos XIX y XX se encuentra con referencias opacas como éstas, tiene tres opciones para salir del paso: primero, hacer caso omiso, por pereza o falta de medios, y por lo tanto perder multitud de detalles que le ayudarían a matizar las intenciones del autor; la segunda opción sería armarse de valor y buscar en obras de consulta muy variadas y dispersas, perdiendo así el hilo de lo que estaba leyendo; o la tercera opción sería hacer uso de este Diccionario de Referencias Culturales en la Literatura Inglesa, en el cual se reúnen un millar de términos localizados en las obras literarias más leídas por estudiantes de Filología Inglesa en España.

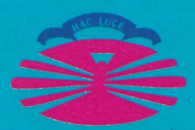

UNIVERSIDADE DA CORUÑA 